

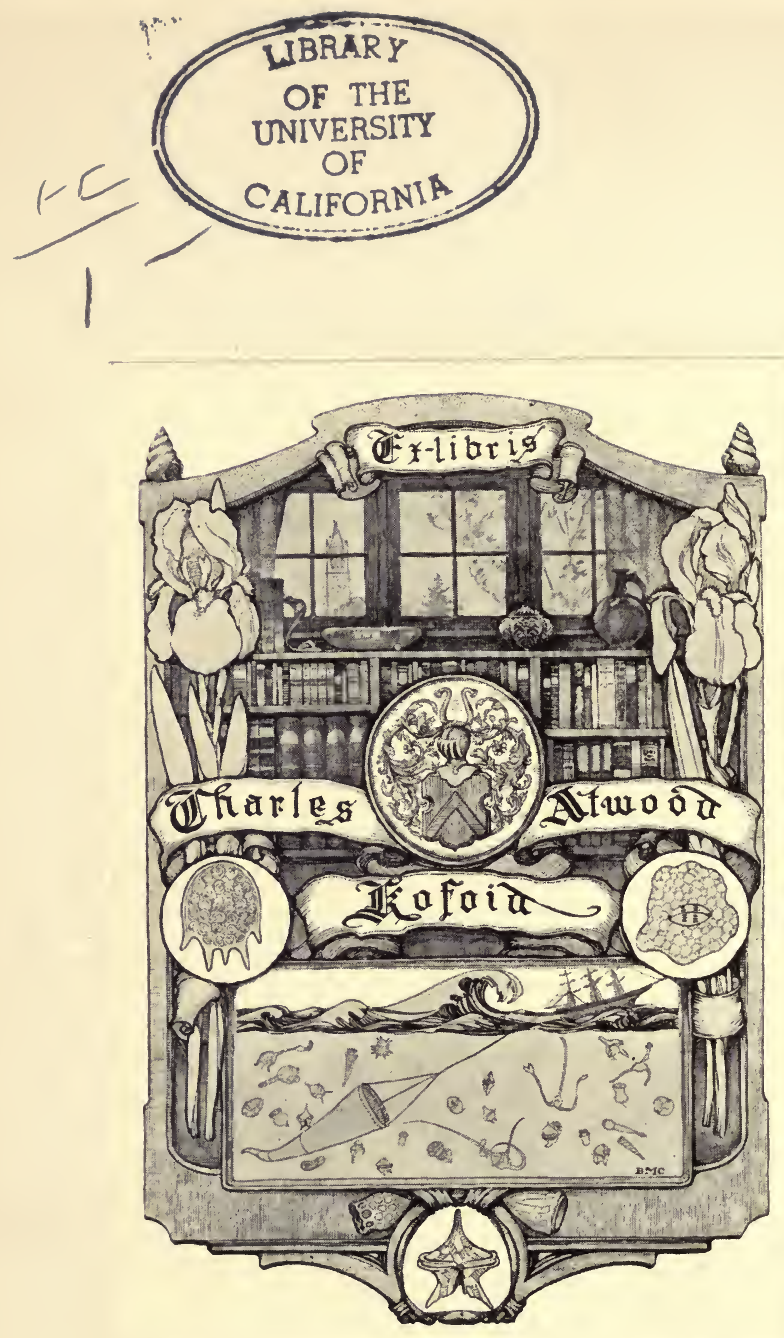


$$
\text { I n }
$$



THE OYSTER 



\section{THE OYSTER}

A POPULAR SUMMARY OF A SCIENTIFIC STUDY

BY

WILLIAM K. BROOKS, PH. D., LL. D.

Henry Walters Professor of Zoology, in the Johns Hopkins University

SECOND AND REVISED EDITION

B A L T I M OR E

THE JOHNS HOPKINS PRESS

1905 
COPYRIGHT, 1905,

BY THE JOHNS HOPKINS PRESS

EBe Eord d6altimore Prebs

THE FRIRDENWALD COMPANY BALTIMORE, MD. 


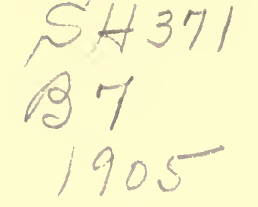

\section{PREFACE.}

The first edition of this book was written in 1890 at the suggestion of President Gilman and other citizens of Baltimore, and it was published by the Johns Hopkins University in $189 \mathrm{I}$, in the hope that it might help to bring about a practical and judicious system of oyster farming in Maryland, and the development and improvement of the natural resources of our waters, by an account of the way in which the structure and habits of the oyster fit it for cultivation as a submarine agricultural product.

To-day, fifteen years after the book was written, the oyster grounds of Virginia and North Carolina, and those of Georgia and Louisiana, are increasing in value, and many of our packing houses are being moved to the south, but there is no oyster farming in Maryland, and our oyster beds are still in a state of nature, affording a scanty and precarious livelihood to those who depend upon them.

Since the facts and reflections which the first edition contained are as instructive now as they were fifteen years ago, no essential change in the book seems to be 
necessary, and most of the new matter refers to minor points. To this there is one exception. I have added to the account of the structure of the oyster a section upon its peculiar fitness for gathering up the germs of cholera and typhoid fever and transmitting them to man, since the importance of clear ideas upon this subject increases with the growth of the cities and towns upon the shores of the Bay and its tributaries, and with the increasing danger of the pollution of the oyster area by sewage. The section upon this important subject is the most notable addition to this edition.

JoHNS Hopkins UNIVERSITY, March 25, 1905 . 


\section{INTRODUCTION TO FIRST EDITION.}

This book (for which I have been asked to write an introductory note) is written for the information of all who care for oysters,- - no matter whether their point of view be that of providers or consumers, - of the oysterman, the money-maker, the housekeeper, the legislator, the editor, or the student of natural history. So well is the book written that many parts of it are as fascinating as a story.

The facts that have led to its preparation are these. After many years of plenty, Maryland is in danger of an oyster famine. The supplies which nature bestows most bountifully have been so treated that scarcity now takes the place of abundance, anxiety and alarm have followed security. Authentic figures showing the decline and fall of the oyster empire of the Chesapeake, startle all who consider them. It is not only the dredgers, the dealers, the shuckers, the packers, the coopers, the tinners, and the carriers, that are to suffer if this state of affairs continues, everybody in Maryland will likewise suffer more or less. An important article of food, that should be as plentiful 
as it is excellent, will grow more scarce, and a branch of industry will be cut off, which employs a large amount of labor and of capital and so contributes to the welfare of the State, the region, and the country. The interior as well as the seaboard, the farmer as well as the oysterman, will be injured unless some remedy is found.

The author of this volume is well known in all. scientific circles as an accurate, clear-sighted and trustworthy observer. His papers are received and quoted by the best authorities in every place where the study of natural history is carried on. Not only can he see with his trained eye and powerful glasses, more than most people, but he can state distinctly and without any deviation from the exact truth, what he sees, and what he thinks of what he sees. His life has been devoted to the careful observation of the forms and changes of form in living beings.

To the study of the oyster he has devoted a large part of his time for more than ten years past, having been encouraged to do so by the Johns Hopkins University, in which he is an honored professor, and by the legislature of the State of Maryland, which he served as an oyster commissioner in $1883-4$. He can hold his own not only among naturalists, but also among practical men. He has dredged in every part 
of the bay. To use his own words, he has tonged oysters in five different States; in the warm waters of the South, he has spent months under the broiling tropical sun, wading over the sharp shells which cut the feet like knives, studying the oysters " at home." He has planted oysters; he has reared them by collecting the floating spat; and he has hatched from artificially fertilized eggs more oysters than there are inhabitants of the United States. More than this, he has diligently studied the experience of other States and countries and has gathered up the knowledge of the world in respect to the life of the oyster, its enemies and its needs, its dangers and its protections. The people of Maryland may rejoice that in just this crisis, the State has the service of such a citizen, ready without any reservations and without any expectations of reward, to give his hard-earned knowledge to the public.

But the author has another claim to be heard. $\mathrm{He}$ is governed by common-sense. The difficulty that he sees is summed up in a single sentence that he prints in capital letters, THE DEMAND FOR CHESAPEAKE OYSTERS HAS OUTGROWN THE NATURAL SUPPLY. The remedy he proposes is to increase the supply by artificial means. To show what is possible for the propagation and protection of young oysters, he describes in 
the most interesting manner, in terms scientific enough to be accurate, not so scientific as to be hard of understanding, the life-history of the bivalve. The oyster's exposure to infantile dangers, its preferred home, its dietary habits, its susceptibility of culture, its wonderful fecundity, are vividly portrayed. Indeed, this modest volume is at once a memoir in natural history and a chapter of political economy.

Daniel C. Gilman.

Office of the President of the

JOHNS Hopkins UNIVERSITY, April 14, 1891. 


\section{INTRODUCTION TO SECOND EDITION.}

The scientific and practical study of the American oyster by the Johns Hopkins University began in I878 with the discovery by Professor Brooks that the American oyster, unlike that of northern Europe, breeds its young by throwing the eggs out into the water, where fertilization and development take place. He was the first to fertilize the eggs artificially and to study the development of the embryo; and he pointed out the practical bearing of his discoveries on the propagation of the oyster. A medal was awarded to him for this work by the "Société d'Acclimatation" (Paris) in I88I.

In 1882 he was appointed by the Governor of Maryland a "Commissioner to examine the oyster beds, and to advise as to their protection and improvement;" and after two years of investigation of the area where oysters are to be found in Maryland, he submitted a report, in $\mathrm{I} 884$, in which the causes of the deterioration of the beds are discussed, and recommendations made for their restoration and development.

Realizing the general need for more accurate knowledge about the oyster and its possibilities in Maryland, he published, in I89I, a popular treatise on the various phases of the oyster question, called "The Oyster." 
Many of Professor Brooks's students have carried on scientific investigations of the life of the oyster, and three have been called upon for practical work in Maryland and elsewhere.

In 1896, Dr. H. McE. Knower was employed to make a biological examination of a site for an extensive oyster farm, and to report, to those who were interested, the results of his examination.

In I899, Dr. Caswell Grave was employed by the U. S. Fish Commission and by the Geological Survey of North Carolina to make a biological examination of the oysters and oyster beds of North Carolina, and, later, to carry on experiments in oyster culture, and to establish an experimental oyster farm. Dr. Grave has devoted three years to this work, and the oyster beds which he has established in the vicinity of Beaufort, $\mathrm{N}$. C., are now open to the public and are supplying oysters for the market. An account of his investigations and experiments was published in 1904.

Dr. O. C. Glaser, who assisted Dr. Grave in his experiments, was employed in 1903 by the Geological Survey of Louisiana to take charge of the Gulf Biological Station, and to carry on experiments in oyster culture in the Gulf of Mexico. An account of his experiments was published in I904.

IRA REMSEN.

Office of the President of the

Johns Hopkins University, March 25, 1905. 
A list of the more important of the papers that deal with the oyster, which have been published by investigators who have been connected with the Johns Hopkins University:

By Professor W. K. Brooks.

I. The Development of the Oyster. Studies Biol. Lab. J. H. U., I88o.

2. The Acquisition and Loss of Food Yolk in Molluscan Eggs. Studies Biol. Lab. J. H. U., I 880 .

3. Observations upon the Artificial Fertilization of Oyster Eggs, and on the Embryology of the American Oyster. Ann. Mag. Nat. Hist., London, I88o.

4. The Biology of the American Oyster. N. C. Med. Press, I880.

5. Report of the Oyster Commission of the State of Maryland. Annapolis, I884.

6. Oyster Farming in North Carolina. Forest and Stream, New York, 1885.

7. On the Artificial Propagation and Cultivation of the Oyster in Floats. J. H. U. Circular, 1885.

8. The Oyster. J. H. U. Press, I89I.

9. Maryland: Its Resources, Industries, and Institutions. The Oyster. Baltimore, I893.

Io. The Axis of Symmetry of the Ovarian Egg of the Oyster. In press. 
By Professor J. P. Lotsy.

II. The Food of the Oyster, Clam, and Ribbed Mussel. Bull. U. S. Fish. Com. I893.

By Dr. H. L. OsBorn.

I2. The Structure and Growth of the Shell of the

Oyster. Studies Biol. Lab. J. H. U., I883.

By Dr. H. McE. KNower.

I3. Maryland: Its Resources, Industries, and Institutions. The Oyster Industry. Baltimore, I893.

By Dr. Caswell Grave.

I4. The Oyster Reefs of North Carolina. A Geological and Economic Study. J. H. U. Circular, I9or.

I5. A Report of Work Carried on for the Development of the Oyster Industry of North Carolina. Bull. U. S. Fish. Commission, I904. By Dr. O. C. Glaser.

I6. Some Experiments on the Growth of Oysters. Science, April, I903.

I7. The Conditions for Oyster Culture at Calcasieu Pass. May, I904.

I8. Observations and Experiments on the Growth of Oysters. Bull. U. S. Fish Commission, Dec., I904.

By Dr. J. L. KellogG.

I9. Notes on the Food Molluscs of Louisiana. I905. By Dr. J. H. Tennent.

20. Feeding Experiments for Determining the Life History of an Oyster Parasite. March, 1905. 21. Life History of the Oyster Parasite, Bucephalus. In press. 


\section{CONTENTS.}

CHAPTER

PAGE

INTRODUCTION, . . . . . . . . . . . v

I. The Possibilities of Oyster Culture, . . . I

II. The Anatomy of the Oyster, . $\quad \cdot \quad \cdot \quad \cdot \quad$ - $\quad$ I5

III. The Development of the Oyster, . . . . $4^{\mathrm{I}}$

IV. The Artificial Cultivation of Oysters, . . 69

V. A Talk about Oysters, . . . . . . . . . 198

VI. The Remedy, . . . . . . . . . . . 207

VII. The Cause of the Dechine of Our Oyster InDUstry, AND the Protection of our NatURAL BEDS, . . . . . . . . . . 



\section{THE OYSTER}

CHAPTER I.

THE POSSIBILITIES OF OYSTER CULTURE.

The citizen of Maryland gives to the oyster a high place in the list of our resources. The vast number of oysters which the Chesapeake Bay has furnished in the past is ample proof of its fertility, but it is difficult to give any definite statement as to its value. Statistics, even in recent years, are scanty and doubtful, and it is not possible to estimate the number of oysters which our beds have furnished to our people with any accuracy, although it may be computed, approximately, from indirect evidence. The business of packing oysters for shipment to the interior was established in Maryland in 1834, and from that date to quite recent years it has grown steadily and constantly, and, though small and insignificant at first, it has kept pace with the development of our country, the growth of our population, and the improvement of means for transportation. For fifty-six years the bay has furnished the oysters to meet this constantly increasing demand. The middle of this period is the 
year I862, and as the greatest development of the business has taken place since, the business of 1862 may be used as an average for the whole period, with little danger of error through excess. We have $\checkmark$ no statistics for 1862 , but in 1865 C. S. Maltby made a very careful computation of the oyster business of the whole bay for the year. He says there were Iooo boats engaged in dredging and 1500 canoes engaged in tonging. The dredgers gathered 3,663,125 bushels of oysters in Maryland and 1,083,209 bushels in Virginia, while $\mathrm{I}, 2 \mathrm{I} 6,375$ bushels were tonged in Maryland and 981,79I bushels in Virginia, or 6,954,500 bushels in all. About half of these were sent to Baltimore, and the rest to the following cities in the following order: Washington, Alexandria, Boston, Fair Haven, New York, Philadelphia, Seaford, and Salisbury. Of the $3,465,000$ bushels which came to Baltimore, 625,000 were consumed in the city and its vicinity, while 2,840,000 bushels were shipped to a distance by Baltimore packers. Ten years later the harvest of oysters from the bay had increased to $17,000,000$ bushels, and it has continued to increase, year after year, up to the last few years. We may safely regard the harvest of 1865 as an approximation to the annual average for the whole period of fifty-six years, and other methods of computation give essentially the same result.

The total harvest of oysters from the Chesapeake Bay since the establishment of the packing houses is therefore about 56 times $7,000,000$, or $392,000,000$ 
bushels, and the local consumption along the shores of the bay brings the grand total fully up to four hundred million bushels.

This inconceivably vast amount of delicate, nutritious food has been yielded by our waters without any aid from man. It is a harvest that no man has sown; a gift from bounteous nature.

The fact that our waters have withstood this enormous draft upon them, and have continued for more than half a century to meet our constantly increasing demands, is most conclusive evidence of their fertility and value; and the citizens of Maryland and Virginia might well point with pride to the boundless resources of our magnificent bay, were it not for two things.

First of these is the fact, which for many years we strove to hide even from ourselves, that our indifference and lack of foresight, and our blind trust in our natural advantages, have brought this grand inheritance to the verge of ruin. Unfortunately this is now so clear that it can no longer be hidden from sight nor explained away, and every one knows that, proud as our. citizens once were of our birthright in our oyster-beds, we will be unable to give to our children any remnant of our patrimony unless the whole oyster industry is reformed without delay.

We have wasted our inheritance by improvidence and mismanagement and blind confidence; but even if our beds had held their own and were to-day as valuable as they were fifty years ago, this would be no just ground for satisfaction, in this age of progress, to 
a generation which has seen all our other resources developed and improved.

Four hundred million bushels of oysters is a vast quantity, and it testifies to the immeasurable value of our waters; but every one who has studied the subject, either on its scientific side or in the light of the experience of other countries, knows that the harvest of oysters from our bay has never, even at its best, made any approach to what it might have been if we had aided the bounty of nature by human industry and intelligence. The four hundred million bushels is the wild crop which has been supplied by nature, without any aid from man, and it compares with what we might have obtained from our waters in about the same way that the nuts and berries which are gathered in our swamps and forests compare with the harvest from our cultivated fields and gardens and orchards.

When we have learned to make wise use of our opportunities, and when the oyster-beds of the bay have been brought to perfection, a harvest of four hundred million bushels in half a century will not be regarded as evidence of fertility.

It will take many years of labor to bring the whole bay under thorough cultivation, and will require a great army of industrious and skillful farmers, and great sums of money; but the expense and labor will be much less than an equal area of land above water requires. While it may be far away, the time will surely come when the oyster harvest each year will be fully equal to the total harvest of the last fifty years, 
and it will be obtained without depleting or exhausting the beds, and without exposing the laborers to harships or unusual risk.

This is not the baseless speculation of an idle fancy. Our opportunities for rearing oysters are unparalleled in any other part of the world. In another place I have shown that, in other countries, much less valuable grounds have, by cultivation, been made to yield oysters at a rate per acre which, on our own great beds, would carry our annual harvest very far beyond the sum of all the oysters which have ever been used by the packers of Maryland and Virginia.

This is capable of proof by the evidence of other countries, but I wish to show now that it is proved with equal conclusiveness by the natural history of the oyster.

The Chesapeake Bay is one of the richest agricultural regions of the earth, and its fertility can be compared only with that of the valleys of the Nile and the Ganges and other great rivers. It owes its fertility to the very same causes as those which have enabled the Nile valley to support a dense human population for untold ages without any loss of fertility; but it is adapted for producing only one crop, the oyster.

All human food is vegetable in its origin, and whether we eat plants and their products directly, or use beef, mutton, pork, fowls or eggs as food, it all carries us back to the vegetable kingdom; for if there were no plants, all animals would starve at once. Every one knows that this is absolutely true of all ter- 
restrial animals, and all naturalists know that it is equally true of sea-food. The blue-fish preys on smaller fishes; many of these on still smaller ones; these in their turn upon minute crustacea; these upon still smaller animals; and these pasture on the microscopic plants which swarm at the surface of the ocean. However long the chain may be, all animals, those of the water as well as those of the land, depend on plants for food, although most of the vegetable life of the ocean is of such a character that its existence is known only to naturalists.

If there were no plants all animals would starve, for no animal is a direct food-producer. It can furnish nothing except what has come to it from plants.

Now, for the purposes of animal life a small plant is as effective as a large one, since however small it may be, it still has the power, which is possessed by no animal, to gather up the inorganic matter of the earth, and to turn it into vegetable matter fit for the nourishment of animals. Microscopic plants can do this work as well as great forests of lofty trees, if they are numerous enough, for size counts for nothing.

Every one knows that the sea is rich in animal life; that it contains great banks covered with cod and haddock; miles and miles of water crowded full of mackerel and herring, and great monsters of the deep such as the whales and sharks. To the superficial observer the vegetation of the sea appears to be very scanty, and, except for the fringe of sea-weeds along the shore, the great ocean seems, so far as plant life is concerned, 
to be a barren desert. If it be true that all animals depend on plants for their food, the vegetation of the ocean seems totally inadequate for the support of its animal life.

The microscope shows that its surface swarms with minute plants, most of them of strange forms, totally unlike any which are familiar; for they have nothing in common with the well known trees and herbs and grasses of the land except the power to change inorganic matter into food which is fit for animals.

Most of these plants are so small that they are absolutely invisible to the unaided eye, and even when they are gathered together in a mass, it looks like slimy discolored water and presents no traces of structure. They seem too insignificant to play any important part in the economy of nature, but the great monsters of the deep, beside which the elephant and the ox and the elk are small, owe their existence to these microscopic plants.

Their vegetative power is wonderful past all expression. Among land plants, corn, which yields seed about a hundredfold in a single season, is the emblem of fertility, but it has been shown that a single marine plant, very much smaller than a grain of mustard seed, would fill the whole ocean solid in less than a week, if all its descendants were to live.

This stupendous fact is almost incredible, but it is capable of rigorous demonstration, and it must be clearly grasped before we can understand the life of the ocean. As countless minute animals are con- 
stantly pasturing upon them, the multiplication of these plants is kept in check; but in calm weather it is no rare thing to find great tracts of water many miles in extent packed so full of them that the whole surface is converted into a slimy mass, which breaks the waves and smooths the surface like oil. The so-called "black water" of the Arctic and Antarctic oceans, the home and feeding ground of the whale, has been shown by microscopic examination to consist of a mass of these plants crowded together until the whole ocean is discolored by them. Through these seas of "black water" roam the right whales, the largest animals on earth, gulping at each mouthful hundreds of gallons of the little mollusca and crustacea which feed on the plants.

In tropical seas, ships sometimes sail for days through great floating islands of this surface vegetation, and the Red Sea owes its name to the coloration of its water by great swarms of microscopic organisms which are of a reddish tinge. The plant life of the ocean is ample for the support of all its animal life, just as the vegetation of the land gives a maintenance to all terrestrial animals.

The source of the food of animals is the vegetable world. What is the source of the food of plants?

Most of it consists of mineral matter, derived from the crust of the earth; but before this can be used by plants it must be dissolved in water. The solid rocks cannot maintain life until they have been ground down and dissolved, and in the form of frost and rain, water 
is continually breaking down and wearing away the hard rocks, and carrying the fragments down to lower levels to form the fertile land of the hillsides and valleys and meadows. As the roots of the plants penetrate this loose material they gather up the mineral food which is dissolved by the rain, and convert it into their own substance, and as their leaves fall and their trunks decay, the decaying vegetable matter gradually builds up the leaf-mould and the meadow-loam which are so well adapted for supporting vegetable life. Each year, however, the heavy rains wash great quantities of this light, rich soil into the rivers, which in times of flood cut into their banks and carry the arable land, which has been built up so slowly, down to lower levels, until at last it finds its way to the ocean and is lost, so far as its use to man is concerned.

In a long, flat river-valley it may be arrested for a time, so that man may make use of it, but its final destination is the ocean, and as this has already been enriched by the washings through untold ages, all that is most valuable for the support of life is now dissolved in its waters, or deposited upon its bottom, where man can make no use of it.

We love to dream of the shipwrecked treasures which lie among the bones of the sailors on the seabottom; of the galleons sunk and lost with their precious cargoes of bullion and jewels from the treasurechambers of the Incas and the palaces of Asia; but all these, and all the "gems of purest ray serene, the dark, unfathom'd caves of ocean bear"; all the thous- 
ands of tons of gold and silver which, as chemists tell us, the sea holds dissolved in its water,-all these are as nothing when compared with these precious washings from the land of all that fits it for supporting life.

Man will some time assert his dominion over the fishes of the sea, and will learn to send out flocks and herds of domesticated marine animals to pasture and fatten upon the vegetable life of the ocean and to make its vast wealth of food available, but at present we are able to do little more than to snatch a slight tribute from the stream of nutritive material which is flowing down into the ocean, as it comes to temporary rest in the valleys of our great rivers.

Every one knows the part which these great rivervalleys have played in human civilization. In the valley of the Nile, of the Tigris, and of the Ganges we find the most dense populations; here were the great cities of the past; here agriculture and architecture were developed, and here art, literature and science had their birth.

We owe to the great river-valleys, where the natural fertility of the soil has lightened the struggle for bread and has afforded leisure for higher matters, all that is most distinctive of civilized man.

The Chesapeake Bay is a great river-valley; not as large as that of the Nile or Ganges, but of enough consequence to play an important part in human affairs, and to support in comfort and prosperity a population as great as that of many famous states. It receives the drainage of a vast area of fertile land stretching 
over the meadows and hillsides of nearly one-third of New York, and nearly all of the great agricultural states of Pennsylvania, Maryland and Virginia. The most valuable part of the soil of this great tract of farming land, more than forty million acres in area, ultimately finds its way to the bay, in whose quiet waters it makes a long halt on its journey to the ocean, and it is deposited, all over the bay, in the form of fine, light, black sediment, known as oyster-mud.

This is just as valuable to man, and just as fit to nourish plants, as the mud which settles every year on the wheat fields and rice fields of Egypt. It is a natural fertilizer of inestimable importance, and it is so rich in organic matter that it putrefies in a few hours when exposed to the sun. In the shallow waters of the bay, under the influence of the warm sunlight, it produces a most luxuriant vegetation; but with few exceptions, the plants which grow upon it are microscopic and invisible, and their very existence is unknown to all except a few naturalists. They are not confined like land plants to the surface of the soil, and while they are found in great abundance on the surface of the mud, they are not restricted to it, for their food is diffused in solution through the whole body of water, and the mud itself is so light that it is in a state of semi-suspension, and the little plants have ample room among its particles.

On land, the plant-producing area is a surface, but the total plant-producing acreage of the bay is many times greater than the superficial area of its bottom. 
As the little plants are bathed on all sides by food, they do not have to go through the slow process of sucking it up through roots and stems, and they grow and multiply at a rate which has no parallel in ordinary familiar plants. They would quickly choke up the whole bay if they were not held in check; but their excessive increase is prevented by countless minute animals which feast upon them and turn the plant substance into animal matter, to become in their turn food for larger animals. As a matter of fact, they are not very abundant, but there is no difficulty in finding them in any part of the bay, by straining the water through a fine cloth. In this way we obtain a fine sediment, which is shown by the microscope to consist almost entirely of them.

The variety of these microscopic plants and animals is very great, and a series of big volumes would be needed to describe the microscopic flora and fauna of the bay. Most of them occur in other waters as well, but many are peculiar to the bay, which is an exceptionally favored spot for their growth.

The exploration of this invisible world with a microscope is an unfailing delight to the naturalist, but at first sight it seems to have no particular bearing on human life. The ability to turn inorganic mineral matter into food for animals and for man does not depend on size, and in this work the microscopic flora of the bay is as efficient as corn or potatoes, but infinitely more active and energetic.

In the oyster we have an animal, most nutritious 
and palatable, especially adapted for living in the soft mud of bays and estuaries, and for gathering up the microscopic inhabitants and turning them into food for man.

The fitness of the oyster for this peculiar work-for bringing back to us the mineral wealth which the rivers steal from our hillsides and meadows-is so complete and admirable, so marvellous and instructive, that it cannot be comprehended in its complete significance, without a thorough knowledge of the anatomy and embryology of the oyster.

This book is not a scientific treatise; its purpose is practical, and it will aim at the treatment of its subject in its relations to practical ends; but we cannot fully appreciate the great possibilities of our bay without something more than the vague and erroneous notions regarding the nature of the oyster which are generally current.

The inestimable value of our inheritance in the black mud of the bay has been pointed out, and it now remains to show that the oyster is an animal which has been especially evolved for life in this mud, and that through its aid we may make our inheritance available. A thorough knowledge of the oyster will teach much more than this. It will show the capacity of the oyster for cultivation, and it will also show why its cultivation is necessary, and why our resources can never be fully developed by oysters in a state of nature. We have never enjoyed the hundredth part of our advantage, nor can we ever do so if we continue 
to rely upon nature alone; and this fact, which has been proved again and again by statistics, is perfectly clear to any one who knows what an oyster is, and what are its relations to the world around it. As its world is chiefly microscopic, no one can penetrate into the secrets of its structure and history without training in the technical methods of the laboratory; and business contact with the oyster cannot possibly, with any amount of experience, give any real insight into its habits and mode of life.

I speak on this subject with the diffidence of one who has been frequently snubbed and repressed; for while I am myself sure of the errors of the man who tonged oysters long before I was born, and who loudly asserts his right to know all about it, it is easier to acquiesce than to struggle against such overwhelming ignorance, so I have learned to be submissive in the presence of the elderly gentleman who studied the embryology of the oyster when years ago as a boy he visited his grandfather on the Eastern Shore, and to listen with deference to the shucker as he demonstrates to me at his raw-box, by the aid of his hammer and shucking-knife, the fallacy of my notions of the structure of the animal.

Still I may be permitted to state that I am not totally without experience. I have dredged oysters in every part of the bay, from Swan Point and the Bodkin, to Craney Island and Lynn Haven. I have tonged oysters in five different States; and in the warm waters of the South, where frost is unknown and the oysters 
flourish above low-tide mark, I have enjoyed the opportunity to explore the natural beds, and have spent months, under the broiling tropical sun, wading over the sharp shells which cut the feet like knives; I have planted oysters; reared them by collecting the floating spat; I have hatched from artificially fertilized eggs more oysters than the number of people in the last census; in the West Indies I have gathered at low water, from a boat, the oysters upon the mangrove bushes overhead; and I boldly claim enough practical experience to acquit me from the charge that my views are theoretical. 


\section{CHAPTER II.}

THE ANATOMY OF THE OYSTER.

The most prominent fact in the organization of the oyster is its shell. Its body is shut in between two long concave stony doors, which are made of limestone, and are fastened together at one end, somewhat in the same way that the covers of a long, narrow check-book are bound together at the back. One of these shells, the flat one, is on the right side of the body, and the other, which is much deeper, on the left. When oysters are fastened to each other or to rocks, the left shell is attached, and the oyster lies on its left side. When it is at home and undisturbed its shell is open, so that the water circulates within it, but when disturbed it shuts its shell with a snap, and is able to keep it firmly closed for a long time. The snapping drives out the water, together with any irritating substances which may find their way in, and on the natural beds the oysters snap their shells shut, from time to time, for this purpose. The snapping is popularly called feeding, but it is nothing of the kind. It serves to drive food out instead of taking it in, and so long as the shell is open a gentle current of water is drawn in by a delicate piece of microscopic machinery 
which will be explained later on. The food of the oyster consists of invisible organisms which float in the water and are drawn in with it.

The apparatus for opening and closing the shell is very interesting. If you were to open a check-book, and were to wedge a piece of rubber between the leaves, close to the back, it would form a spring, which would be squeezed by closing the book, and would open it again when released. A book with such a spring would be open at all times, except when forcibly closed. Wedged in between the two shells of the oyster, at their narrow ends, is an elastic pad, the hinge-ligament, which acts in exactly the same way. When the shell is forcibly closed the ligament is squeezed, and it expands when it is released and thus throws the free edges of the shells apart. The ligament is not alive. It is formed, like the shell itself, as an excretion from the living tissues of the oyster, and its action is not under the control of the animal. It keeps the shell open at all times, unless it is counteracted, and for this reason an oyster at rest and undisturbed, or a dead oyster, always has its shell open.

The active work of squeezing the passive ligament and closing the shell is done by a large, powerful muscle, made up of a bundle of contractile fibres which run across the body between the shells, and are fastened to their inner surfaces over the dark-colored spots which are always to be seen on empty oyster shells. The muscle is known to oyster-openers as the heart, and they assure you that when this is cut, the vital 
point, the seat of the oyster's life, is reached and that a wound here causes instant death. This is of course an error, and cutting the muscle causes the shell to open simply because it destroys the animal's power to close it; but a fresh oyster on the half-shell is no more dead than an ox which has been hamstrung. Any one who has struggled with an oyster-knife to force open an obstinate thick-shelled specimen, knows the great strength of this little muscle. It is said that when fishermen are caught by the feet or hands between the shells of the giant clam of the Pacific, they never escape alive, but are held, as if by a vise, until the tide rises and drowns them; but firmly as the muscle of the oyster holds the shell together, a little skill is all that is needed to overcome it. Some years ago, while on the State Oyster Commission, I stood with my watch in my hand, in a Crisfield packinghouse, and timed a young man, who, with nothing but a small thin knife, opened thirty oysters in a minute. He worked with the precision of a machine, and made six motions for each oyster. One hand took the oyster from the pile at his side, the other cut the muscle from the upper shell; a third movement threw the shell away; a fourth forced the oyster from the other shell; a fifth threw it into a tin bucket, and the second shell was thrown aside by the last movement. He was very proud of his skill and of the prizes he had taken, and although he seemed to have abundant assurance, he explained that his movements were retarded by his diffidence in the presence of state commissioners, 
and he said that, when free from embarrassment, he could "shuck" thirty-six oysters a minute.

The work of closing the shell is done by the muscle. but we must go very much farther in the study of the oyster in order to find why it closes. It is opened by the mechanical properties of the ligament, but the cause of its closure cannot be the mechanical properties of the muscle, for these are just the same whether it is open or at rest. Careful investigation shows the existence of a wonderful apparatus, consisting of the muscle which does the work, of nerves which connect the muscle with the brain, of other nerves which run to the more exposed parts of the oyster's body, and of sense organs which are connected with the ends of these sensory nerves, and serve to put the animal into communication with the external world. Though very much simpler, the mechanism is essentially like that of our own bodies. The oyster's shell is lined by a fleshy mantle, which is fringed by a border of darkcolored sensory tentacles, which are partially exposed when the shell is opened. The approach of danger is perceived by these organs, which transmit a sensation of danger along the sensory nerves to the brain, and this in turn sends a nervous discharge along another set of nerves to the muscle, and this shortens under the stimulus and pulls the shells together and holds them fast.

The contrast between the opening and the shutting of the oyster's shell is an excellent illustration of the difference between vital activity and non-vital action. The 
explanation of the movement which opens the shell is found in the physical properties of the ligament, and a piece of rubber in the same place would produce the same effect; but while the closure of the shell is undoubtedly due to the physical properties of the muscle, we must carry our investigations very much farther in order to find the reason for its action, for we must learn what was the change, external to the oyster, which excited the sense organs, and we must ask how the oyster has learned to associate such a sensation with the presence of danger, and how it has learned that the danger may be escaped by closing the shell.

It is much more easy to ask this question than to answer it. The oyster is by no means a simple animal, and our efforts to study and understand its structure bring us, at the first step, face to face with problems of the most profound character; problems which will tax all the resources of investigators and philosophers for many generations. We shall not enter into these deep questions here, as we shall confine ourselves to simpler matters.

The muscle is attached to the shell at some distance from the hinge, in order that it may have leverage and work to advantage; and it must therefore be able to move as the shell grows, for in an oyster three inches long its area of attachment is outside what was the extreme border of the shell when this was only an inch long. The muscle travels by the addition of new fibres on its outer surface, as those on its inner border are absorbed and removed. As it is moved, the old 
impression on the shell is gradually covered up by the new deposits of lime, and, in an empty shell, it may be traced for some distance up towards the hinge, where it gradually becomes more faintly marked, as the layers of new shell grow thicker. A very good idea of the way the shell grows and keeps pace with the growth of the body, may be gained by the careful examination of the muscular impression on its inner surface.

Every fool knows why a snail has a house, but the king could not tell how an oyster makes his shell. We can now give a satisfactory answer to what will not, I hope, be thought a fool's question: "Canst tell how an oyster makes his shell?" The shell, on each side of the body, is lined by a thin, delicate, fleshy fold, the mantle; which may be compared to the outer leaf on each side of the check-book, next the cover. It lies close against the inside of the shell, and forms a delicate living lining to protect the body and the gills, and it is also the gland which makes the shell.

At all times, while the animal is alive, it is laying down new layers of pearl over its whole inner surface, and as each successive layer is a little larger in area than the one before, the shell increases in size as well as in thickness. In the oldest part of the shell, near the hinge, there are many layers, and the shell is thick, while the edge, which is new, is quite thin and sharp. Each layer is very thin, hardly thicker than a sheet of tissue paper, but the deposition of layer on layer gradually results in a solid box of stone.

Shells which grow on rough, irregular surfaces con- 
form to their shape as perfectly as if they had been moulded into the ridges and furrows, like soft clay. An oyster growing in the neck of a bottle takes the smooth, regular curve of the glass, and on the claw of a crab an oyster shell sometimes follows all the angles and ridges and spines, as if it were made of wax instead of inflexible stone. Its apparent plasticity and the mouldings of its surface are due to the flexibility of the soft edge of the mantle. When the oyster is at rest this protrudes a little beyond the edge of the shell, so that each new layer is a little larger in area than the last one. The soft mantle readily conforms to the shape of the body to which the oyster is fastened, and however irregular this may be, the new shell takes its shape and closely adheres to it, because the new deposits are laid down directly upon it.

This shows the error of the current belief that an old oyster cannot fasten itself. Since the adhesion takes place around the growing edge, an oyster may fasten itself at any time; and clusters of oysters are often found with their shells soldered together near their tips. Of course this can occur only after they are well grown.

Oysters are able to close up broken places in their shells, and most molluscs sometimes absorb and rebuild parts of their shells. If any foreign body gets in between the shell and the mantle, shelly matter is deposited upon it. The pearls of the pearl oyster are formed in this way. Some small particle works its way in, and forms a nucleus which is gradually 
covered by layer after layer of pearl. It has been shown that, in some cases at least, the nucleus of a pearl is the dead body of a microscopic parasite of the mollusc. The birilliant lustre, as well as that of motherof-pearl, which is nothing but polished shell, is due to the interference of light caused by the laminated structure.

It is said that the Chinese manufacture pearls, or rather make the pearl oyster do the work for them, by inserting strings of small shot between the shell and the mantle. Did you ever see one of the sacred clam shells which the Chinese Buddhists believe to have a miraculous origin? They are often found in collections. The inside of the shell has a beautiful pearl lustre, and along it is a row of little fat images of Buddha, squatting with his legs crossed under him, and his elbows on his knees: they are formed of pearl precisely like that which lines the rest of the shell, a little raised above its surface and outlined in faint relief, but they are part of the shell, with no break nor joint. In the process of manufacturing them, the shell of the living animal is wedged open, and thin images, punched out of a sheet. of bell-metal, are inserted. The animal is then returned to the water, and is left there until enough new shell has been formed to cover them with a varnish of pearl thick enough to fasten them, and to hide the metal, while permitting the raised outline to be seen.

Several years ago it occurred to me that a series of microscopic specimens of stages in the growth of the 
shell might be obtained in the same way, and that the whole history of the process might be traced by studying them. At my suggestion, one of my students put into the shells of a number of oysters thin glass circles, such as are used to cover microscopic specimens. The oysters were then returned to the water, and were left undisturbed until new shell began to be formed on the glasses. These were then taken out and studied under the microscope.

At the end of twenty-four hours the glass was found to be covered by a transparent, faintly brown film of thin gummy deposit, which exhibited no evidences of structure, and contained no visible particles of lime, although it effervesced when treated with acids, thus showing that it contained particles too small to be visible with a microscope. The gummy film is poured out from the wall of the mantle, and in forty-eight hours it forms a tough leathery membrane fastening the glass cover over to the inside of the shell. At about this time the invisible particles of lime begin to aggregate and to form little flat crystals, hexagonal in outline and about $\frac{1}{2500}$ of an inch long. The crystals grow and unite into little bundles or groups, and new ones appear between the old ones, until, at the end of six days, the film has completely lost its leathery character and has become stony, from the great amount of lime present in it. In three or four weeks the glass cover is completely built into the shell and can no longer be seen, and its place is only to be traced by its form, which is perfectly preserved upon the inner 
surface of the shell. When broken out it is found to be coated with a thick plate of white shell, which is beautifully smooth and pearly upon the side nearest the glass.

Microscopic examination of this plate shows that it is made up of an immense number of minute crystals, packed and crowded together into a solid mass, without any regular arrangement. These observations show that the new layers are thrown off in the form of a gummy excretion from the mantle, with the lime in solution, and that the particles unite with each other and form crystals while the gum is hardening.

The oyster obtains the lime for its shell from the water, and while the amount dissolved in each gallon is very small, it extracts enough to provide for the slow growth of the shell. It is very important that the shell be built up as rapidly as possible, for the oyster has many enemies continually on the watch for thin-shelled specimens. In the lower part of the bay I have leaned over a wharf and watched the sheepshead moving up and down with their noses close to the piles, crushing the shells of the young oysters between their strong jaws and sucking out the soft bodies. As I have watched them I have seen the juices from the bodies of the little oysters streaming down from the corners of their mouths, to be swept away by the tide.

The sooner a young oyster can make a shell thick enough to resist such attacks the better, not only for the oyster but for us also; for once past this dangerous 
stage of development, there is a prospect that it may live to complete its growth; though it is true that the fully grown oyster has many enemies which either crush the shell or pull it apart, or else bore holes through it in order to reach the delicate flesh within. At all times in its life its chance of survival is greatest when the supply of lime is so abundant that it is able to construct a thick, massive shell quickly. The rate of growth of any animal must be regulated by the supply of that necessary ingredient of its food which is least abundant, as may be illustrated in many ways. To run a locomotive the engineer must have fuel and water and oil. He needs very little oil, but that little he must have. After this is gone, an unlimited supply of fuel and water will not help him. He must have oil or stop. So, too, if he have plenty of oil and fuel, but only a little water, he must stop as soon as the water fails. In general, the amount of work he can do is determined by his supply of that of which he has least. If food in general is abundant while there is a scarcity of one necessary article, growth can take place only so fast as the scarce article can be procured. A superfluity of other things is of no value, for it cannot be utilized.

There are many reasons for believing that the growth of oysters is limited by the supply of lime, and that all the other necessary ingredients of their food are so abundant that an increase in the supply of lime would cause more rapid growth, greater safety from enemies, and an increase in the number of oysters. 
All kinds of shelled molluscs grow more rapidly, and reach a greater size, and have stronger and thicker shells in coral seas, where the supply of lime is unlimited, than in other waters. In some parts of the Bahamas the large pink-lipped conch, the one which we often see for sale in the fruit stores of Baltimore, is so abundant that whole islands, large enough to be inhabited, are entirely made up of the broken fragments of these beautiful shells, which have been pounded to pieces and heaped up by the waves.

The fresh-water mussels of our western rivers are very large in limestone regions, and so abundant that the bottom is almost paved with them, while in another river, perhaps only a few miles away, but flowing through a country where there is little lime, they are few and very small, with thin, fragile shells.

If you turn over the old bones which are sometimes found in the woods and fields, you will nearly always find a number of snails which have been drawn to them for the sake of the lime.

In order that the oyster may grow rapidly, and may be securely protected from its enemies, it must have lime. The lime in the water of the bay is derived in great part from the springs of the interior, which, flowing through limestone regions, carry some of it away in solution, and finally carry it down the rivers and into the bay. Some of it is no doubt derived from deposits of rock in the bed of the ocean, and some from the soil along the shores. The geologist tells us that the limestone rock has all of it at one time been part 
of the bodies of living animals. Limestone is either old reefs of fossil coral, or beds of extinct shells, or the skeletons of other animals and plants which lived in remote ages and stored up the lime from the ocean at a time when it was more abundant than it is now. The oyster gets the greater part of its lime from these sources in this roundabout way, but a very considerable portion is obtained in a much more direct way, by the decomposition of old oyster shells.

We save up egg shells to feed laying hens, but we recklessly waste our oyster shells, and treat them as if they were of no value. Some are burned for lime; some are used for making roads and wharves; some are used for filling in low land; some are dumped in great piles at convenient spots in the bay, where they sink far down into the mud and are lost.

I shall soon show that there is another far more important reason why they should be returned to the beds, but their value as food for the oyster is very great, and should lead us to return them to the beds. On the oyster-beds an old shell is soon honeycombed by boring sponges and other animals, and as soon as the sea-water is thus admitted to its interior, it is rapidly dissolved and diffused. In a few years nothing is left. It has all gone back into a form which makes it available as oyster food, and it soon begins its transformation into new oyster shells. In this way the oysters obtain some of their lime directly, without being compelled to draw on the inland beds of ancient 
fossils, and this source of supply would be greatly increased if all the shells could be returned to the beds.

The difference between the right and the left shells of the oyster has a very profound significance, for in science nothing is trivial or unimportant. Most of the near relations of the oyster, like the clam and the fresh-water mussel, have the two sides of the body, and the two shells, alike. These animals are not fastened nor stationary like the oyster. They move from place to place in search of food, and their line of locomotion lies in the plane which divides the body into halves. They are erect and bilaterally symmetrical like other locomotor animals, such as the horse, the fish, the butterfly and the crab. The full-grown oyster has no locomotor power and it lies on its left side, but in the early part of its life it is very active, and is then bilaterally symmetrical like the clam. When it ceases its wanderings and settles down for life, it topples over, falls on its left side, and fastens itself by its left shell, which soon grows deep and spoon-shaped, while the right one becomes a flat movable lid. The body, which was originally symmetrical, becomes distorted or twisted to fit the difference in the shells, and naturalists see in the fact that the locomotor relations of the oyster are symmetrical through life, while the oyster loses its symmetry as soon as it settles down, one of the proofs that it is descended from locomotor ancestors. There are many other proofs that this has been its history, and that it has, in comparatively modern times, learned to fasten itself to rocks above 


\section{PLATE I.}

FIGURE I. The left side of an oyster lying in one shell, with the other shell removed. The mantle has been turned back a little, to show its fringe of dark-colored tentacles, and in order to expose the gills. The part of the mantle which is turned back in this figure marks the place where the current of water flows in to the gills.

FIGURE 2. An oyster in the left shell, with the right shell and right fold of the mantle removed, to show the gills and the body of the oyster.

$a$ is the hinge, $b$ the edge of the mantle, $c$ is the muscle, $d$ is the pericardium, $f$ is the hinge ligament, $g$ the gills, $h$ the lips. 

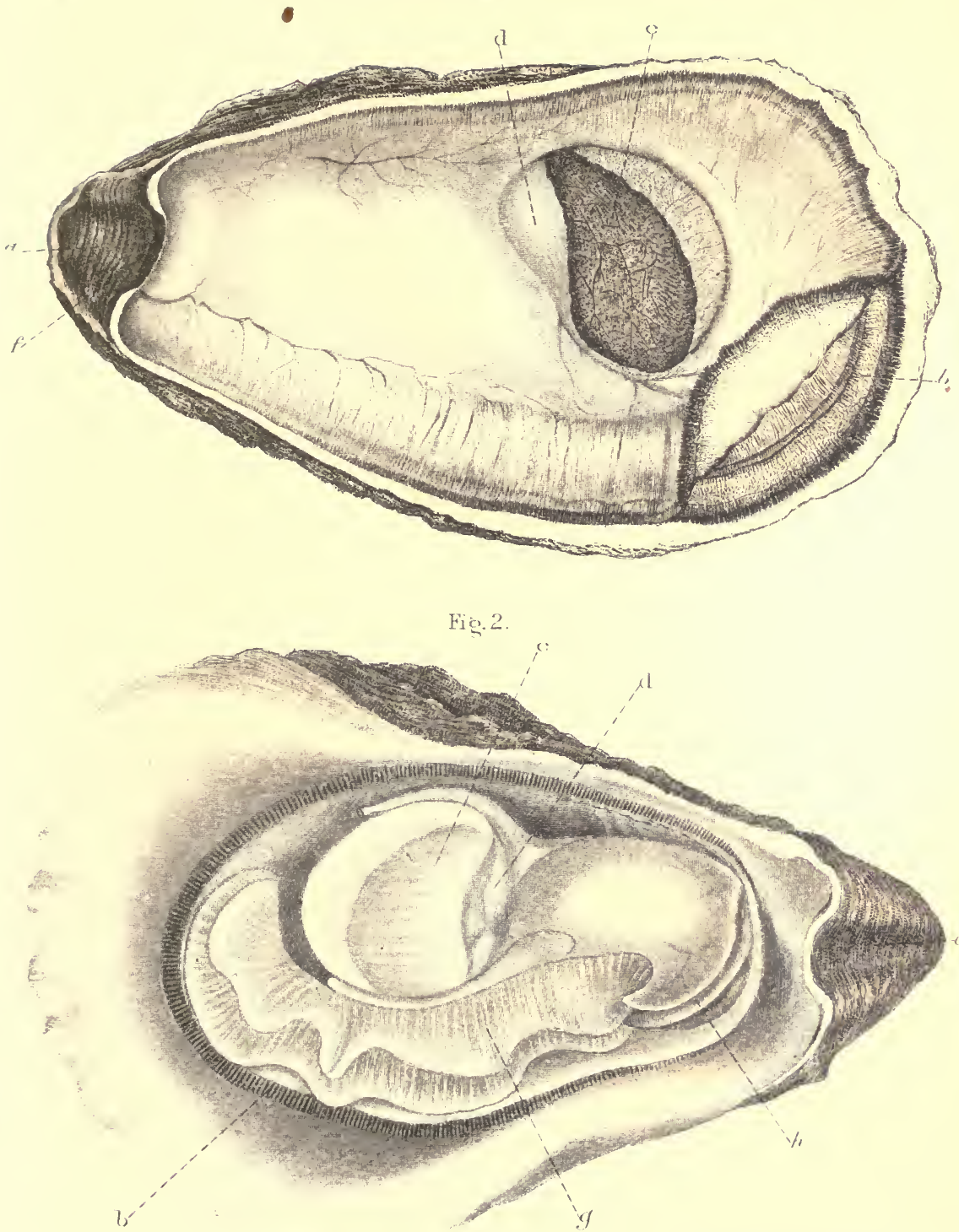

A. Hoen \& Co. Lithocaustic Baltimore. 

the soft mud of our bays and estuaries, in order to avail itself of the rich vegetation; that it has lost its symmetry in order to fit it for this mode of life. The oyster is a very ancient animal, and its sedentary habits belong to the more modern part of its history ; although this change took place very long ago, so far as human chronology goes, for fossil oysters are found in many parts of the world.

In order to understand the anatomy of the oyster, a clear conception of the structure and significance of its gill is most important. In all the bivalve molluscs the gills are very complicated, and they dominate the whole structure of the body in such a way that an anatomical sketch of the animal is of necessity little more than an account of the gills. A thorough knowledge of the oyster-gill will not only throw light on the purpose and use of all its other organs: it will at the same time help us to understand the great value of the animal as a means for making the microscopic inhabitants of our waters useful, and it will also show how well it is adapted for cultivation, and why it is impossible for natural oysters to stock the whole bay without aid from man.

The labor which is necessary before we can have a clear, accurate picture of the gills; of their complicated structure; their relation to other parts of the body; their use and their origin, is considerable, but it is well worth while; for the gills give us the key to the whole significance of the oyster. The oyster's gill cannot be understood without close attention to all the 
details of a long, complicated and minute description, which from the nature of the case cannot be stated briefly, although it may all be put in simple language.

A gill is, of course, a breathing organ, for aerating the blood by exposing it to the oxygen in the water; and the oyster has a heart for driving the blood which has been purified in the gills to the various organs of the body. It is easy to see and study the oyster's heart, but in order to do so the animal must be opened with great care, by cutting the muscle with a thin sharp blade, as near the shell as possible. If this is done, a small semi-transparent space will be seen close to the inner edge of the muscle. The thin membrane which covers the space is the pericardium, or the chamber which holds the heart, Plate I, $d$, and through its transparent wall this may be seen slowly pulsating; for an oyster is not killed by opening its shell, and its heart continues to beat for hours, or, under favorable conditions, for days. If the pericardium be gently lifted and cut with sharp scissors, the heart, Plate II, $d$, with its blood-vessels, will be exposed. It consists of two chambers, the auricle, which receives the pure blood from the gills, and the ventricle, which drives it through arteries to the various organs of the body.

While the gill of an oyster is a breathing organ, like the gill of a fish or crab or conch, this is only one of its many uses. The fish and the crab and the conch have other organs for supplying the gills with a stream of fresh water, but the gills of the oyster, besides purifying the blood, keep up a circulation of water for 
themselves. They are also organs for gathering up food from the water, and after it has been gathered they become organs for carrying it to the mouth. They are also reproductive organs, adapted for securing the fertilization of the eggs, and thus providing for the propagation of the species. In the European oyster and in the mussel they are also brood-chambers, in which the young are held and protected and nourished during their early stages of growth, until they are large enough to care for themselves.

An organ which is at once a gill, a pump for supplying the gills with water, a food-collector, an organ for carrying the food into the mouth, a reproductive organ, and a nursing-chamber, must, of course, be complicated. The oyster's gill does all these things, and does them all well. It is not a jack-of-all-trades, but a machine which is beautifully adapted for carrying them all on at the same time, in such a way that each use helps the other uses, instead of hindering them. This is the more remarkable since an ordinary mollusc, such as the conch, has distinct organs for all these purposes, although the oyster's gill does everything just as well and just as readily as the various organs of the conch.

There are four gills in the oyster, two on each side of the body. They are long, flat, thin, leaf-like organs, Plates I and II, $g$, placed side by side, and nearly filling the mantle chamber, in which they hang. Each gill is made up of two leaves, so that there are in all eight gill-leaves. 


\section{PLATE II.}

An oyster in the right valve of the shell, dissected so as to show the internal organs. The anterior end of the body is at the top of the figure, and the dorsal surface on the right hand.

$b$ the mantle, $c$ the muscle, $d$ the heart, $g$ the gill, $h$ the lips, $i$ the intestine, $j$ the liver, $m$ the mouth, $s$ the stomach. 


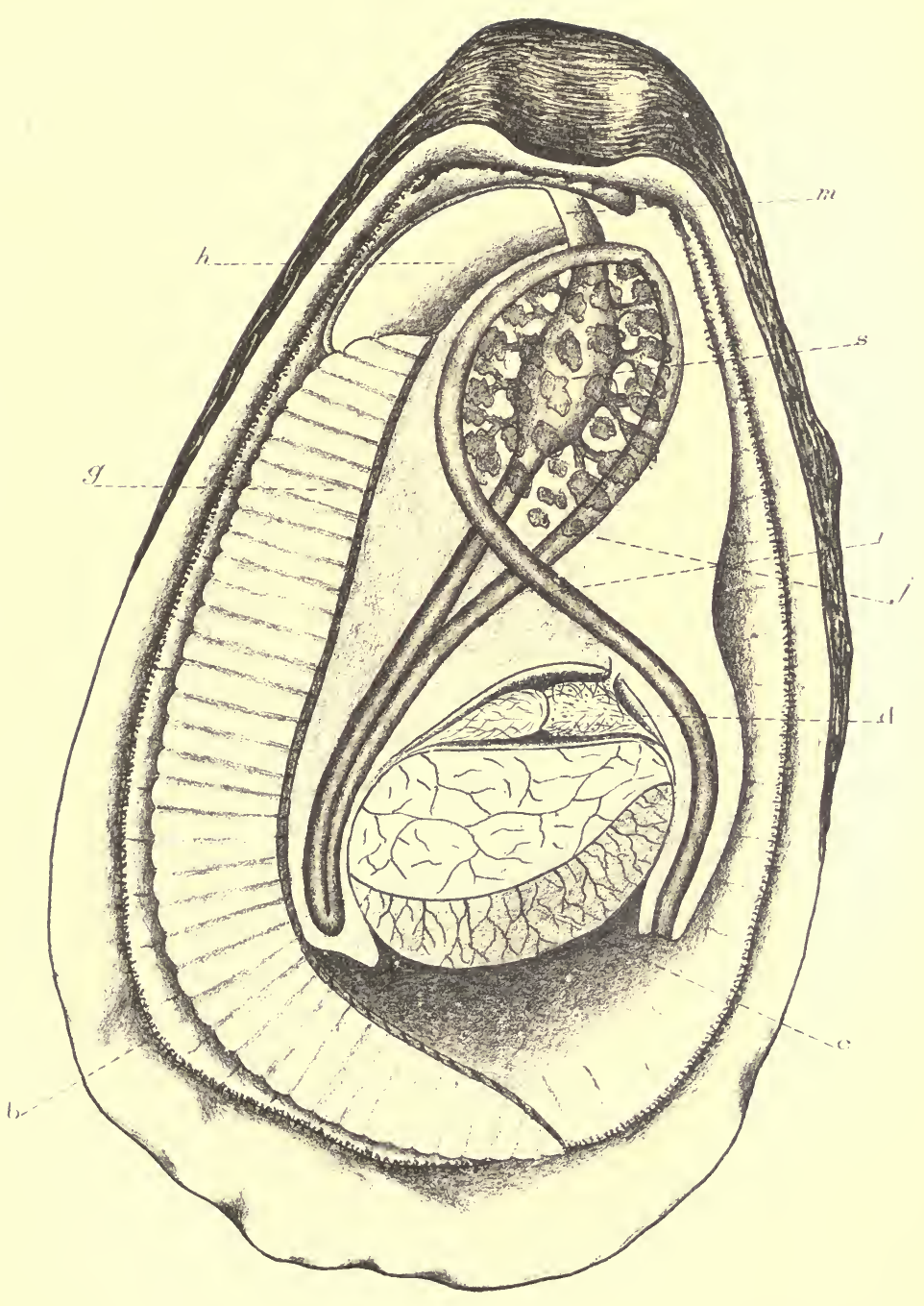

A.Hoen \& Co.Lith 

If you gum together the ends of a folded sheet of foolscap paper, so as to make a flat pocket, this, when held vertically, with the opening above, will form a pretty good model of a single gill.

The closed portions of the four gills hang down into the mantle-chamber, side by side, but their upper edges are fastened to each other, and to the inside of the mantle, in such a way that they form a folded partition, something like a double $\mathrm{W}$, which divides the mantle-chamber into two parts: a lower chamber, in which the gills hang, known as the gill-chamber, and an upper chamber, into which the pockets open. This chamber is known as the cloaca, the Latin word for a sewer, or channel for waste water, and I hope to show you the fitness of the name soon.

The partition between the two chambers is formed somewhat in this way. The upper edge of the outer leaf of the outer gill is united, along its whole length, to the inner surface of the mantle. The upper edge of the inner leaf of the outer gill is united to the same edge of the outer leaf of the inner gill. The upper edges of the inner leaves of the two inner gills are united to each other on the middle line of the body.

If you were to make four pockets out of four sheets of paper, and were then to gum two of them together along their free edges, you would make a double pocket, which might be opened out so that a section through it would be like a W. This would serve as a model of the two gills on one side of the body, and two more sheets, treated in the same way would make 
a model of the other two gills. Now gum two W's together, side by side, and the double $\mathrm{W}$ will be a model of the four gills. Now open a very large bookcover, just far enough to gum the upper outer edge of one $\mathrm{W}$ to the inside of one cover, and the opposite edge of the other $\mathrm{W}$ to the other, and you will have a rough model of the coarse anatomy of the oyster's gills, like the diagram in Fig. I of Plate III. The space between the covers is the mantle-chamber, divided by the gills into a lower portion or gill-chamber, in which the gills hang, and an upper cloacal chamber, into which the pockets open.

So far I have spoken of the gills as if the pockets reached, without interruption, from end to end, but this is not the case. Each pocket is divided up, by a series of vertical partitions, into a number of small cavities-the water tubes, each of which ends blindly below, and opens above into the cloaca.

To represent them in our model we must gum the two leaves of each pocket together from top to bottom along the series of vertical lines about an inch apart. Our model is very much larger than the actual gill, of course.

The spaces between the partitions which are thus formed will represent the water tubes, w, in Figs. I and 3 of Plate III, closed below and opening above into the cloaca, and our model will now illustrate the anatomy of the gill, so far as it can be made out without a microscope.

I must now speak of the minute anatomy. If a 
small piece of one of the gills be cut out, and spread flat upon a glass slide so that its surface may be examined under a microscope, it will be found to be thickly covered with parallel ridges running from top to bottom, like the lines on the sheet of paper, each ridge being separated from the next one by a deep furrow. Fig. 3 of Plate III is a greatly magnified drawing of a cross-section of a small part of a gill, including one water tube, $w$, and the partitions $a, a$, between it and the adjacent tubes; $r, r, r$ are the ridges, and $p, p$ water pores. In the bottoms of the furrows there are many minute openings-the water pores, which pass through the wall of the gill into the water tubes, and thus form the channels of communication between the two divisions of the mantlechamber.

The ridges themselves are hollow, or rather, each one contains a minute blood-vessel, which runs throughout its entire length, so that each wall of each gill is practically a grating of parallel, vertical bloodvessels, in which the blood is purified by contact with the water which fills the gills and the chamber in which they hang. The purified blood is then forced into larger vessels, which carry it to the heart, by which it is pumped to all parts of the body, to be again returned to the gills after it has become impure.

The gills are therefore easily intelligible, so far as they are simply organs of respiration; they hang in the water which fills the mantle-chamber, and their 
walls are filled with blood-vessels in which the blood comes into close contact with the water.

The way in which the current of fresh water is kept up to bathe the gills continually with a new supply is: more complicated.

When one of the ridges on the surface of the gill is. examined with a high power of the microscope, it is found to be fringed on each side by a row of fine hairs, Plate III, Fig. 2, $c$, c, each one less than $\frac{1}{500}$ inch long, and so fine that a good microscope must be used to see them. They project from the sides of the ridges, over the furrows between them, and therefore overhang the water pores in the bottoms of the furrows.

In a fragment cut from a fresh gill, each one of these hairs is constantly swaying back and forth, with a motion like that of an oar in rowing, quick and strong one way, and slower the other way. They all move in time, but they do not keep stroke, for each one comes to rest an instant before the one on one side of it, and an instant after the one on the other side. So that waves of motion are continually running from one end of each ridge to the other, like the waves which you have seen running over a field of ripe grain, as each stalk bends before the wind and then recovers.

What would happen if a boat's crew were to row with all their strength, with the boat tied to a wharf? As they could not pull the boat through the water, they would push the water past the boat. This is exactly what the hairs do. They set up a current in the water. Each one is so small that its individual 
effect is inconceivably minute, but the innumerable multitude causes a vigorous circulation, and each one is set in such a position that it drives the water before it from the gill-chamber into one of the water pores, and so into one of the water tubes inside the gill. As these are filled they overflow into the cloaca and fill that. If the mantle were closed, all the water would soon be pumped out of the gill-chamber into the cloaca, but you remember that an oyster at rest always has the mantle open. As fast as the gill-chamber is emptied by the hairs, fresh water streams in from outside, to be, in its turn, driven through the water pores into the water tubes, and through them into the cloaca, whence it is driven out between the open shells and away from the oyster.

So much for the gills as organs for maintaining a current of water. We come now to the way in which they procure food.

The food of the oyster consists of microscopic organisms, minute animals and plants, which swim in the water. They are pretty abundant in all water, but those who do not work with the microscope have very erroneous ideas on the subject. When a professional exhibitor shows you, under the microscope, what he calls a drop of pure water, it is nothing of the sort. It is either a collection made by filtering several barrels of water, or else it is a drop squeezed from a piece of decayed moss, or from some other substance in which microscopic organisms have lived and multiplied.

Sea water is like fresh water in this respect, and an 
oyster must strain many gallons of water to get its daily bread; but the gills, with their hundreds of thousands of microscopic water pores, are most efficient strainers.

The surface of the gills is covered by an adhesive excretion, for entangling the microscopic organisms contained in the water, and as this circulates over and through the gills, they stick fast like flies on fly-paper. The hairs which drive the water through the gills, push the slime, with the food which has become entangled in it, towards the mouth, which is well up towards the hinge; for it is hardly necessary to say that what the oystermen call the mouth is only the opening between the halves of the mantle.

On each side of the mouth, Plate II, $m$, there is a pair of fleshy organs, Plate I and II, $h$, called the lips, although they are more like mustaches than lips, for they hang down on each side of the mouth. One on the right is joined to one on the left, above the mouth, while the other two are joined below it, so that the mouth itself lies in a deep groove or slit between the lips.

The ends of the gills fit into this groove, and as the hairs slide the food forward, it slips at last between the lips and slides into the mouth, which is always open. As this process is going on whenever the oyster is breathing, the supply of food is continuous, and while it consists, for the most part, of invisible organisms, the oyster's stomach is usually well filled. It is not necessary to describe the oyster's stomach and intes- 
tine, and dark-colored liver, as these will be understood from the figure. The chief purpose of the anatomical sketch is to show the wonderful way in which the gills of the oyster fit it for gathering up the microscopic life of our bay, and for turning it into valuable human food. Looked at from this point of view, the minute anatomy of the animal becomes eminently practical, as it enables us to understand its true relation to man.

In view of the very exceptional fertility of the bay, and its boundless capacity for producing microscopic vegetation, the immense importance of an animated strainer, perfectly adapted for filtering very great quantities of water, for gathering up the microscopic life which it contains for digesting and assimilating it, and for converting it into food of the most attractive and nutritious character, cannot be overestimated; but after we have studied the embryology of the oyster, we shall understand why the natural oysters alone can never utilize all the resources of our waters. We shall see why it is that the oyster is so well fitted for domestication and cultivation, and why the cultivation of oysters will render the Chesapeake Bay incomparably more valuable than it has ever been even before our natural beds began to deteriorate.

THE OYSTER AS A SOURCE OF THE INFECTION OF HUMAN BEINGS WITH CHOLERA AND TYPHOID FEVER.

The reader of the preceding pages will see that the oyster is an admirably constructed machine for filtering 


\section{PLATE III.}

(Drawn by J. L. KellogG.)

Figure I. A diagram to show the double-w-like arrangement of the eight leaves forming the four gills. The gill-chamber of the mantle is supposed to be on the right and the cloacal chamber on the left. $w$ is the opening of a water tube.

FIGURE 2. A very highly magnified view of a crosssection of two of the gill ridges, to show the blood channels, and the gill-cilia, $c, c$.

FIGURE 3. A highly magnified cross-section of part of a gill, including one water tube, $w$, and the partitions, $a, a$, between it and the adjacent tubes. $r, r, r$, the ridges, $p, p$, the water pores. 


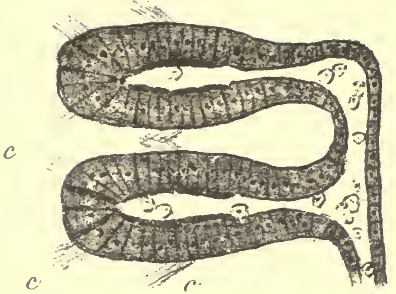

Fio. 2.

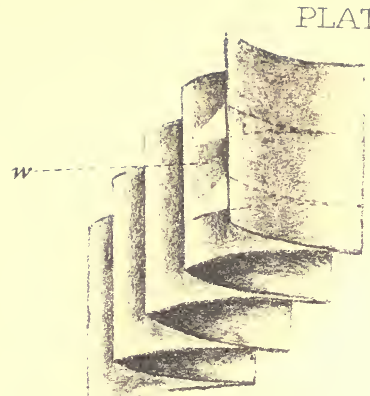

Fig.

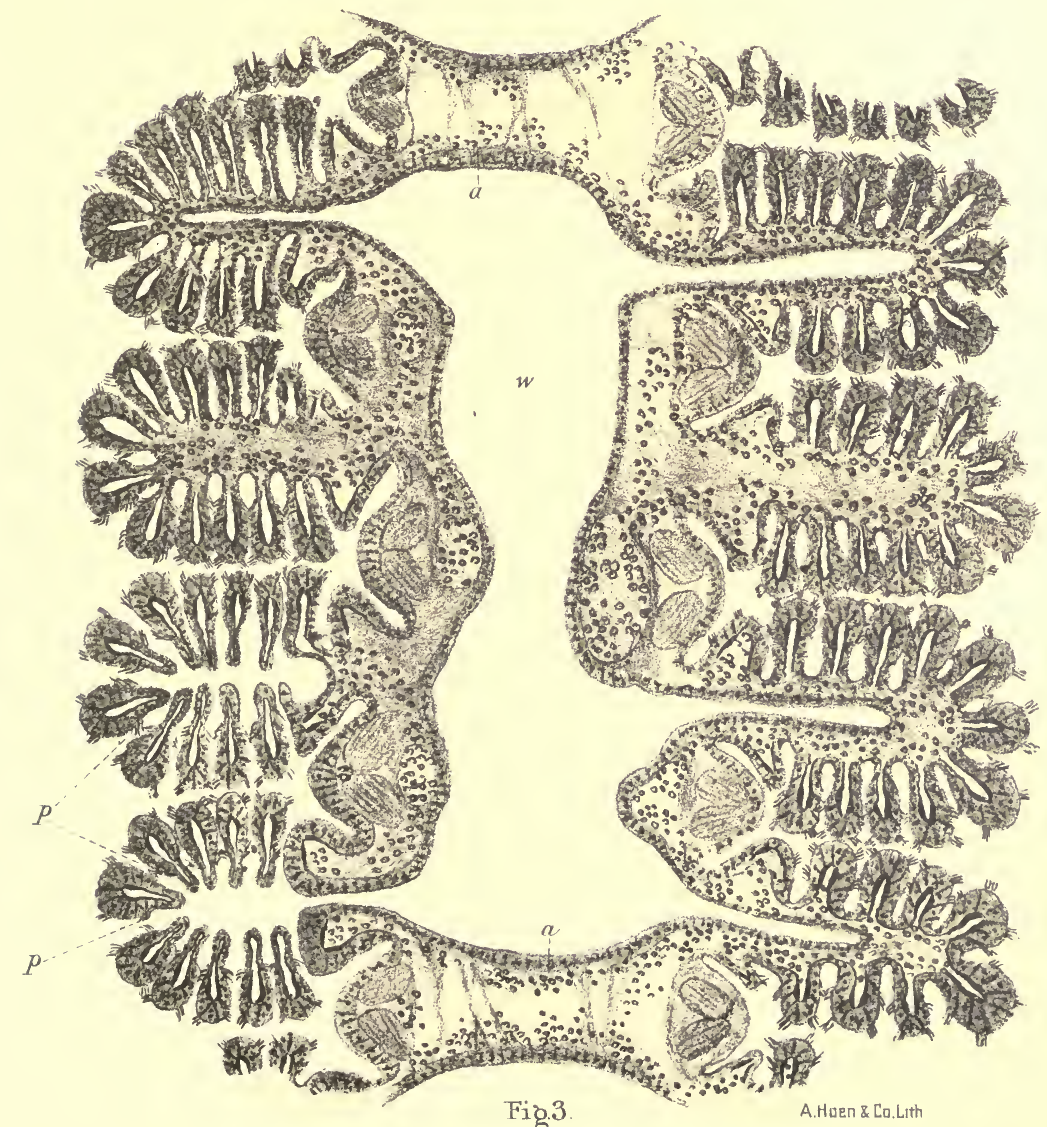



out the microscopic organisms that float in the water. Many gallons-probably many barrels-of water are drawn through the gills of each oyster every day, and the microscopic beings that it may contain strained out and entangled upon the surface of these natural strainers, and pushed along towards and into the oyster's mouth, in a stream that, while almost as slow as the movement of the minute hand of a watch, is steady and almost uninterrupted. Each microscopic organism is a long time in travelling from the point where it first touches the gill into the oyster's stomach. All this time it is alive, and capable of reproducing its kind and becoming the parent of new generations, when removed from the gill and placed under suitable conditions. Most of these organisms are wholesome to man, and all that enter into the oyster's stomach are quickly killed and converted into its palatable and nutritious substance, but, so long as they are travelling along the gills, all are alive, and some extremely dangerous to man. The oyster exercises choice in the selection of its food, rejecting some of the microscopic organisms, and swallowing others; but those that are discharged into the water with the sewage of cities are not, unfortunately, among the ones that are rejected; and before these have entered the oyster's stomach, they are most favorably placed for gaining entrance into human stomachs and multiplying there.

It has been known to naturalists for many years that epidemics of clolera and typhoid fever have arisen through the contamination of oysters by sewage; and, 
within recent years, so many cases of typhoid fever have been traced to oysters that this source of danger to the health and life of human beings is now recognized and, perhaps, exaggerated by the readers of the newspapers; although this danger, as well as the danger to the fair fame of our oysters, is real and serious, and increasing with the growth of the cities and towns upon the shores of the Chesapeake Bay and its tributaries.

The danger of the pollution of the open waters of the Bay is slight, and dead organic matter is here quickly oxidized and destroyed by the agitation and aeration of the water by the waves. In my opinion, no one need fear to eat true salt-water oysters raw, but every "fresh-water oyster" and every "fattened oyster" is too dangerous to be eaten raw.

A menace to health concerns us all, and every citizen should do his part to protect our oysters from the slightest breath of suspicion. A bad name would be the most serious by far of all the obstacles to the development of a flourishing oyster industry in our waters.

So long as we use oysters for food, and eat them raw, the whole Bay should be treated as drinking water, for while no one does drink its water, most of us are fond of eating raw oysters.

Every citizen of Maryland or Virginia should make it his business to put a stop to the discharge of sewage into our waters, and the great cities should take the lead in this and set a good example.

There is one practice so pernicious and so useless 
that all should unite in protesting against its continuance. This is the so-called "fattening" of oysters. When oysters are removed from more saline water to that which is less salt, they absorb water quickly, and become plump, or " fat," but the fatness is nothing but water. The "fattening" is usually carried on in the mouths of rivers or in habors, which are always near towns and polluted by sewage.

Every "fattened" oyster is too suspicious to be eaten raw, and the outbreaks of typhoid fever which have been traced to oysters most clearly have been traced to "fattened" oysters. All the fresh water that a "fattened" oyster has absorbed is at once extracted by cooking, so the "fattening" of oysters that are to be cooked is not only an unnecessary expense, but a fraud on the consumer, who is sold filthy water from the harbors of cities at the price of oysters. 


\section{CHAPTER III.}

THE DEVELOPMENT OF THE OYSTER.

The body of an oyster is not a simple, unorganized lump of flesh, but a complicated organism, made up of many parts, each one so related to the other parts that we must study the whole animal before we can understand the admirable adjustment of each organ to its use.

The oyster is unintelligible until we have studied the organs which compose it, and the organs themselves are unintelligible unless they are studied as constituent parts of the whole.

The oyster is a unit, a complete individual whole, made up of units of a lower order, the organs, in somewhat the same way that a regiment of soldiers is a unit, made up of units of a lower order, the companies.

A description of the organs of the oyster does not, however, by any means complete the analysis of its body, for when any part is studied under a microscope, after it has been properly prepared, it is found to be made up of units of a still lower order, just as each company is made up of individual soldiers, or as the ten dimes which make a dollar are themselves made up of cents. 
Every part consists of cells, which are united into organs, in nearly the same way that these are united to form the oyster; and in order that what I shall say about its development from the egg may be intelligible, this fact must be held clearly in mind.

Each cell is a minute portion of living matter, with an individuality of its own, like the individualities of the soldiers which form the regiment.

The properties of each organ are due, in part, to the way in which the cells are arranged, and in part to the properties of the cells themselves, for the cells which enter into one organ may be quite different from those which enter into another.

Each of the cells which form the glandular surface of the mantle is itself a gland, and is quite different from a muscle cell, so that, in a certain sense, the activity of the mantle in forming the shell is the sum of the activities of its cells, just as the evolutions of a regiment are the sum of the actions of the soldiers, but a regiment can do many things which would be beyond the power of an unorganized mob, and the formation of the shell is due to the activity of the mantle as a whole.

In an adult oyster we have gland cells in the mantle, muscle cells in the muscles, nerve cells in the nervous system, ciliated cells in the gills, and so on; but if we study the animal at earlier and earlier stages, we find that these distinctions disappear, until, in ultimate analysis, all the cells are alike so far as the microscope tells us. 
They are simply minute, definitely limited masses of living matter, with the power to grow when furnished with food; and after their size has thus increased, they have the power to multiply by splitting up into smaller and more numerous cells, which in their turn grow and multiply in the same way.

They at first exhibit no traces whatever of the uses to which they are to be put, but as they grow older they gradually become specialized in various directions and are built up into the tissues and organs of the body, losing at the same time their sharp distinctness and fusing with each other.

Just as certain cells become gland cells, others muscle cells, and so on, certain cells of the adult body become set apart as reproductive cells; eggs in the female and male cells in the male.

The egg cells grow until they become very much larger than any of the ordinary cells of the body; at the same time their outlines become sharply defined, and they become dark-colored and granular. The granular appearance is due to the fact that as they approach maturity they become filled with food, which is stored away in them as a provision for the time when they are to be cast off from the body of the oyster, to lead an independent existence.

The male cells are very much smaller than the eggs, they contain little food, and when they are mature each of them is furnished with a Tong cilium or vibrating hair, by means of which the cell is able to swim 
in the water, while the egg is motionless and sinks to the bottom as soon as it is set free.

When the reproductive elements are fully ripe they are discharged from the body into the cloacal chamber of the mantle. The male cells are swept out into the ocean by the current produced by the hairs on the gills. As they contain no food, their power to live independently is very limited, and all soon die except those that come into contact with eggs.

In the American oyster the eggs are swept out into the water in the same way. The eggs of the European oyster are much larger and heavier, and they fall into the water tubes of the gills and lodge there. Here they are exposed to the current of water which circulates through the gills, and this current brings with it some of the male cells which swim in the water around the oyster-bed. As soon as one of them comes into contact with an egg it fuses with it and loses its individuality and is lost in the substance of the egg, which is thus fertilized and at once begins its development into a new oyster.

There is no such provision for securing the fertilization of the eggs of the American oyster. They are thrown out into the water, like the male cells, to be fertilized by accident, and while many of them meet with male cells, innumerable multitudes sink to the bottom and are lost. It is fortunate for other animals that this is the case, for our oyster is so prolific that if all the eggs were to be fertilized and were to live and to grow to maturity, they would fill up the entire 
bay in a single season. Far from being an exaggeration, this statement is much short of the truth. An average Maryland oyster of good size lays about sixteen million eggs, and if half of these were to develop into female oysters, we should have, from a single female, eight million descendants in the first generation, and in the second eight million times eight million or $64,000,000,000,000$.

In the third generation we should have eight million times this or $512,000,000,000,000,000,000$.

In the fourth, 4,096,000,000,000,000,000,000,000,000.

In the fifth, 33,000,000,000,000,000,000,000,000,000,ooo,ooo female oysters, and as many males, or, in all, $66,000,000,000,000,000,000,000,000,000,000,000$.

If each oyster fill eight cubic inches of space, it would take $8,000,000,000,000,000,000,000,000,000,000,000$ to make a mass as large as the earth, and the fifth generation of descendants from a single female oyster would make more than eight worlds, even if each female laid only one brood of eggs. As the oyster lives for many years, and lays eggs each year, the possible rate of increase is very much greater than that shown by the figures.

The waste of oyster eggs through lack of fertilization is simply inconceivable, but it is possible to fertilize them artificially by mixing the eggs and the male cells in a small quantity of water, where they are certain to come into contact with each other. In this way about 98 per cent of the eggs may be saved and made to produce young oysters, and I have had at 
one time in a small tumbler of water a number of active and healthy oysters, greater, many times, than the whole human population of Maryland.

If several oysters are opened during the breeding season, which varies according to locality and climate, as will hereafter be shown, a few will be found with the reproductive organ greatly distended and of a uniform opaque-white color. These are oysters which are spawning or ready to spawn, that is, to discharge their eggs. Sometimes the ovaries are so gorged that the ripe eggs ooze from the openings of the oviducts before the mass is quite at the point of being discharged. If the point of a knife be pushed into the swollen ovary, a milk white fluid will flow out of the cut. Mixing a little of this with sea water, and placing it on a slide underneath a cover, a lens of Ioo diameters will show, if the specimen is a female, that the white fluid is almost entirely made up of irregularly, pear-shaped, ovarian eggs, each of which contains a large, circular, transparent, germinative vesicle, surrounded by a layer of a granular, slightly opaque yolk. Perfectly ripe eggs will be seen to be clean, sharply defined, and separate from each other. If the specimen be male, a glance through the microscope shows something quite different from the fluid of a female. There are no large bodies like the eggs, but the fluid is filled with innumerable numbers of minute granules, which are so small that they are barely visible when magnified Ioo diameters. They are not uniformly distributed, but are much more 
numerous at some points than at others, and for this reason the fluid has a cloudy or curdled appearance. By selecting a place where the granules are few and pretty well scattered, very careful watching will show that each of them has a lively, dancing motion; and examination with a power of 500 diameters will show that each of them is tadpole-shaped, and consists of a small oval, sharply defined "head," and a long, delicate " tail," by the lashing of which the dancing is produced. These are the male cells, whose union with the eggs or ova of the female is necessary to the fertilization of the latter, and the consequent hatching of living oysters.

The number of male cells which a single male will yield is great beyond all power of expression, but the number of eggs which an average female will furnish may be estimated with sufficient exactness. An unusually large American oyster will yield nearly a cubic inch of eggs, and if these were all in absolute contact with each other, and there were no portions of the ovaries or other organs mixed with them, the cubic inch would contain $500^{3}$, or $125,000,000$. Dividing this by two, to allow for foreign matter, interspaces and errors of measurement, we have about $60,000,000$ as the possible number of eggs from a single very large oyster.

In another place I have shown that, by mixing eggs extracted from a female with male cells, it is an easy matter to secure their union in a watch crystal or in a glass beaker. 
The body of the oyster, like that of all animals, except the very simplest, is made up of organs, such as the heart, digestive organs, gills and reproductive organs, and these organs are at some period in the life of the oyster made up of microscopic cells. Each of these consists of a layer of protoplasm around a central nucleus, which, in the egg, is a large, circular, transparent body, known as the germinative vesicle. Each cell of the body is able to absorb food, to grow, and to multiply by division, and thus to contribute to the growth of the organ of which it forms a part. The ovarian eggs are simply the cells of an organ of the body, the ovary, and, so far as the microscope shows, they differ from the ordinary cells only in being much larger and more distinct from each other; and they have the power, when detached from the body, of growing and dividing up into cells, which shall shape themselves into a new organism like that from whose body the egg came. Most of the steps in this wonderful process may be watched under the microscope, and, owing to the ease with which the eggs of the oyster may be obtained, this is a very good egg to study.

About fifteen minutes after the eggs are fertilized, Plate IV, Fig. I, they will be found to be covered with male cells. In about an hour the egg will be found to have changed its shape and appearance. It is now nearly spherical, and the germinative vesicle is no longer visible. The male cells may or may not still be visible upon the outer surface. In a short time a little trans- 
parent point makes its appearance on the surface of the egg, increases in size, and soon forms a little, projecting, transparent knob-the pole cell.

Soon after, a second pole cell is formed, and the female pronucleus unites with the male pronucleus to form the nucleus of the developing egg, which egg now becomes pear-shaped, with the pole cells at the broad end of the pear, and this end soon divides into two parts, so that the egg is now made of one large mass and two slightly smaller ones, with the pole cells between them. Plate IV, Fig. 2.

The later history of the egg shows that at this early stage it is not perfectly homogeneous, but that the protoplasm which is to give rise to certain organs of the body has separated from that which is to give rise to others.

If the egg were split vertically we should have what is to become one half of the body in one part and the other half in the other. The single spherule at the small end of the pear is to give rise to the cells of the digestive tract of the adult, and to those organs which are to be derived from it, while the two spheres at the large end are to form the cells of the outer wall of the body and the organs which are derived from it, such as the gills, the lips and the mantle, and they are also to give rise to the shell. The upper portion of the egg soon divides up into smaller and smaller spherules, Plate IV, Figs. 3, 4, 5, 6, until we have a layer of small cells wrapped around the greater part of the surface of a single large spherule. This spherule now divides 
up into a layer of cells, and in a sectional view the embryo is seen to be made up of two layers of cells; an upper layer of small transparent cells, which are to form the outer wall of the body, and which have been formed by the division of the spherules which occupy the upper end of the egg, and a lower layer of much larger cells which are to become the walls of the stomach, and which have been formed by the division of the large spherule.

This layer is seen in the section to be pushed in a little toward the upper layer, so that the lower surface of the disk-shaped embryo is not flat, but very slightly concave. This concavity is destined to grow deeper until its edges almost meet, and it is the rudimentary digestive cavity. Fig. 7. A very short time after this stage has been reached, and usually within from two to four hours after the eggs were fertilized, the embryo undergoes a great change of shape. Plate IV, Fig. 8.

A circular tuft of long hairs, or cilia, now makes its appearance at what is thus marked as the anterior end of the body, and as soon as these hairs are formed they begin to swing backward and forward in such a way as to constitute a swimming organ, which rows the little animal up from the bottom to the surface of the water, where it swims around very actively by the aid of its cilia. This stage of development, which is of short duration, is of great importance in rearing the young oysters, for it is the time when they can best be siphoned off into a separate vessel and freed from the danger of being killed by the decay of any eggs which 
may fail to develop. On one surface of the body at this stage there is a well-marked groove, and when a specimen is found in a proper position for examination, the opening into the digestive tract is found at the bottom of this groove. The embryo now consists of a central cavity, the digestive cavity, which opens externally by a small orifice, the primitive mouth, and which is surrounded at all points, except at the mouth, by a wall which is distinct from the outer wall of the body. Around the primitive mouth these two layers are continuous with each other.

This stage of development, in which the embryo consists of two layers, an inner layer surrounding a cavity which opens externally by a mouth-like opening, and an outer layer which is continuous with the inner around the margins of the opening, is of very frequent occurrence, and it has been found, with modifications, in the most widely separated groups of animals, such as the starfish, the oyster, and the frog, and some representatives of all the larger groups of animals, except the Protozoa, appear to pass during their development through a form which may be regarded as a more or less considerable modification of that presented by our oyster-embryo. This stage of development is known as the gastrula stage.

Certain full-grown animals, such as the fresh-water hydra and some sponges, are little more than modified gastrulas. The body is a simple vase, with an opening at one end communicating with a digestive cavity, the wall of which is formed by a layer of cells, 
which is continuous around the opening with a second layer, which forms the outer wall of the body. This fact, together with the fact that animals of the most widely separated groups pass through a gastrula stage of development, has led certain naturalists to a generalization, which is known as the "gastrula theory." This theory or hypothesis is that all animals, except the Protozoa, are more or less direct descendants of one common but very remote ancestral form, whose body consisted of a simple two-walled vase, with a central digestive cavity opening externally at one end of the body.

Soon a small, irregular plate makes its appearance on each side of the body. These little plates are the two valves of the shell, and in the oyster they are separated from each other from the first, and make their appearance independently.

Soon after the shells make their appearance the embryos cease to crowd to the surface of the water, and sink to various depths, although they continue to swim actively in all directions, and may still be found, occasionally, close to the surface. The region of the body which carries the cilia now becomes sharply defined, as a circular, projecting pad, the velum, Figs. 8, 9, IO, I I ; and this is present and is the organ of locomotion, at a much later stage of development.

The two shells grow rapidly and soon become quite regular in outline, but for some time they are much smaller than the body, which projects from between their edges, around their whole circumference, except 


\section{PLATE IV.}

THE DEVELOPMENT OF THE OYSTER.

All the figures are highly magnified, and all except Figure 12 are reproduced from the author's drawings from nature. Figure 12 is copied from a figure by R. T. Jackson in the American Naturalist, December, I890.

Figure I. A newly laid egg with the male cells fasened to its surface.

Figure 2. An embryo in the two-celled stage.

FIGURE 3. An embryo at the beginning of the fourcelled stage.

Figure 4. An embryo at the end of the four-celled stage.

FIGURE 5. An embryo in the eight-celled stage.

Figure 6. An embryo at the beginning of the sixteen-celled stage.

Figure 7. An optical section of an embryo at the beginning of the swimming stage. $s g$, shell gland; $s t$, stomach.

Figure 8. A swimming embryo a little older than the one shown in Figure 7.

FIGURE 9. The stage in which the first traces of the shell make their appearance. $s$, shell; $s t$, stomach.

Figure IO. The swimming oyster, about three days old. $s$, the edge of the shell; $s t$, stomach; $i$, intestine.

FIGURE II. A swimming oyster about six days old. FIGURE I2. An oyster which has become attached. 

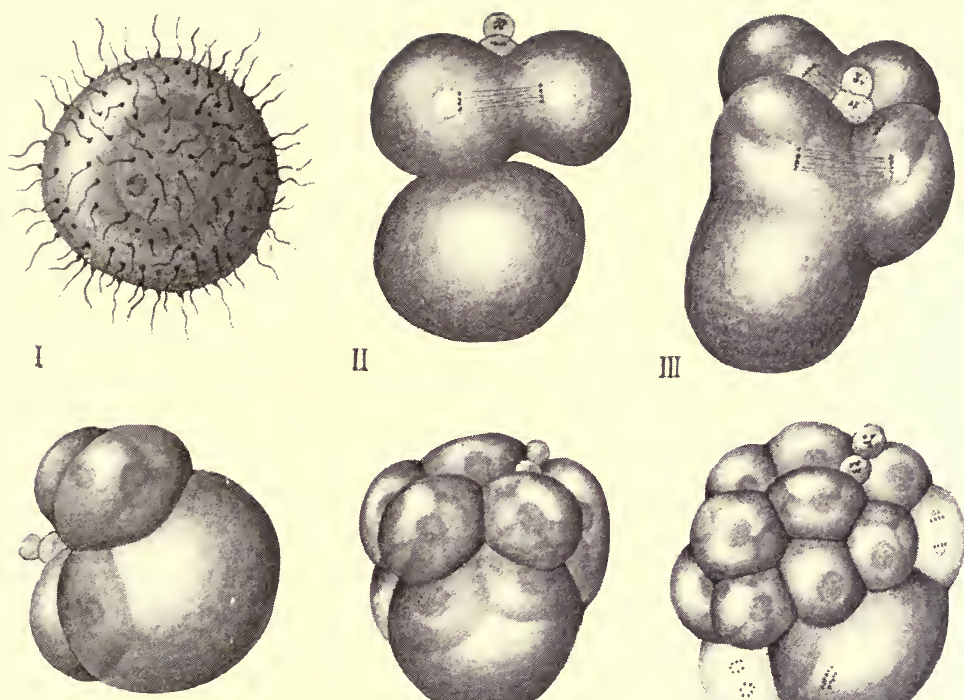

IV

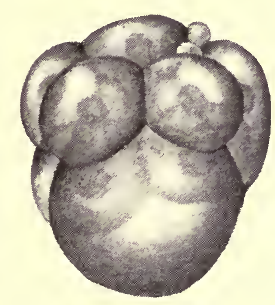

V
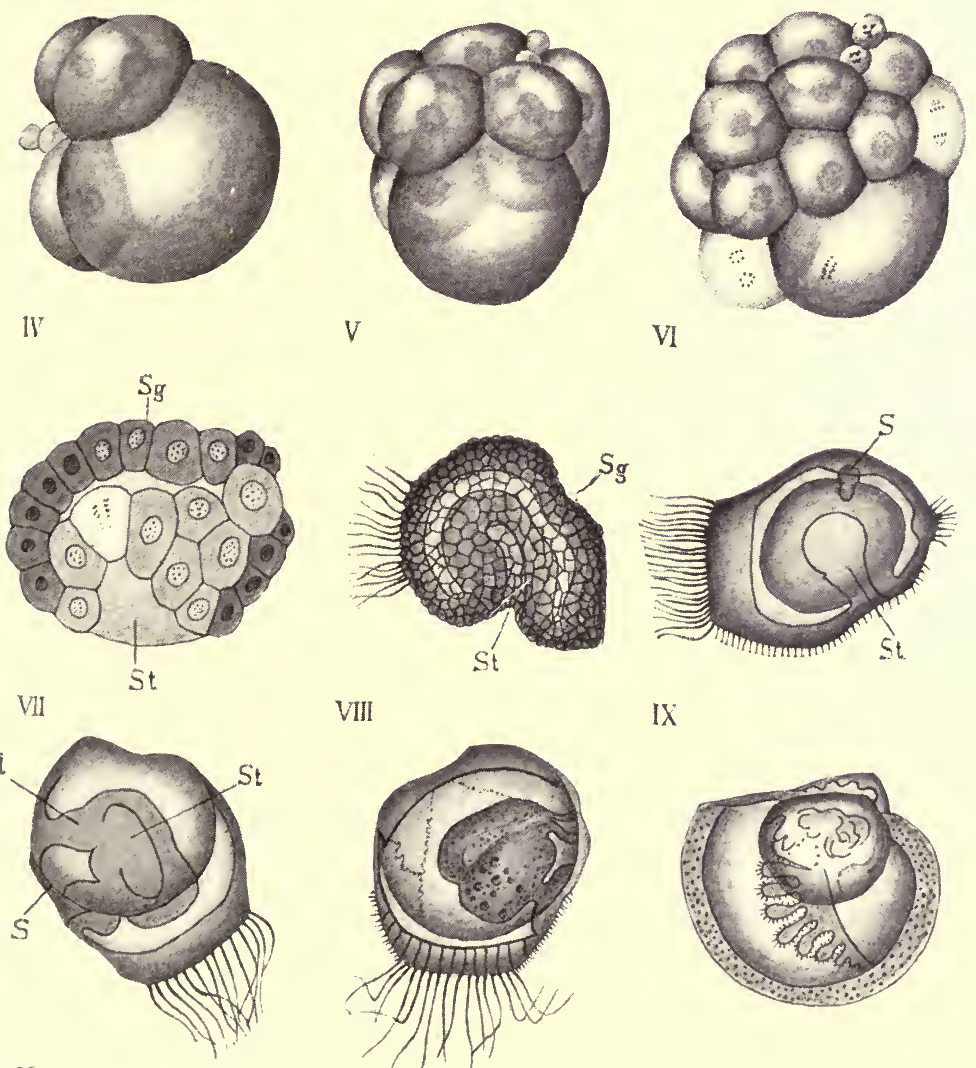

X

VIII

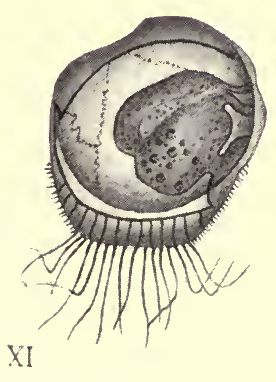

IX

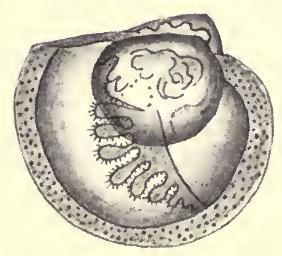

C.Kell ner

XII 

along a short area, the area of the hinge, upon the dorsal surface, where the two valves are in contact.

The two shells continue to grow at their edges, and soon become large enough to cover up and project a little beyond the surface of the body, and at the same time muscular fibres, Fig. II, make their appearance. They are so arranged that they can draw the edge of the body and the velum in between the edges of the shell. In this way that surface of the body which lines the shell becomes converted into the two lobes of the mantle, and between them a mantle cavity is formed, into which the velum can be drawn when the animal is at rest. While these changes have been going on over the outer surface of the body, other important internal modifications have taken place.

Soon the outer wall of the body becomes pushed inward, to form the mouth. The digestive cavity now becomes greatly enlarged, and cilia make their appearance upon its walls; the mouth becomes connected with the chamber which is thus formed, and which becomes the stomach, and minute particles of food are drawn in by the cilia, and can now be seen inside the stomach, where the vibration of the cilia keeps them in constant motion. Up to this time the animal has developed without growing, and is scarcely larger than the unfertilized egg, but it now begins to increase in size.

Soon after the mouth has become connected with the stomach this becomes united to the body wall at another point a little behind the mouth, and a second 
opening, the anus, is formed. The tract which connects the anus with the stomach lengthens and forms the intestine, and, soon after, the sides of the stomach become folded off to form the two halves of the liver, and various muscular fibres now make their appearance within the body.

Such is the history of the oyster-embryo. Its practical utility is in the fact that while the American oyster $\checkmark$ lays a vast number of eggs, they are exposed to dangers so constant and innumerable, that under ordinary conditions few ever come to life, or at any rate succeed in living long enough to anchor themselves and take on the protection of shells. This is only another example of a fact well known to naturalists. The number of eggs laid, or even of individuals born, has very little to do with the abundance of a species, which is determined, mainly, by the external conditions to which it is exposed.

Life of the Young Oyster.-The young American oyster leads a peculiarly precarious life, since it is first thrown out an unfertilized egg, so that the chance that it will immediately meet with a male cell must be very slight; yet if it does not it will perish, for the seawater soon destroys unimpregnated eggs. Having by good chance become fertilized by meeting a male cell, the next period of great danger is the short time during which the embryos swarm at the surface of the water. They are so perfectly defenseless, and so crowded together close to the surface, that a small fish, swimming along with open mouth, might easily swal- 
low, in a few mouthfuls, a number equal to a year's catch. They are also exposed to the weather, and a sudden cold wind or fall in temperature, such as occurred several times during my experiments, killed every embryo. The number which are destroyed by cold rains and winds must be very great indeed. As soon as they are safely past this stage, and scatter and swim at various depths, their risks from accidents and enemies are greatly diminished. $U p$ to this point, which is reached in from twenty-four hours to sixdays, there is no difficulty in rearing them in an aquarium, provided uniform warm temperature be preserved.

Although I failed to keep the young oysters alive until they were large enough to handle and plant, my experiments showed the possibility of rearing them in unlimited numbers, so soon as some practical method of preserving them alive during their infancy should be discovered.

The next great step in this direction is due to Lieut. Winslow. While I was carrying on my experiments at Crisfield, in 1879, this officer was engaged in examining the oyster-beds of Tangier Sound, and he made frequent visits to the laboratory and learned my methods. The next year, while stationed at Cadiz, Spain, on naval duty, he repeated the experiments with Portuguese oysters, and showed that these, like the American oysters, have the sexes separate, and that the eggs are fertilized in the water; that the young are independent of parental protection, and that 
they can be artificially reared like the oysters of our waters. His results were given in a paper which was read before the Maryland Academy of Sciences, in November, I88I, and this paper was afterwards printed in the American Naturalist.

The next great step was the discovery of a simple and practical method of rearing the young oysters which are hatched artificially, and this step, which completes the solution of the problem, and puts it within our power to remove forever all danger of the extermination of the oyster, is the contribution of a French naturalist, M. Bouchon-Brandeley. This author, like Winslow, experimented with the Portuguese oysters, and while he does not seem to have been acquainted with Winslow's paper, he arrived at the same conclusion, and showed that the sexes are separate, that the eggs are fertilized in the water and that the young may be hatched artificially; but he also went one step further, and succeeded in rearing in this way a very great number of seed-oysters fit for planting.

His paper was translated and printed April 19, I883, in the Bulletin of the U. S. Fish Commission. The following extracts from this translation show the character of the methods which are employed, and the results which were obtained:

"When after two years we had learned for a certainty that the sexes of Ostrea angulata are confined to separate individuals, we immediately conceived that it was possible to artificially fertilize the eggs of this 
mollusc. We were likewise encouraged by the experiments which Brooks, of the Johns Hopkins University of Baltimore, had made upon Ostrea virginica, likewise unisexual, and which had enabled him to follow the development of the embryos to the formation of the shell."

"M. Tripota, one of the veteran ostraculturists, and at the same time one of the most competent, very willingly, at the request of the commissioner, M. Jouan, placed at our disposal, with a grace and disinterestedness for which we are under great obligations, two beautiful unsubmersible claires, which received fresh water for several days during the spring tide, and which were soon arranged for our use by means of some slight internal alterations. Separated from each other by a straight, massive wall of earth, these two ponds, with an area of about Ioo meters each, and an average depth of 80 centimeters to I meter ( 27 inches to 3 feet), were placed in communication by means of a pipe, which was closed at either end by a sponge, to keep out any sediment in suspension in the water. In this manner all doubt as to the origin of the spat which was collected was guarded against."

"For the outlet, an apparatus consisting of a wall of find sand confined by boards permitted the water to percolate through it, but prevented the embryos from escaping with it. The lowermost claire only was utilized in our experiments. The uppermost claire, in which we stored the water whenever it was possible, served as a reservoir from which to decant, the supply 
pipe allowing nothing to pass into the experimental claire except clear water."

"This arrangement completed, the products of artificial fecundation, impregnated in various ways, were poured into the experimental reservoir. This took place in the second week in June."

"On the 24th July the tiles were examined. This time all had spat attached. In fact, each of the tiles immersed had young oysters attached, to the number of twenty or thirty, measuring about a centimeter (twofifths of an inch) in diameter. This spat was evidently derived from the spawn put out during the end of June or the commencement of July; but their small size had prevented us from seeing them when the inspection was made at that time. On the $24^{\text {th }}$ July we had specimens about a month old. This fact was all the more remarkable, in that, up to that same time, the collectors placed in the Gironde, in the very center of the spawning beds, did not show a sign of spat."

"The problem which we had put before ourselves had accordingly received, from a scientific and practical point of view, a solution in conformity with our hopes. It was possible to obtain spat by means of artificial fecundation, and to capture it in confined waters. And we no longer had the slightest reason to doubt the identity of that which had caught on our tiles, nor to suppose that it came from the waters without, since there was as yet none apparent in the Gironde, and the tiles in the upper claire, which served 
to feed the experimental claire, were completely exempt."

Such, briefly sketched, is the early history of the oyster, and the process of rearing oysters artificially; but the development of the oyster is of vastly greater interest than a mere description would indicate. It contains enough material for philosophical meditation and for scientific research to occupy many generations of students. The practical importance of a knowledge of its embryology does not end with the facts, for we shall find among the deductions which naturalists have drawn from it much that will help us to appreciate and to utilize the oyster as food.

When the egg is first laid it is a little globule of living matter, with no visible indication of the structure of an oyster, although it is a potential oyster, and is destined to build up, slowly, but surely, from the vegetable food in the water, every part of a complicated adult like that which produced it. It is not, however, an oyster in miniature. Our utmost means of observation do not reveal in it anything whatever, at all like the structure of the adult. Such structure as the microscope does show is the structure of a cell, like one of those which make up the oyster's body, and the process of development is at first simply a process of cell-multiplication, not the unfolding and enlargement of a rudimentary oyster. If we compare an adult oyster to a brick house, then the egg corresponds to a brick, not to a little house, and development begins by cell-division or the multiplication of bricks rather 
than by the growth of a little house. So far a's the microscope tells us, there is nothing like an oyster in the egg, yet it must be there in some form, for an oyster's egg never becomes anything except an oyster. If we knew only the higher animals we might suppose that the development of an egg is guided in some way by the influence of the parent; but there can be no such directing influence in the case of the oyster egg, for this is thrown on the world to take care of itself before its development begins. The force which causes it to become an oyster cannot come from parental influence, nor can it be due to anything in the external world, for hosts of other animals live in the water with the oyster, and side by side with the oyster eggs float those of starfishes, annelids and countless other animals, all exposed to exactly the same external conditions, and yet each develops after its own kind, and builds up cell by cell an animal like its parent.

There is no escape from the belief that the directing force is in the egg itself, and when the microscope was first used to study the early stages of animals, naturalists thought they could discover in the egg the little image in miniature of the future animal, and they taught that this exists in a perfect but dormant and unexpanded condition in the egg, and that the process of development is nothing more than the growth and expansion of this germ.

More careful study with better instruments and improved methods has failed to verify this supposed discovery, and so far as our present means of research 
go, they reveal nothing whatever in the egg which resembles the adult in any particular, nor do they show anything in the oyster egg which should cause it to become an oyster rather than some other animal. The testimony of all observers, based upon the study of all kinds of animals, is that the egg is not comparable to the adult in miniature, but to one of the constituent cells of its body; that the development of an egg is not the unfolding of a germ, but a process of cell-multiplication. The egg divides into a number of cells like itself, and these divide and subdivide until they are very numerous. At first they are alike, but they soon become specialized in different directions, and thus gradually build up the tissues and organs of the body. These gradually acquire their final form, but they are at first simple cell-aggregates, out of which the complex whole is finally built up by the combination and organization of the simple units, somewhat as a regiment of soldiers is organized from a mob of men.

The directing influence must be in the egg, although it has so far eluded all efforts to discover it. The adult oyster, with its complicated organs, so beautifully and wonderfully fitted to its needs, and so intricately related to each other as parts of a complex whole, is a most interesting subject for study. No one can study the structure of any animal without admiring the fitness of all its parts for their work. As we trace out the use of one part after another, and the oyster becomes intelligible to us, its completeness impresses us 
more and more; but if we are thus impressed by the study of a complicated mechanism, adapted for bringing about complicated results, what must be our reflections when we find in the egg the capacity for producing the same results without any visible mechanism whatever! Everything which seems so admirable in the adult, when it is the result of organization, exists potentially in the egg, where there is no discoverable organization; and if the result of the process of development, the complete oyster, is wonderful and interesting, how much more wonderful is the process itself. To those who can picture in imagination its hidden structure, an egg is one of the most marvellous bodies in the universe. Elsewhere we have complex results from complex means, but here we have the most complex of all things, a living body, arising without any visible machinery.

Even after the cells which result from the multiplication of the egg cell become pretty numerous and begin to shape themselves into a complicated body, this at first bears no close resemblance to an oyster, and while the ultimate outcome is an oyster like the parent, I should give my readers a very incomplete and erroneous picture of the history of its development if I did not lay stress upon the very remarkable fact that this result is not reached directly.

The mature oyster is a sedentary animal with no power of locomotion. It lies on its side, soldered to the bottom by the outside of the deep spoon-shaped left shell, for which the flat right shell forms a mova- 
ble lid. Its gills are very complicated organs, adapted for drawing into the fixed shell a steady current of water, and they pour into the open mouth of the animal a constant stream of food, so that eating goes on as uninterruptedly as breathing, and is just as much beyond the control of the animal. The adult oyster makes no efforts to obtain its food, it has no way to escape from danger, and after its shell is entered it is perfectly helpless and at the mercy of the smallest enemy. So far as active aggressive life goes it is almost as inert and inanimate as a plant, and its life is purely vegetative. This is the adult oyster. The young oyster is very different. It is an active animal, swimming from place to place. Its gills are not leaf-like, and they do not divide the mantle-chamber into two parts. They are nothing but breathing organs, and are simple finger-like tentacles which hang down into the water. There is no gill-current as there is in the adult, and the young oyster must find its own food by swimming through the water. Its two shells are also exactly alike, and therefore quite different from those of the adult.

The egg therefore tends, at first, to build up an animal which differs greatly from the adult, in structure as well as in habits, and naturalists believe, as I have already said, that our modern oysters are the descendants of an ancient form which was not sedentary, and the egg at first exhibits a decided tendency to build up this ancestor rather than an oyster.

Some of you may ask how we know that the remote 
ancestors of the oyster were different from modern oysters. This is a fair question, and I will try to give an outline of the reasons for this opinion. Perhaps an illustration may help us.

When a Baltimorean visits New York or Savannah or Boston or Chicago, he finds that while the people of these cities talk the same language, it is with a difference. They all talk what they call English, but when an Englishman comes among us he tells us that it is not English, and it is quite clear to an American who visits England that the people there do not know how to talk United States, although the differences are trivial ones, of accent and idiom, and do not in the least hinder conversation.

If, however, we cross the narrow strip of water which separates England from the German Empire, we find a strange language, which at first seems totally unfamiliar and unintelligible, but as our ears become more accustomed to the strange sounds we find many which are not as unintelligible as they seemed at first.

When a German talks of his vater, his mutter, his bruder, his schwester, when he asks us to share his brod und butter, or offers us a glas wasser, we need no dictionary to tell us what he means.

We know that the Americans and the English of to-day are descended from common ancestors, only a few generations back, from whom they have inherited their common language, and we know from literature that this was not exactly the same as modern English or modern American, and history also tells us that 
still further back, Anglo-Saxon and modern German had a common starting-point. Philologists therefore make use of the resemblances between languages to trace out their origin, and whenever they find that two or three languages have a common plan, a fundamental similarity of grammatical structure, they believe that they are divergent modifications from a common starting-point. In some cases printed language has preserved an actual history of the process, but in other cases, where there is no such history, the student of comparative grammar forms his conclusions by comparison; and, even where the primitive language is lost, he is able to reconstruct it in part, for he knows that it must have been characterized by all the features which its derivatives have in common.

Now, animals exhibit resemblances of very much the same character as those between languages, and when we find that several representatives of a great group are constructed upon the same fundamental plan, we infer, just as the philologist does, that they are the divergent descendants of a common ancestor, from whom they have inherited the features which they have in common.

The philologist is sometimes able to verify his conclusion by the proofs which have been preserved in books and inscriptions, and he regards this as evidence that, in other cases where no such record is preserved, his results are equally trustworthy.

Occasionally the student of comparative anatomy, like the student of comparative grammar, finds a fossil 
form which unites in itself the characteristics of several widely separated descendants, and is thus enabled to test and to verify the conclusions which he has reached by comparative study.

In this way, through the study of details too numerous and minute to be described here, it can be shown that the oyster is descended from a mollusc which was furnished with locomotor organs and sense organs, and which wandered about in search of food, and had altogether a much wider and more varied life than that of the oyster. Its gills were very simple and were nothing but breathing organs, and the many uses which they serve were provided for by distinct organs. Very long ago, as we measure time, but quite late in the history of the mollusca, as the continental areas were elevated and became covered with terrestrial vegetation, and fringed by bays and sounds of brackish water, it gradually became modified in such a way as to fit it for life in these estuaries. Its locomotor organs and its organs for discovering and capturing food were gradually lost, as it learned to feed upon the microscopic life of the mud-flats. The gills then gradually became modified and fitted for maintaining the circulation of water, and for filtering out the minute food particles it contains.

Food is most abundant on the muddy bottom, but in estuaries this is so deep and soft that a locomotor animal would sink and smother in it, so the oyster has gradually become converted into a fixture, and has learned to fasten itself when young to something 
firm enough to keep it out of the soft mud, but near enough to it to be within easy reach of the vast supply of food which it affords. As a fixed animal does not need to have the two sides of its body balanced, the fixed oyster has become one-sided, and has thus been still better fitted for its peculiar mode of life.

These changes, while they are on the whole advantageous, since they enable the oysters to avail themselves of inexhaustible supplies of food, are not without disadvantage. The oyster has become so perfectly adapted for a life on those hard bodies which occur in the soft mud of estuaries, that it cannot live anywhere else, and the young oysters that do not find a proper home soon die. In shallow bays and sounds hard substances are rare and far apart, and many young oysters must perish from inability to find a proper resting place. To meet this danger the oyster's birth rate has been enormously increased, so that among its innumerable descendants some few may be able to find proper homes, and may grow up to maturity in their turn. 


\section{CHAPTER IV.}

THE ARTIFICIAL CULTIVATION OF OYSTERS.

If the Chesapeake Bay is as rich in food for oysters as I have said, and if the oyster multiplies at such a rate of increase, how can our supply be in any danger, or how can there be any need for man to maintain and develop the oyster-beds? At first sight it does not seem possible that an animal which is protected from enemies by a strong stony shell, and which is capable of giving rise to several million eggs each season, can be in any danger of extermination; and it seems as if the oyster ought to be able to hold its own in the struggle for existence, and to increase and multiply in spite of adverse circumstances.

We should rather expect to find the whole bottom of the bay paved with oysters, and for many years, the statement that there is any need for measures to prevent the destruction of our natural beds and the total. extermination of our oysters has been met with ridicule, and it has been flatly contradicted by persons whose qualifications for expressing an opinion would seem to be very great.

In I884 a commissioner, who had been appointed by the General Assembly of the State of Maryland to 
examine and report upon the condition of the oysterbeds of the State, with such recommendations as might seem advisable for the protection of the oyster industry, reported that " he has no fears but what the present oyster supply will be kept up to its present standard, and within a few years increased. The supply is now greater, probably, than ever before, and the prices higher, taking the season through. It is the increased demand and consequent higher prices that has created the oyster panic in the public mind to a great extent. The undersigned is not fully in accord with the majority report in the belief that the oyster property of the State is in imminent danger of complete destruction. This is not likely, unless we fail to give the interest even ordinary care and protection. Whilst in some localities the beds have been greatly depleted by overwork, and in others destroyed chiefly in shallow water tonging ground, the beds and bars as a rule have been greatly enlarged by working them. .. The oyster supply of our waters, taken as a whole, it is likely is as large as ever it was."

In view of this statement, and similar ones from other men who have enjoyed every opportunity to learn the truth of the matter and to qualify themslves to speak upon it with authority, it is not at all strange that there should be much confusion in the public mind and that the prejudiced statements of those who have profited by the destruction of the public property should outweigh the testimony of disinterested students.

The history of the oyster-beds of Europe, and of 
those in many of the Northern States, should have been enough to warn us, years ago, of the need for the protection and development of our own beds; but our people have been too confident of the inexhaustible vitality of our . own beds to heed the warning. So long as the consumption of oysters was restricted to regions in the immediate vicinity of the bay, the number of oysters which could be taken from each bed and put upon the market each season was so small that it could be furnished without taxing the beds; but more than twenty-six years ago, November, I879, I called attention to the fact that the perfection of our facilities for packing and transporting oysters had produced such a great demand, that the danger of destroying our best beds was growing greater every day, and was keeping pace with the growth of our population and the improvements in transportation; and I called the attention of those who believe that the supply is sufficient for all demands to the history of other countries.

No one who is familiar with the history of the oysterbeds of other parts of the world can be surprised at the deterioration of our own beds. Everywhere, in France, in Germany, in England, in Canada, and in all northern coast states, history tells the same story. In all waters where oysters are found at all they are usually found in abundance, and in all of these places the residents supposed that their natural beds were inexhaustible until they suddenly found that they were exhausted. The immense area covered by our own beds has en- 
abled them to withstand the attacks of the oystermen for a much longer time, but all who are familiar with the subject have long been aware that our present system can have only one result-extermination.

An estimation of the effect of excessive fishing may be formed by examining its results upon such beds in England and France as have records upon the subject. The most instructive of these are the records of the production of the beds of Cancale Bay, on the northwest coast of France, which extend over a period of sixty-eight years-from I800 to I868. The beds in the bay comprise an area of about 150 acres, and from 1800 to 1816 produced from 400,000 to 2,400 ,ooo a year. This, however, was the period of the Napoleonic wars, and the fishing was much disturbed by the presence of the English cruisers. During this time the beds became so thickly stocked that the oysters were said to be a yard thick in some places. After the close of the war the fishing improved, and the oysters were removed in larger and increasing numbers until 1843. From 1823 to 1848 it was supposed that the dredgers were living upon the oysters accumulated during the period of enforced rest from 1800 to $I 816$. In 1817 the number of oysters produced was $5,600,000$, and until 1843 there was a constant increase, the number taken in the latter year being $70,000,000$. In 1848 it was $60,000,000$; thenceforward there was a constant decrease. From 1850 to 1856 the decrease was from $50,000,000$ to $18,000,000$, supposed to be the effect of overdredging. From 1859 to 1868 the decrease was 
from $16,000,000$ to $1,079,00$; the oysters having almost entirely disappeared from the beds, though, on account of the suffering condition of the inhabitants of the shores, it was almost impossible to prevent it. In I870 there was a complete wreck of the bottom which could only be remedied by a total prohibition of the fisheries for several years.

From the beds of the districts of Rochefort, Marennes, and Island of Oleron, on the west coast of France, there were taken in $1853-54$ 10,000,000 oysters, and in $1854-55 \times 5,000,000$. On account of exhaustive fishing only 400,000 could be obtained in $1863-64$.

According to the testimony of $\mathrm{Mr}$. Webber, mayor of Falmouth, England, about 700 men, working 300 boats, were employed in a profitable oyster fishery in the neighborhood of Falmouth until I866, when the old laws enforcing a "close time" were repealed, under the impression that, owing to the great productive powers of the oyster, it would be impossible to remove a sufficient number to prevent the re-stocking of the beds. Since I866 the beds have become so impoverished from excessive and continual fishing, that in 1876 only 40 men and 40 boats could find employment, and small as the number is, they could not take more than 60 or Ioo oysters a day, while formerly, in the same time, a boat could take from ro,000 to 12,000.

According to the statement of Mr. Messum, an oyster dealer and the secretary of an oyster company at Emsworth, England, made before the Commission for 
the Investigation of Oyster Fisheries, in May, I876, there were in the harbor of Emsworth, between the years of 1840 and 1850 , so many oysters that one man in five hours could take from 24,000 to 32,000 . In consequence of over-fishing, in 1858 scarcely ten vessels could find loads, and in 1868 a dredger in five hours could not find more than twenty oysters.

The oyster fisheries of Jersey, in the English Channel, at one time afforded employment to 400 vessels. In six or seven years the dredging became so extensive and the beds so exhausted that only three or four vessels could find employment, and the crews of even that small number had to do additional work on shore in order to support themselves.

In view of such facts as these, no one who appreciates the magnitude of the oyster industry of the Chesapeake Bay can doubt that the protection of our beds is a matter of vital importance, for it is quite clear that we cannot trust to the natural fecundity of the oyster.

It is well known to naturalists that the number of individuals which reach maturity in any species of animal or plant does not depend on the number which are born. The common tapeworm lays hundreds of millions of eggs in a very short time, yet it is comparatively rare. The number of children born to each pair of human beings during their lifetime of sixty or seventy years can be counted on the fingers, yet man is the most abundant of the large mammals. The abundance of a species is mainly determined by the ex- 
ternal conditions of life, and the birth-rate has very little to do with it.

In the case of the oyster, the adult is well protected, by its shell, against the attacks of most of the enemies which are found in our waters, and as its food is very abundant and is brought to it in an unfailing supply by water, it is pretty sure of a long life after it has reached its adult form; but the life of the young oyster is very precarious: that of the young American oyster peculiarly so, since it is exposed to many enemies and accidents at the time when it is most helpless. The oyster of Northern Europe lays from one to two million eggs, while our oyster lays about ten times as many, but the protection which is afforded to the young European oyster by the shell of the parent more than balances the greater birth-rate of our oyster.

The most critical time in the life of the American oyster is undoubtedly the time when the egg is discharged into the water to be fertilized, for the chance that each egg which floats out into the bay to shift for itself will immediately meet with a male cell is very slight, and infinite numbers of eggs are lost from this cause. The next period of great danger comes as the little embryos begin to swim and crowd to the surface of the water. They are so totally defenseless and are so close together that a little fish swimming along with open mouth may swallow thousands in a few mouthfuls, and I have found that at this time a sudden fall of temperature is fatal to them, and a cold rain may destroy millions. As soon as they are safely past this 
stage and have scattered and begin to swim at various depths, their danger from accidents and enemies is greatly diminished, and their chance of reaching maturity increases rapidly. Experiments which I carried on many years ago show that there is no difficulty in rearing them up to this point in captivity, and that in a very small aquarium millions of them may be safely carried past the most precarious part of their lives and freed from their greatest dangers.

Although the mortality at their early stages is so excessive, the number of young oysters which pass through them in safety without artificial help is very great, and if there were no other dangers or uncertainties there would be no need of measures for their protection. As they swim to and fro in the water they are carried to great distances by the tides and currents, and they reach all parts of the region of water within several miles of the parent bed. In a favorable season, any plant, or bush, or piece of driftwood which floats near an oyster-bed becomes covered with small oysters, although the nearest bed may be miles away; and the fact that young oysters may be thus collected in any part of our bay shows that they are distributed everywhere, and we might expect the adults to have an equally general distribution. This is by no means the case, and nothing can be farther from the truth than the idea that the bottom of the oyster area is uniformly covered with oysters or ever has been, although it is quite true that oysters may be reared artificially over nearly the whole of it. The idea that it is only neces- 
sary to throw a dredge overboard anywhere in the oyster area, and to drag it along the bottom for a short distance in order to bring it up full, is totally erroneous. Such a condition of things is quite within the reach of the cultivator, but it never exists under natural influences alone. In this country, as well as in Europe, the oysters are restricted to particular spots called "banks," or "beds," or " rocks," which are as well defined and almost as sharply limited as the tracts of woodland in a farming country-they are so well marked that they may be laid down on a chart, or they may be staked out with buoys; and even in the best dredging grounds they occupy such an inconsiderable part of the bottom that no one would have much chance of finding oysters by promiscuous dredging, in ignorance of their location. Although the young are distributed every year by the tides and currents over all parts of the bottom, the dredge seldom brings up even a single oyster outside the limits of the beds, under natural conditions.

The restriction of the oysters to certain points does not depend on the supply of food, for this is everywhere abundant, nor to any great degree upon the character of the water. It is almost entirely due to the nature of the bottom.

The full-grown oyster is able to live and flourish in soft mud so long as it is not buried too deeply for the open edge of the shell to reach above the mud and draw a constant supply of water to its gills; but the oyster embryo would be ingulfed and smothered at 
once if it were to fall on such a bottom, and in order to have the least chance of survival it must find some solid substance upon which to fasten itself, to preserve it from sinking in the soft mud, or from being buried under it as it shifts with wind and tide. In the deposits which form the soft bottom of sounds and estuaries solid bodies of any sort rarely occur, and the so-called "rocks" of the Chesapeake are not ledges or reefs, but accumulations of oyster shells.

Examination of a Coast Survey chart of any part of the Chesapeake Bay or of any of its tributaries will show that there is usually a mid-channel, or line of deep water, where the bottom is generally soft and where no oysters are met with, and on each side of this an area where the bottom is hard, running from the edge of the channel to the shore. This hard strip is the oyster area. It varies in width from a few yards to several miles, and the depth of water varies upon it from a few feet to five or six fathoms, or even more. But there is usually a sudden fall at the edge of the channel, where the oysters stop, and we pass to soft bottom. The oyster bottom is pretty continuous, except opposite the mouth of a tributary, where it is cut across by a deep, muddy channel. The solid oysterrocks are usually situated along the outer edge of this plateau, although in many cases they are found over its whole width nearly up to low-tide mark, or beyond. As we pass south along the bays and sounds of Virginia and North Carolina, we find that the hard borders of the channel come nearer and nearer to the 


\section{PLATE V.}

Oysters fastened to the upper surface of a round boulder, which had formed the ballast of some vessel and had been thrown overboard in the Bay, where the lower half had become embedded in the bottom. The figure, which is about one-fourth the size of the specimen, shows the way in which the oysters grow, in dense crowded clusters, on any solid body which raises them above the mud. 


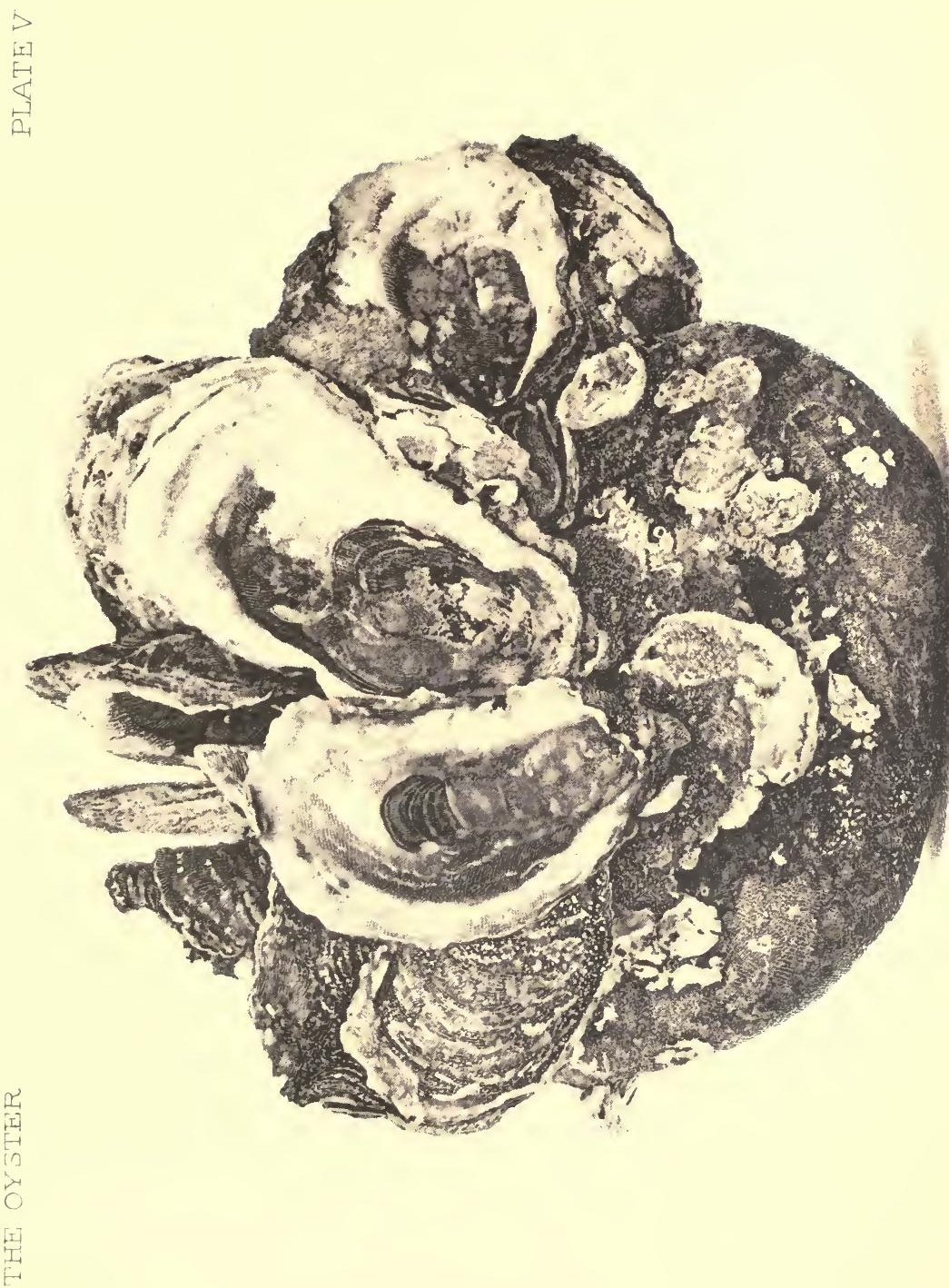



surface, until in the lower part of North Carolina there is on each side of the channel a wide strip of hard bottom, which is bare at low tide and covered with oysters up to high-water mark, although the oysters are most abundant and largest at the edge of the deep water, where they form a well-defined reef. In our own waters there is usually a strip along the shore where no oysters are found, as the depth of water is not great enough to protect them in winter. The whole of the hard belt is not uniformly covered with oysters, but it is divided up into separate oyster rocks, between which comparatively few can be found.

The boundaries of a natural rock which has not been changed by dredging are usually well defined, and few oysters are to be found beyond its limits. The oysters are crowded together so closely that they cannot lie flat, but grow vertically upwards, side by side. They are long and narrow, are fastened together in clusters, and are known as " coon oysters."

When such a bed is carefully examined it will be found that most of the rock is made up of empty shells, and a little examination will show that the crowding is so great that the growth of one oyster prevents adjacent ones from opening their shells, and thus crowds them out and exterminates them. Examination shows, too, that nearly every one of the living oysters is fastened to the open or free end of a dead shell which has thus been crowded to death, and it is not at all unusual to find a pile of five or six shells thus united, showing that number two had fastened, when small, 
to the open end of number one, thus raising itself a little above the crowd. After number one was killed number two continued to grow, and number three fastened itself to its shell, and so on. Usually the oysters upon such a bed are small, but in some places shells twelve or fourteen inches long are met with. The most significant characteristic of a bed of this kind is the sharpness of its boundaries. In regions where the oysters are never disturbed by man it is not unusual to find a hard bottom, which extends along the edge of the shore for miles, and is divided up into a number of oyster rocks, where the oysters are so thick that most of them are crowded out and die long before they are full-grown, and between these beds are areas where not a single oyster can be found. The intervening area is perfectly adapted for the oyster, and when a few bushels of shells are scattered upon it they are soon covered with young, and in a year or two a new oyster rock is established upon them, but when they are left to themselves the rocks remain sharply defined. What is the reason for this sharp limitation of a natural bed? Those who know the oyster only in its adult condition may believe that it is due to the absence of power of locomotion, and they may hold that the young oysters grew up among the old ones, just as young oak trees grow up where the acorns fall from the branches. This cannot be the true explanation, for the young oysters are swimming animals, and they are discharged into the water in countless numbers, to be swept away to great distances by the currents. As 
they are too small to be seen at this time without a microscope, it is impossible to trace their wanderings directly, but it is possible to show indirectly that they are carried to great distances, and that the water for miles around the natural bed is full of them. They serve as food for other marine animals, and when the contents of the stomachs of these animals are carefully examined with a microscope, the shells of the little oysters are often found in abundance. While examining the contents of the stomach of Lingula in this way I have found hundreds of the shells of the young oysters in the swimming stage of growth, although the specimens of Lingula were captured several miles from the nearest oyster-bed. As Lingula is a fixed animal, the oysters must have been brought to the spot where the specimens were found, and as Lingula has no means of capturing its food, and subsists upon what is swept within its reach by the water, the presence of so many inside its stomach shows that the water must have contained great numbers of them.

It is clear, then, that the sharp limitation of the area of a natural oyster-bed is not due to the absence in the young of the power to reach distant points. There is another proof of this, which is familiar to all oystermen-the possibility of establishing new beds without transplanting any oysters.

I once observed an illustration of this. On part of a large mud-flat which was bare at low tide there were no oysters, although there was a natural bed upon the same flats, about half a mile away. 
A photograph, by Dr. Caswell Grave, of an unworked bed, thickly covered with long narrow oysters, among which mussels are crowded. 


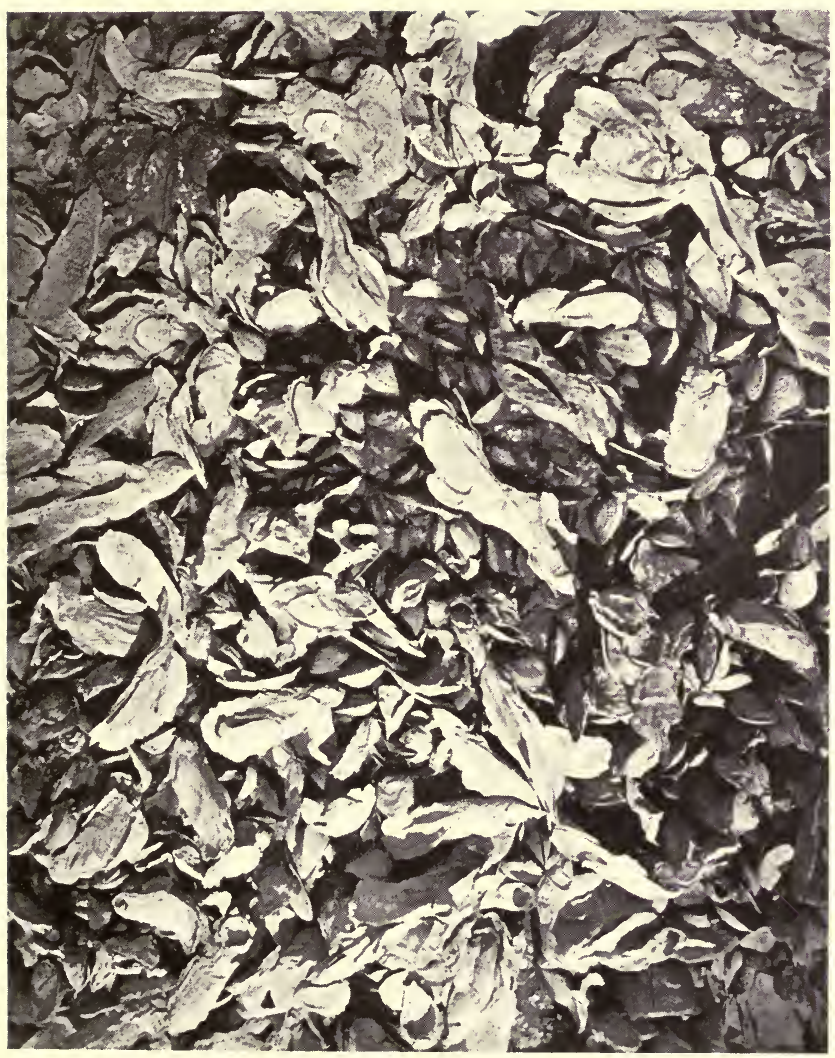



A wharf was built from high-tide mark across the flat out to the edge of the channel, and the shells of all the oysters which were consumed in the house were thrown on to the mud alongside the wharf. In the third summer the flat in the vicinity of the wharf had become converted into an oyster-bed, with a few medium-sized oysters and very great numbers of young, and the bottom, which had been rather soft, had become quite hard; in fact, the spot presented all the characteristics of a natural bed. Changes of this sort are a matter of familiar experience, and it is plain that something else besides the absence in the oyster of locomotor power determines the size and position of a bed.

Now what is this something else?

If the planting of dead shells will build up a new bed, may we not conclude that a natural bed tends to retain its position and size because the shells are there?

This conclusion may not seem to be very important, but I hope to show that it is really of fundamental importance, and is essential to a correct conception of the oyster problem.

Why should the presence of shells, which are dead and have no power to multiply, have anything to do with the perpetuation of a bed?

We have already called attention to the fact that oysters are found on the hard bottom on each side of the channel, while they are not found in the soft mud of the channel itself, and it may at first seem as if there were some direct connection between a hard bottom 


\section{PLATE VII.}

A photograph, by Dr. Caswell Grave, of a worked bed covered with well shaped marketable oysters. 


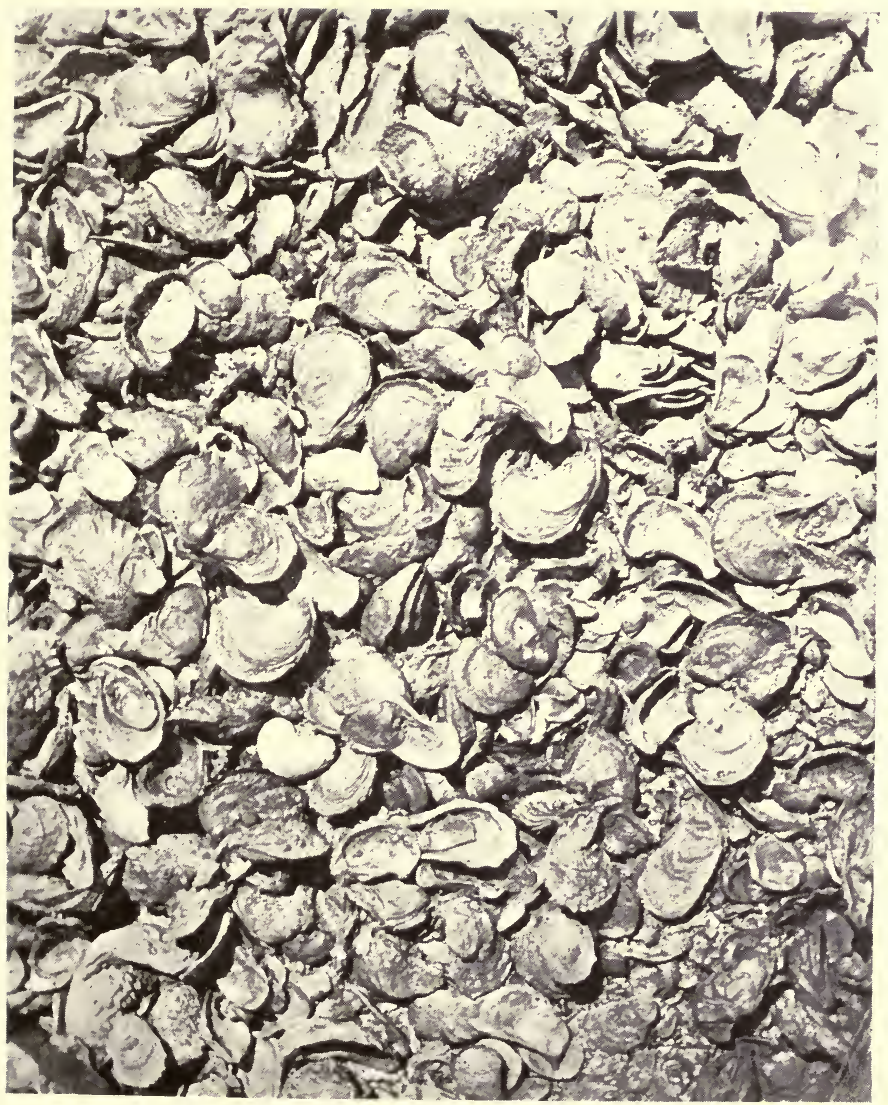



and the presence of oysters, but the fact that no oysters are found upon the hard, firm sand of the ocean beach shows that this is not the case. As a matter of fact, they thrive best upon a soft bottom. They feed upon the floating organic matter which is brought to them by the water, and this food is most abundant where the water flows in a strong current over a soft organic mud. When the bottom is hard there is little food, and this little is not favorably placed for diffusion by the water, while the water which flows over soft mud is rich in food.

The young oysters which settle upon or near a soft bottom are therefore most favorably placed for procuring food, but the young oyster is very small-so small that a layer of mud as deep as the thickness of a sheet of paper would smother and destroy it.

Hence the young oysters have the habit of fastening themselves to solid bodies, such as shells, rocks or piles, or floating bushes, and they are thus enabled to profit by the soft bottoms without danger.

Owing to the peculiar shape of an oyster shell, some portions usually project above the mud long after most of it is buried, and its rough surface furnishes an excellent basis for attachment. It forms one of the very best supports for the young, and a little swimming oyster is especially fortunate if it finds a clean shell to adhere to when it is ready to settle down for life. Then too, the decaying and crumbling shells are gradually dissolved in the sea water, and thus furnish the lime which the growing oyster needs to build up its 
own shell. As long as the shell is soft and thin, the danger from enemies is very great, and this danger is greatly diminished as soon as the shell becomes thick enough to resist attack. It is, therefore, very necessary that the shell should be built up as rapidly as possible, and an abundant supply of food in general will be of no advantage unless the supply of lime is great enough for the growth of the shell to keep pace with the growth of the body. All sea water contains lime in solution, but the percentage is, of course, greatest near the sources of supply. It is well known that on coral reefs, which are entirely made of lime, all kinds of shelled molluscs flourish in unusual abundance, and have very strong and massive shells; and our common land and fresh-water snails are much larger and more abundant in a limestone region than in one where the supply of lime is scanty. In such regions it is not unusual to find the snails gathered around old decaying bones, to which they have been drawn in order to obtain a supply of lime for their shells.

From all these causes combined it results that a young oyster which settles upon a natural oyster-bed has a much better chance of survival than one which settles anywhere else, and a natural bed thus tends to perpetuate itself and to persist as a definite, welldefined area; but there is still another reason. As the flood-tide rushes up the channels it stirs up the fine mud which has been deposited in the deep water. The mud is swept up on the shallows along the shore, and if these are level, much of the sediment settles 
there. If, however, the flat is covered by groups of oysters, the ebbing tide does not flow off in an even sheet, but is broken up into thousands of small channels, through which the sediment flows down, to be swept out to sea.

The oyster-bed thus tends to keep itself clean, and for these various reasons it follows that the more firmly established an oyster-bed is, the better is its chance of perpetuation, since the young spat finds more favorable conditions where there are oysters, or at least shells, already, than it finds anywhere else.

Now, what is the practical importance of this description of a natural bed?

It is this: Since a natural bed tends to remain permanent, because of the presence of oyster shells, the shelling of bottoms where there are no oysters furnishes us with a means for establishing new beds or for increasing the area of the old ones.

The oyster dredgers state, with perfect truth, that by breaking up the crowded clusters of oysters and by scattering the shells, the use of the dredge tends to enlarge the oyster-beds. The sketch which we have just given shows the truth of this claim, but this is a very rough and crude way of accomplishing this end, and I shall now give a description of the means which have been employed in different places to accomplish the same result more efficiently and methodically.

Within recent years, much attention has been given to the possibility of increasing the supply of oysters by artificial means. 


\section{PLATE VIII.}

An old shoe, one-fourth natural size, upon which there are forty oysters, large enough to be marketable, besides a great number of smaller ones. 


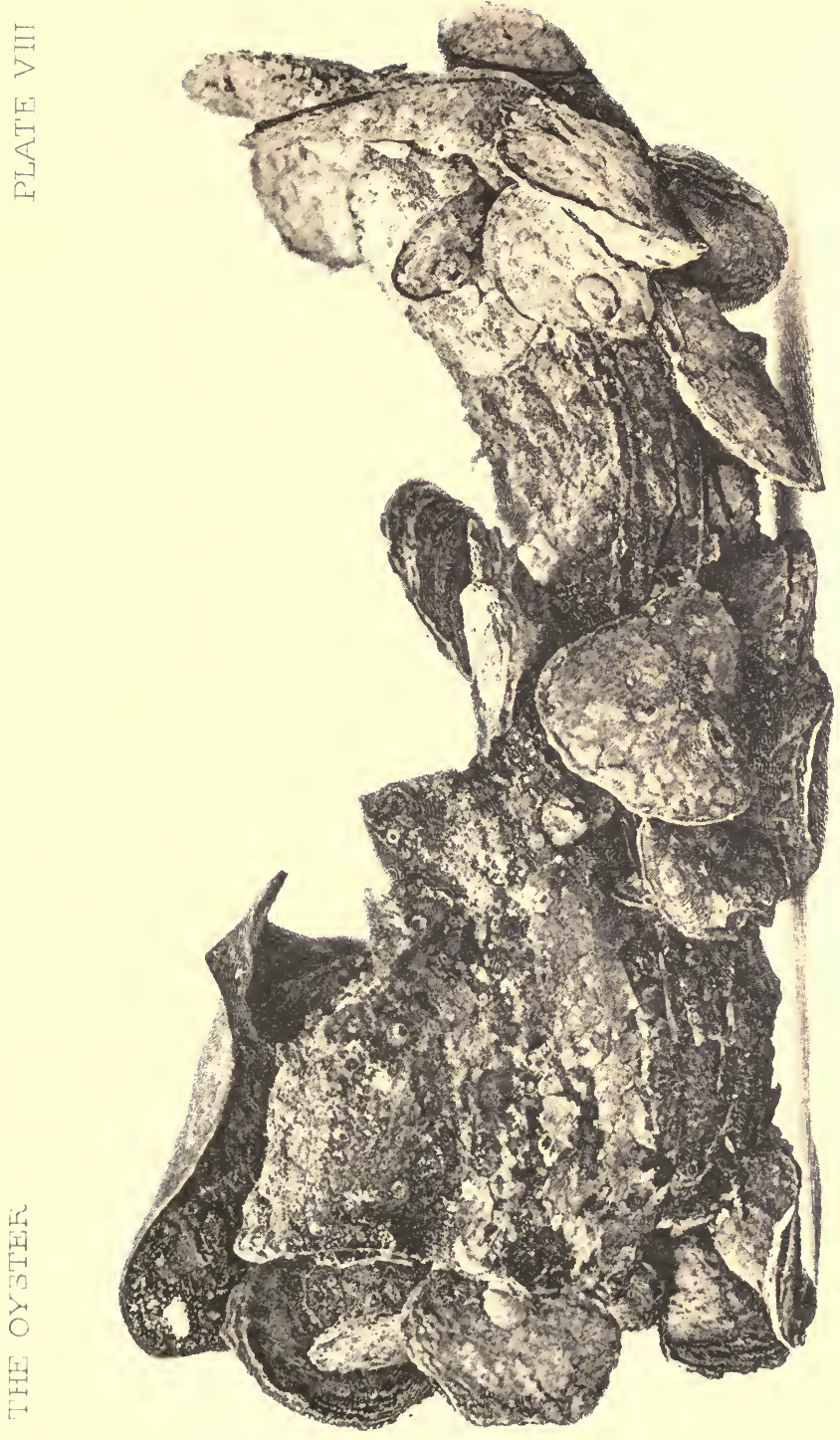



The oyster is well known to be enormously prolific, a single one giving birth in one season to many million young; and it is obvious that the annual supply would be enormously increased if all the young which are born could be reared to maturity.

Unfortunately, this is not the case, and under a state of nature millions of oysters are born for each one which grows to maturity. Möbius has shown that in Europe each oyster which is born has only one chance in one million one hundred and forty-five thousand of reaching maturity; I have shown that the chances of each American oyster are very much less.

One of the most important discoveries of the last fifty years is, that it is quite possible to save many of these oysters by artificial means; and experiments which have been carried on in France, as well as in many parts of our own country, prove that this can be done, successfully and economically, on a very large scale.

Soon after it is born the young oyster fastens itself to some solid body. It is at first so small that it is smothered and killed at once if it falls upon a muddy or slimy bottom, and its only chance for life is in the discovery of some perfectly clean, hard body to which it may fasten itself. Many young oysters are killed by accidents or enemies after they have fastened themselves, but by far the greater number perish through failure to find proper places for attachment; and the whole secret of oyster culture is to furnish proper bodies for the attachment of the young. 
Many methods of doing this have been devised and employed, and the possibility of increasing the area and value of the natural beds, and of building up new beds, or restoring old ones, in this way has been proved.

As this is by far the most important aspect of the oyster problem, I shall devote considerable space to the history of these experiments, and to a description of the means and apparatus which have been employed for the purpose.

Although the development of this industry on a large scale is quite modern, seed oysters for planting have been raised artificially upon a small scale in Italy for more than a thousand years, by a very simple method.

Pliny tells us that the artificial breeding of oysters was first undertaken by a Roman knight, Sergius Orata, in the waters of Lake Avernus, and that the enterprise was so successful that its director soon became very rich.

At the present day the methods which were introduced, and probably invented by Orata, are still employed by the oyster cultivators of Lake Fusaro, a small salt-water lake. Upon the deep, black mud of the lake they have constructed here and there heaps of rough stones, high enough to keep them above the mud and slime; upon these rocks, oysters which were taken from the sea have been placed to supply the spat, and these breeding oysters grow and multiply and do not need to be renewed, unless they are killed by some accident such as a volcanic eruption. Each pile of 
rocks is surrounded by a circle of stakes, firmly planted in the mud, while their upper ends are united above water by a cord, from which, between each two stakes, a small bundle of twigs is suspended so that it hangs in the water near the bottom. At the spawning season the oysters upon the central pile of rocks discharge countless myriads of embryos into the water, and many of them, finding, close at hand, suitable material for their attachment, fasten themselves in great numbers to the twigs, and grow rapidly until, at the proper season, the cultivators take up the stakes and bundles, and after removing those oysters which are of a suitable size for the market, they replace the stakes and fagots, and leave the small oysters to continue their growth until the next season.

In quite modern times the study of these old methods of oyster culture has resulted in the development of the improved methods which are now employed in France.

In 1853 , M. De Bon, then Commissioner of Marine, was directed by the minister to attempt to restock certain exhausted beds by planting new oysters upon them, and during this work, which was perfectly successful, he discovered that, contrary to the general opinion, the oyster can reproduce itself after it has been transplanted to bottoms on which it never before existed, and he at once commenced a series of experiments to discover some way to collect the spat emitted by these oysters, and he soon devised a successful apparatus, which consisted of a rough board floor, 


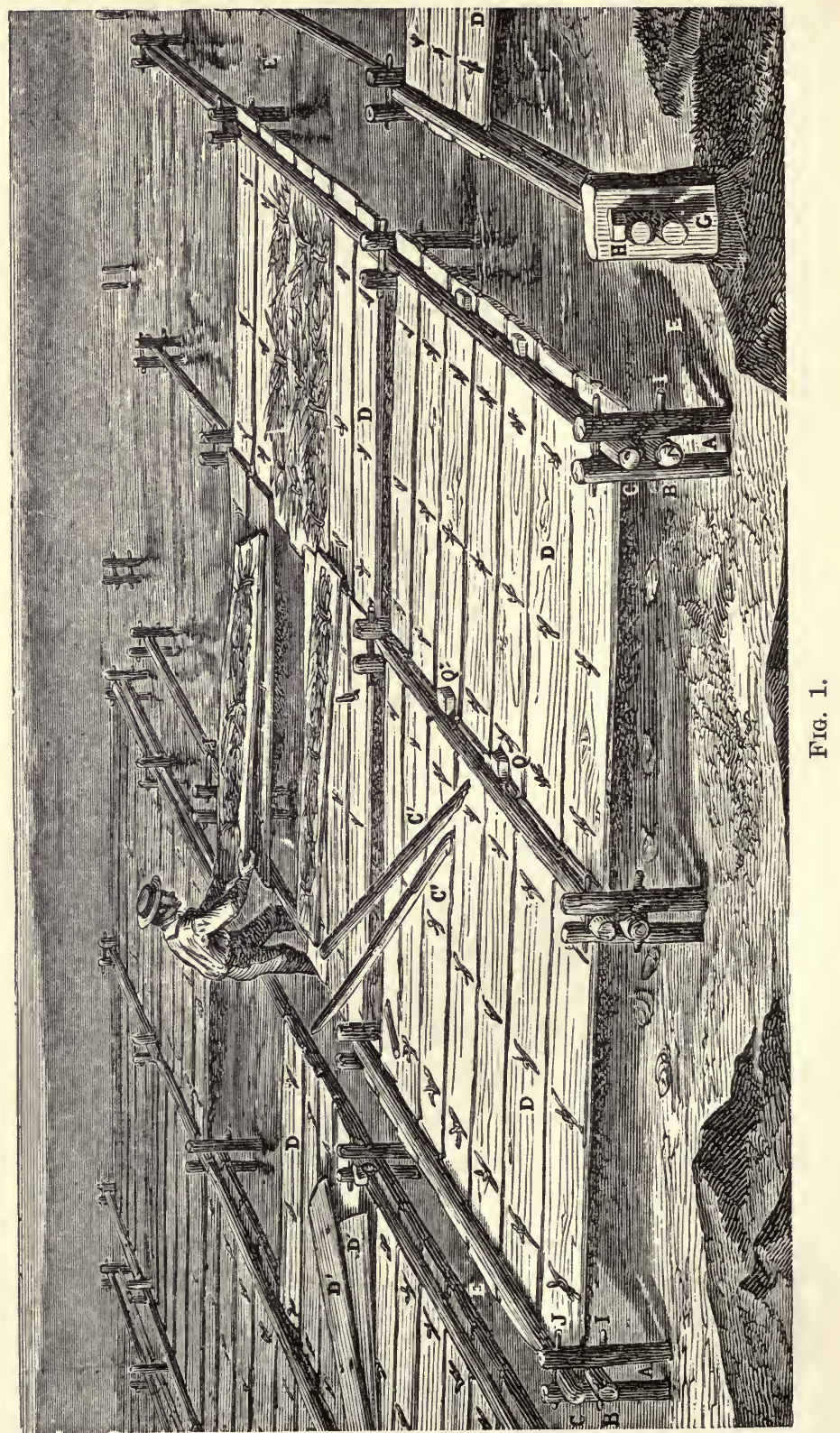


(Figure I), raised about eight inches above the bottom, near low-tide mark, covered by loose bunches of twigs.

With this apparatus, constructed on a very small scale, he obtained results which showed that spat may be collected in this manner without difficulty; but no attempt to put the new method into practical use was made until the subject was taken up by the well known French fish-cultivator Coste, who, in a report to the Minister of Agriculture and Commerce in 1855, giving an account of his examination of the methods used at Lake Fusaro, expresses his desire to try similar methods in France.

Two years later the Emperor supplied the means for experiments on a large scale, and commissioned Coste to conduct them. Three million oysters, purchased for the purpose, were conveyed by two small steamers and a flotilla of small boats, to a place which had been selected, where oyster shells had previously been spread to serve as collectors, and after the oysters were planted, long rows of bundles of fagots were let down and anchored about a foot above them, as shown in Figure 2.

At the close of the season the shells and branches, one of which is shown in Figure 3, were found to be covered with young oysters, and more than twenty thousand oysters were counted on one bundle.

Before he began his work, he stated in his report for I858, that out of twenty-three natural beds which formerly constituted a great source of wealth, eighteen had been completely destroyed, while the remaining 


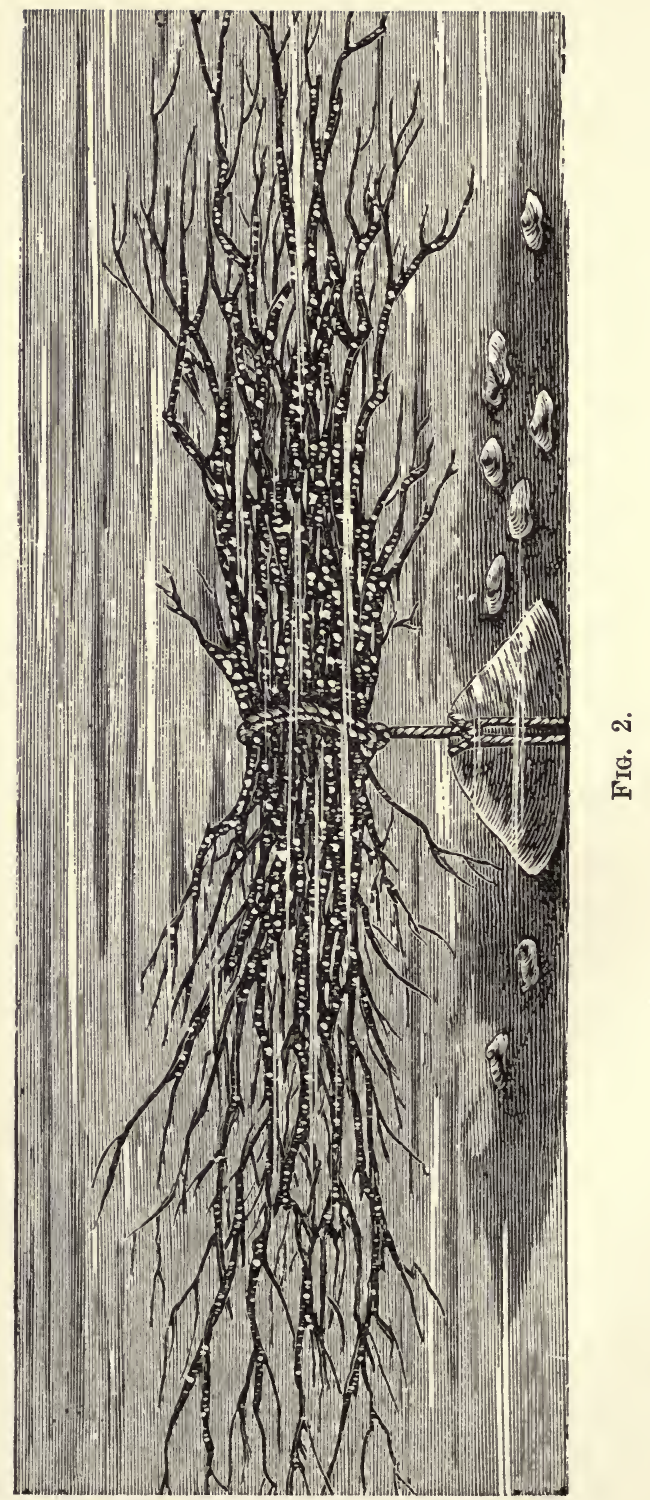




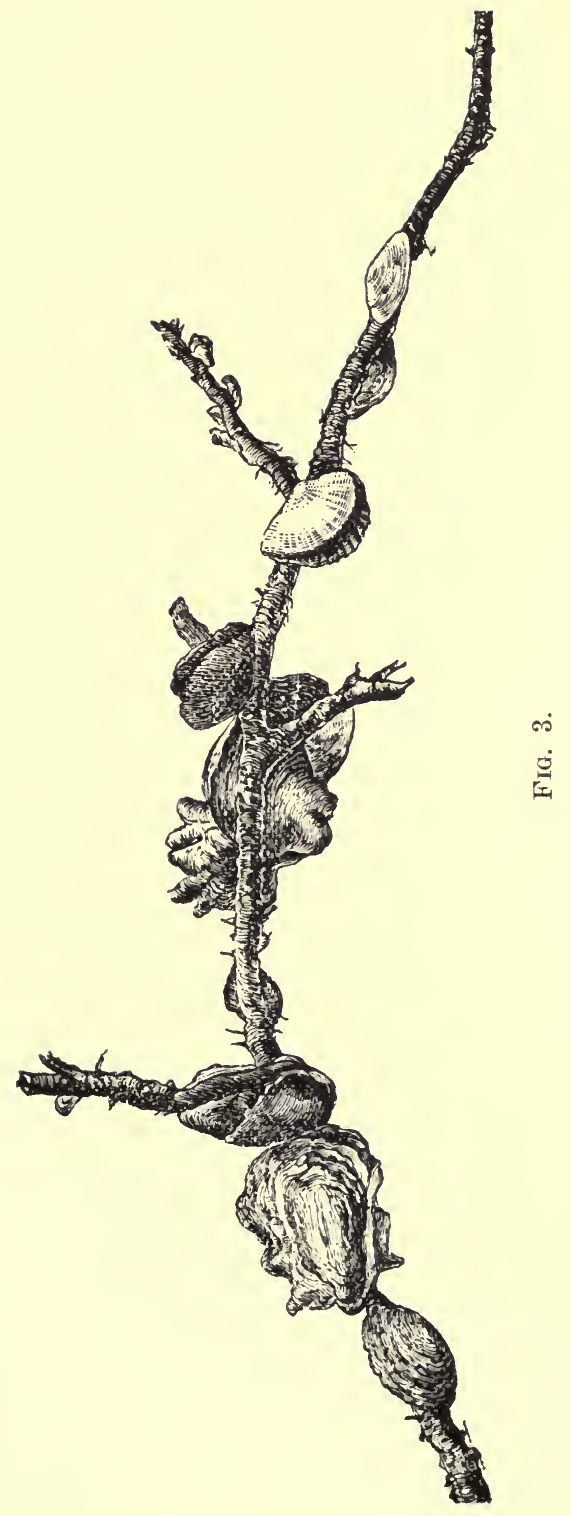


beds had been so impoverished that they no longer yielded enough oysters for planting. In another locality, where thirteen valuable beds formerly furnished employment for two hundred vessels and fourteen hundred men for six months in each year, and yielded an annual harvest valued at $\$ 60,000$ to $\$ 80,000$, only three beds remained, and these were so depleted that twenty boats could in a few days carry away all the oysters.

In I863, during six tides, upon only one-half of an area of Ioo acres which had been restocked, he obtainued 16,000,000 marketable oysters.

Land was then ceded by the government to individuals, to be cultivated in the same way, and one area of 492 acres was in a few years stocked with oysters valued at $\$ 8,000,000$.

The government farms were never very successful, but the industry has prospered and grown steadily under private management, and the oyster-farmers, taught by their own experience and by the results attained by the government in experimental parks, became more self-reliant; they improved their implements and their methods of work. It may be affirmed that in the two principal centers in which it is now carried on, the basins of Arcachon and Morbihan, this industry then emerged from its period of uncertainty. The great profits realized there during the past few years have brought oyster culture again into favor, and turned toward it a current of labor and capital much 
greater than that which flowed in the same direction after the publication of M. Coste's report.

One of the most interesting and instructive lessons to be learned from this history of oyster farming in France is that private industry in this field, as in all others, can accomplish more than government; and, as the cultivation of private farms spreads, the advisability of devoting all suitable grounds to this use becomes more and more apparent.

Experience teaches, the world over, that the most efficient agent for the preservation and development of natural wealth is private enterprise.

The opposition in Maryland at present to the granting of any natural oyster-bed to private holders is very strong indeed, but little insight into the future is needed to perceive that the disappearance of this feeling would result in an enormous increase in the prosperity of our people.

\section{OYSTER FARMING IN AMERICA.}

The American system of oyster farming, which presents some features of resemblance to the French system, and also many differences, has grown up as the result of private enterprise, without any help or any direct encouragement from government.

The French people are generally held to be the originators of modern oyster farming, but, as an American, I take pleasure in pointing out that our own industry, which is now so extensively developed in Connecticut, has not been borrowed from France, but has grown up independently. 
Several years before Coste and De Bon commenced their experiments, the oystermen of East River, having observed that young oysters fastened in great numbers upon shells which were placed upon the beds at the spawning season, started the practice of shelling the beds, in order to increase the supply, and in 1855 , or three years before Coste represented to the French Emperor the importance of similar experiments, the State of New York enacted a law to secure to private farmers the fruits of their labor, and a number of persons engaged in the new industry on an extensive scale. Among these pioneers in this field were Mr. Fordham, Capt. 'Henry Bell, Mr. Oliver Cook, Mr. Weed, Mr. Hawley and others.

The industry has grown steadily from that time, and East River is now said by Ingersoll to be the scene of the most painstaking and scientific oyster culture in the United States. The interest and importance of the subject is so great that I quote the whole of Ingersoll's account of its origin, development, and present methods:

"I have no doubt that, whatever was the date of its origin, the credit of first truly propagating oysters from seed caught upon artificial beds or prepared receptacles, belongs to the men of City Island. It had been a matter of common observation that objects tossed into the water in summer sometimes became covered with infant oysters. The sedges along the edge of the marshes, and the buoys, stakes and wharf-piles were similarly clothed. If the circumstances were favorable 
this deposit survived the winter, and the next spring the youngsters were large enough to be taken and transplanted. It was only a short step in logic, therefore, to conclude that if objects were thrown thickly into the water on purpose to catch the floating spawn, a large quantity of young oysters might be secured, and saved for transplanting at very slight expense. The next question was-What would best serve the purpose? Evidently, nothing could be better than the shells which year by year, accumulated on the shore from the season's opening trade. They were the customary resting-places of the spawn, and at the same time were cheapest. The City Island oysterman, therefore, began to save his shells from the lime-kiln and the road-master, and to spread them on the bottom of the bay, hoping to save some of the oyster spawn with which his imagination densely crowded the sea-water. This happened, I am told, more than fifty years ago, and the first man to put the theory into practice, it is remembered, was the father of the Fordham Brothers, who still pursue the business at City Island. In I855 Captain Henry Bell, of Bell's Island, planted shells among the islands off the mouth of Norwalk River, and a short time after, under the protection of the new law of 1855 , recognizing private property in such beds, Mr. Oliver Cook, of Five Mile River; Mr. Weed, of South Norwalk; Mr. Hawley, of Bridgeport, and others, went into it on an extensive scale. Some of these gentlemen appear never to have heard of any previous operations of this sort. Discovering it for 
themselves, as it was easy and natural to do, they supposed they were the originators; but if any such credit attaches anywhere, I believe it belongs to the City Island men. It was soon discovered that uniform success was not to be hoped for, and the steady, magnificent crops reaped by the earliest planters were rarely emulated. Many planters, therefore, distrusted the whole scheme, and returned to their simple transplanting of natural-bed seed; but others, with more consistency, set at work to improve their chances by making more and more favorable the opportunities for an oyster's egg successfully to attach itself, during its brief natatory life, to the stool prepared for it, and afterward to live to an age when it was strong enough to hold its own against the weather. This involved a closer study of the general natural history of the oyster.

"The first thing found out was that the floating spawn would not attach itself to or 'set' upon anything which had not a clean surface; smoothness did not hinder-glass bottles were frequently coated outside and in with young shells-but the surface of the object must not be slimy. It was discovered, too, that the half-sedimentary, half-vegetable deposit of the water, coating any submerged object with a slippery film, was formed with marvelous speed. Thus shells laid down a very few days before the spawning-time of the oysters sometimes become so slimy as to catch little or no spawn, no matter how much of it is floating in the water above them. This taught the oystermen 
that they must not spread their shells until the midst of the spawning season; that one step was gained when they ceased spreading in May and waited until July. Now, from the $5^{\text {th }}$ to $15^{\text {th }}$ of that month is considered the proper time, and no shell-planting is attempted before or after."

These dates are for the waters of New York. In Maryland, the month of June is most favorable for the attachment of spat. The date varies, however, according to the locality, the depth of water, the character of the season and other influences. Good judgment as to the proper time for shelling the bottom can be acquired only by experience, but a series of exact experiments in different parts of the bay would be of great value, as they would afford data for the guidance of private cultivators.

"The knowledge of the speed with which the shells become slimy was turned to account in another way. It was evident that the swifter the current the less would there be a chance of rapid fouling. Planters, therefore, chose their ground in the swiftest tideways they could find."

"The mere manner of spreading the shells was also found to be important. If they are rudely dumped over, half their good is wasted, for they lie in heaps. The proper method is to take them from the large scow or sloop which has brought them ashore, in small boat-loads. Having anchored the skiff, the shells are then flirted broadcast in all directions, by the shovelful. The next boat-load is anchored a little 
further on, and the process repeated. Thus a thin and evenly-distributed layer is spread over the whole ground. Just how many bushels a man will place on an acre depends upon both his means and his judgment. If he is shelling entirely new ground, he will spread more than he would upon an area already improved; but I suppose 250 bushels to the acre might be recommended as an average quantity."

This is very much too small a quantity, and in our waters, five or six times as many shells, from Ioo to I 200 bushels, should be used. The amount that is required depends upon the nature of the bottom, many more shells being needed for a muddy bottom than for a hard one.

"Having spread his shells in midsummer, the planter, by testing them early in the fall, can tell whether he has succeeded in catching upon them any or much of the desired spawn. The young oysters will appear as minute flakes, easily detected by the experienced eye, attached to all parts of the old shell. If he has got no set whatever, he considers his investment a total loss, since by the next season the bed of shells will have become so dirty that the spawn will not take hold if it comes that way. Supposing, on the contrary, that young oysters are found attached in millions to his cultch, as often happens, crowding upon each old shell until it is almost hidden, what is his next step?

"The ordinary way in the East River and elsewhere, is simply to let the bed remain quiet, until in the course of three or four years, such oysters as have 
survived are large enough to sell, when the bed is worked-at first, probably, with tongs and rakes, getting up the thickest of the crop. This done, dredges are put on, and everything that remains-oysters, shells and trash-is removed and the ground left clean, ready for a second shelling, or to be planted with seed.

"In the process of growth of the young oysters lodged upon the fields of cultch, when left undisturbed, there is, and must of necessity be, a great waste under the most favorable circumstances. Leaving out all other adversities, this will arise from overcrowding. More 'blisters' attach themselves upon a single shell than can come to maturity. One or a few will obtain an accession of growth over the rest, and crowd the others down, or overlap them fatally. Even if a large number of young oysters attached to a single stool do grow up together equally, their close elbowing of one another will probably result in a closed, crabbed bunch of long, slim unshapely samples, of no value save to be shucked. To avoid these misfortunes, and, having got a large quantity of young growth, to save as much as possible of it, the more advanced and energetic of the planters, like the Hoyts, of Norwalk, pursue the following plan: When the bed is two years old, by which time all the young oysters are of sufficient age and hardiness to bear the removal, coarse-netted dredges are put on, and all the bunches of oysters are taken up, knocked to pieces, and either sold as 'seed,' or redistributed over a new 
portion of bottom, thus widening the planted area, and at the same time leaving more room for those single oysters to grow which have slipped through the net and so escaped the dredge. The next year after, all the plantation, new and old, is gone over and suitable stock culled out for trade, three-year old East River oysters being in demand for the European market. This further thins out the beds, and the following (fourth) year the main crop of fine, well-shaped, wellfed oysters will be taken, and during the succeeding summer, or perhaps after a year, the ground will be thoroughly well cleaned up and prepared for a new shelling.

"All these remarks apply to a reasonably hard bottom which requires no previous preparation. In portions of Long Island Sound, especially off New Haven, it has been needful to make a crust or artificial surface upon the mud before laying down the shells. This is done with sand, and has been alluded to in the chapter on New Haven harbor.

"Just what makes the best lodgment for oysterspawn intended to be used as seed, has been greatly discussed. Oyster shells are very good, certainly, and as they are cheap and almost always at hand in even troublesome quantities, they form the most available cultch, and are most generally used. Small gravel, however, has been tried on parts of the Connecticut coast with great success, the advantage being that not often more than one or two oysters would be attached, and therefore the evil of bunchiness would be avoided. 
Where scallop shells, as in Narragansett Bay, or, as in northern New Jersey mussels and jingles, Anomia, can be procured in sufficient quantities, they are undoubtediy better than anything else, because they not only break easily in culling, but are so fragile that the strain of the growth of two or more oysters attached to a single scallop or muscle-valve will often crack it in pieces, and so permit the several members of the bunch to separate and grow into good shape singly. I am not aware that any of the elaborate arrangements made in France and England for catching and preserving the spat have ever been imitated here, to any practical extent. The time will come, no doubt, when we shall be glad to profit by this foreign example and experience.

"Although the effort to propagate oysters by catching drifting spawn upon prepared beds has been tried nearly everywhere from Sandy Hook to Providence, it has only, in the minority of cases, perhaps I might say a small minority of cases, proved a profitable undertaking to those engaging in it; and many planters have abandoned the process, or at least calculated but little upon any prepared beds, in estimating the probable income of the prospective season. This arises from one of two causes: Ist, the failure of spawn to attach itself to the cultch; or, $2 \mathrm{~d}$, in case a 'set' occurs, a subsequent death or destruction.

"The supposition among oystermen generally has been that the water everywhere upon the coast was filled, more or less, with drifting oyster-spat during 
the spawning season, whether there was any bed of oysters in the immediate neighborhood or not. In other words, that there was hardly any limit to the time and distance the spat would drift with the tides, winds and currents. I think that lately this view has been modified by most fishermen, and I am certain it greatly needs modification; but, as a consequence of the opinion, it was believed that one place was as good as another, so long as there was a good current or tideway there, to spread shells for spawn, whether there were any living oysters in proximity or not. But that this view was fallacious, and that many acres of shells have never exhibited a single oyster, simply because there was no spat or sources of spat in their vicinity, there is no reason to doubt.

"Having learned this, planters began to see that they must place with or near their beds of shells living mother-oyster, called 'spawners,' which should supply the desired spat. This is done in two ways-either by laying a narrow bed of old oysters across the tideway in the center of the shelled tract, so that the spawn, as it is emitted, may be carried up and down over the breadth of shells waiting to accommodate it, or by sprinkling spawners all about the ground, at the rate of about ten bushels to the acre. Under these arrangements, the circumstances must be rare and exceptional when a full set will not be secured upon all shells within, say twenty rods of the spawners. Of course fortunate positions may be found where spawn is produced in abundance from wild oysters, or from con- 
tiguous planted beds, where the distribution of special spawners is unnecessary; yet even then it may be said to be a wise measure.

" The successful capture of a plenteous 'set,' however, is not all of the game. This must grow to salable maturity before any profits can be gathered, and it so often happens that the most promising beds in September are utterly wrecked by January, making a total loss of all the money and labor expended, that more than one planter has decided that it does not pay to attempt to raise oysters upon shells, so long as he is able to buy and stock his grounds with half-grown seed-a decision which may be based upon sound reasoning in respect to certain localities, but which certainly will not apply to all of our northern coast.

"The great drawback to East River oyster-planting, of every kind, is the abundance of enemies with which the beds are infested. These consist of drum-fish, skates, and, to a small degree, of various other fishes; of certain sponges and invertebrates that do slight damage, and of various boring molluscs, the crushing winkle, and the insidious star-fish or sea-star. It is the last-named plague that the planter dreads the most, and the harm that may be directly traced to it amounts to many tens of thousands of dollars annually in this district alone. Indeed, it seems to have here its headquarters on the American oyster coast, where it has utterly ruined many a man's whole year's work."

Ingersoll states that 20 bushels of shells laid down anywhere in the upper part of Barnegat Bay, New 
Jersey, will produce Ioo bushels of seed oysters, but that there is no protection for this industry, as popular construction makes such beds " natural ground."

At Brookham Bay, off the south coast of Long Island, in the region of the well-known "blue point" oysters, it has been the custom for several years to lay down shells, scrap-tin, etc., for the attachment of the young, and when this is done near any oyster-bed, or whenever spawning oysters are planted among the shells, there is rarely a failure to get plenty of young.

The Delaware planters often find that after a bottom has been used for many years for planting, the young oysters grow upon the shells which gradually accumulate, and a very valuable artificial oyster-bed is thus established. The law-abiding citizens respect the private ownership of these beds, and they are a source of wealth to their possessor.

I quote from the "Report of the Shell-Fish Commissioners," of Connecticut, for I883, the following statement of the present condition of the industry in that State:

"The deep-water cultivators proceed in three different ways to make beds. (I). The bottom being properly cleared off, the seed oysters, mixed with the gravel, jingles and other shells just as they are gathered from the natural beds, are distributed thereon more or less uniformly, and there left to grow. (2). Or the bottom is spread over with clean oyster shells just before the spawning season begins, brood oysters, twentyfive bushels to the acre, are distributed over the bed. 
(3). Or, if the bed is in the neighborhood of natural beds, the shelled bed is left without further preparation to catch the spawn as it is drifted above it. Sometimes the shells fail to 'catch a set,' and this makes it necessary to rake over the shells the following year, or to cover them over with more fresh shells for the next spawning. There is always an abundance of spawn in the waters of the Sound, and when a set is secured an enormous crop is the result. On a private deep-water bed, during the past summer, the dredge was drawn at random in the presence of the commissioners, and from an ordinary-size shovelful there were counted 206 young oysters in excellent condition, of the average size of a quarter of a dollar. As many as a hundred young oysters have been counted growing on a medium-sized oyster shell.

"The beds are carefully tended, and no pains are spared to kill all the enemies of the oysters found among them. By continual vigilance the private beds are kept comparatively free from them. The larger proprietors of deep-water beds use steamers for this work, as also in doing their work of planting, raking over and dredging, and they use larger dredges than the sail vessels can, as they are also worked by steam at a great saving of labor and expense. When the oysters have grown on these beds to a merchantable size they are sometimes sold directly from the beds, but more frequently they are transplanted into brackish or fresh waters, where they are permitted to remain for a short period to freshen and fatten for market." 


\section{PLATE IX.}

Figure I. A pipe, upon the bowl of which six oysters have grown; from the Chesapeake Bay.

FIGURE 2. An oyster shell upon the inside of which about one hundred and fifty young oysters have fasened themselves. This is from the lot of shells which were sold by Mr. Church, of Crisfield, from the pile of shells at his packing-house, to an oyster farmer in Long Island Sound. Mr. Church visited the farm five weeks after the shells were shipped, and took up a number of the shells, and he states that the one which is here figured is a fair sample. 

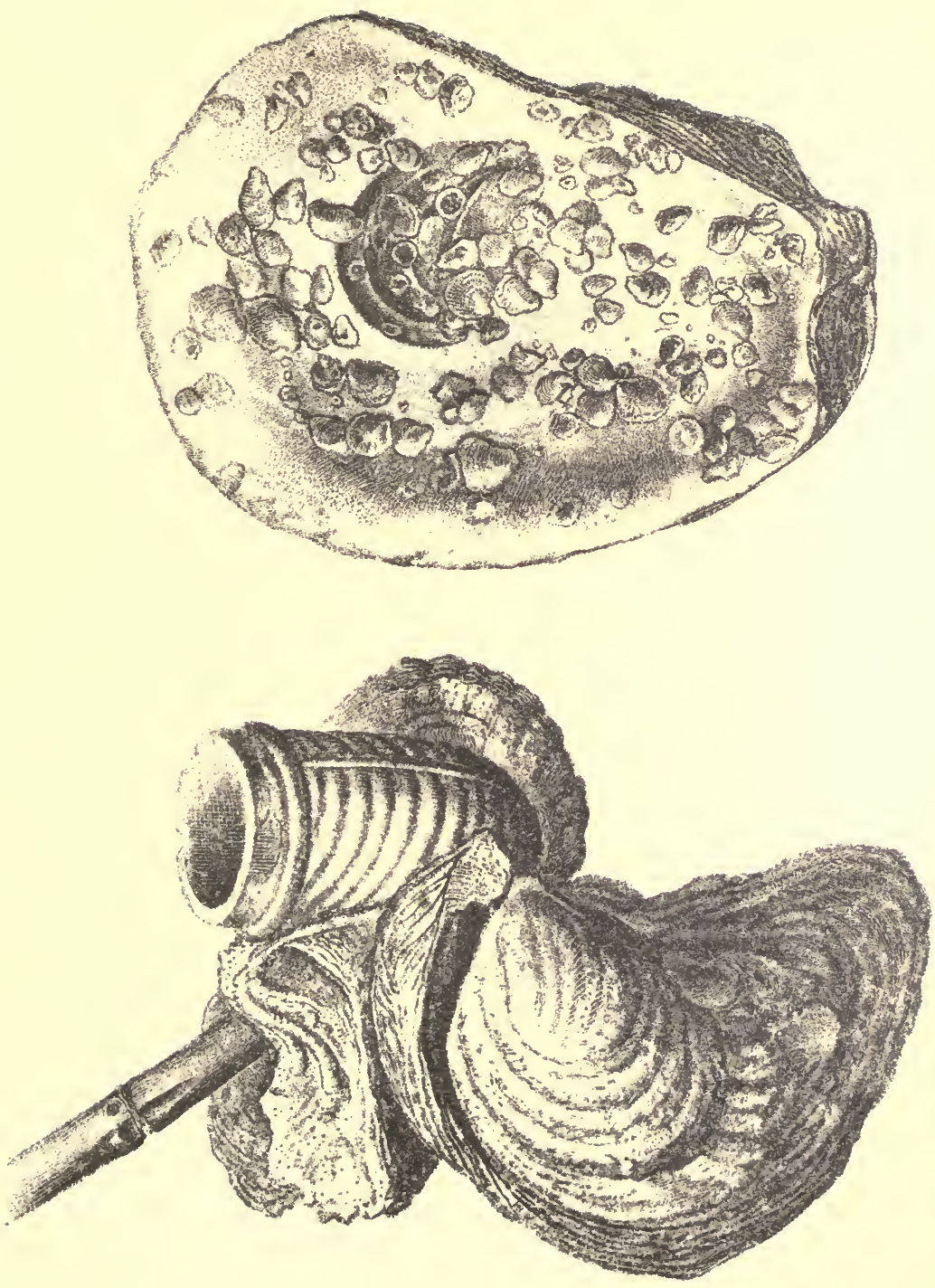

The Connecticut oystermen have many obstacles and risks, from which our own waters are free, and many of the farms have been completely ruined by starfish and other enemies, but notwithstanding all these drawbacks, the crop, which was 336,000 bushels in I880, had increased in I888 to I,454,000 bushels.

During the period of his employment by the French Government to replenish the oyster grounds, Coste devised a number of plans for furnishing an attachment for the oyster spat, and these devices have been greatly improved by other experiments.

Most of them could be employed in our own waters with advantage, and in order to make our people acquainted with them, we will give a brief description of the more important substances which have been thus employed. Some of them are adapted for certain localities, while others can be used to best advantage under other conditions. Our people have long been noted for their ingenuity, and there is no doubt that, as the great importance of oyster-farming comes to be appreciated among us, we shall have many great improvements in the methods of procuring seed oysters, better adapted for our own needs than any which are here described, but our account will serve to show our people the general direction in which their inventive skill must be directed.

Oyster Shells.-At present no spat-collector seems to be better adapted for use in our waters upon hard bottoms than oyster shells, and they are now the cheapest collectors that can be used. 
In order to serve this purpose the shells must be perfectly clean, and as the old dead shells, which have lain for a long time upon the oyster-beds, are torn to pieces by the boring sponge and covered with mud and slime, hydroids, sea-weed and sponges, they are much less effective than those which are placed in the water just before the spawning season.

In regions where there is no danger from frost, or where the young growth is to be planted in deeper water before winter, the shells may be deposited at or even above low-water mark, and in the sounds of North Carolina oysters thrive even at high-tide mark. The shells should be deposited in the early summerin June, July and August-in localities where there is enough current to sweep the swimming young past them. A hard bottom is to be preferred, but this method may be employed with great advantage upon any soft bottoms which are near the surface. In this case the shells should not be uniformly distributed, but placed in piles or ridges. If these ridges are properly arranged with reference to the direction of the current, they will produce secondary currents, and will thus cause the soft mud to flow off between them. In this way any bottom which is bare or nearly bare at low tide, and which is exposed to the winds and waves, may in time be swept nearly clear of mud. Each time the tide comes in the mud is stirred up and suspended in the water, and as the tide ebbs this suspended matter is swept into the channels between the obstructions and is carried away. Shells are very 
effective as spat-collectors. Shell wharves built out into deep water, so as to catch and turn the passing current, are often found to be covered with young oysters at all stages of growth and in good condition for planting.

The month of June is usually the best time for shelling the bottom. The early part of the month for warm seasons and shallow water, and the end of the month for cold springs, or deep water. The quantity of shells varies according to circumstances, but in most cases rooo bushels to the acre are not too many.

In shallow waters, where the shells are uncovered at low tide, they may be examined to pick out, for distribution upon the planting grounds, those which have young oysters upon them, but in deeper waters the shells must be picked up with tongs or dredges, or they may be strung upon wires and sunk in deep water on suitable frames.

The chief objection to the use of shells is that the method is a wasteful one. It is not unusual for fifty or a hundred young oysters to fasten upon one shell, and as the shells are too strong to be broken without injuring the young oysters, these cannot be detached, and most of them are soon crowded out and killed by the growth of the others.

The use of tiles has, therefore, been introduced in France to avoid this loss.

As tiles can be employed without difficulty in deep water, they are well adapted for use in our bay. Those which are used in France are much like a common 
drain pipe sawed in two longitudinally. They cannot be obtained in our markets at present, although they could be made very cheaply if there were any demand for them. Each tile is about 18 inches or 2 feet long, 6 or 8 inches wide, concave on one side and convex on the other. The shape of the tile is important, as nearly all the oysters fasten themselves upon the concave surface. They adhere so firmly that it is difficult to detach them without injury, and to avoid this the French oyster-breeders coat the tiles with a thin whitewash, which can be scaled off with the young oysters when these are large enough to be distributed upon the planting grounds.

The following is an account of the method of coating the tiles as employed in France.

The liming is done in two very different ways at Morbihan, according to whether it is intended to entirely free the oysters from the tile, or to allow a portion of the tile to remain attached to each shell.

When we come to speak of the removal of the oysters from the collectors, we will make some remarks concerning the matter of leaving a portion of the tile attached to the young. For the present we will merely state that under that system the tile is cut, leaving a portion adhering to each oyster, forming a sort of heel.

Some of our farmers, who breed oysters in this manner, cover their tiles with a slight coating of hydraulic cement. The young oyster attaches itself to the cement, but the coating being very thin is soon 
worn away, leaving the oyster quite firmly fixed to the tile.

Others, on the contrary, who prefer to separate the oysters entirely from the tile with the blade of a knife, when they are about six months old, generally cover the tile with two layers, and proceed in a different manner.

Quicklime is slacked just before it is to be used, and is put, while still in a state of ebullition, into a large vat, where two-thirds the same quantity of sand have been placed. The mixture is stirred until it has attained the consistency of clear broth. The collectors, held by the lower end, are dipped into the vat. One immersion suffices, after which they are taken in handbarrows and exposed to the air to dry before setting them up. This excellent coating should be prepared with fresh water only; sea-water prevents its adhering for any length of time to the tiles, and if it comes off the labor is of course lost. After this coating of lime has hardened, the tiles are dipped a second time into a bath of hydraulic cement, after which they are ready for use.

Tiles may be used as spat-collectors in either deep or shallow water. On the French coast they are chiefly employed above low-tide mark or in very shallow water, and they are then spread out so as to cover a considerable area. In some cases lines of stakes are driven into the ground, about a foot apart, transverse string-pieces are fastened to them about a foot above the bottom, a row of tiles is laid upon them, concave 
surface down, another row of tiles is placed at right angles upon the first layer, and the whole is weighted with stones. Other ways of arranging the tiles are shown as Figs. 5, 6, and 7 .

As soon as the oysters are large enough to handle, they should be removed from the tiles and distributed on the planting ground, for they usually become so crowded together on the tiles that they have no room to grow.

When used in deep water they may be fastened to a frame, which may be sunk upon or near a natural oyster-bed. So far as I am informed, Lieut. Francis Winslow is the only person who has ever made use of tile-collectors in American waters, but the remarkable results which he obtained with them in Tangier Sound, in 1879, show that they are well suited for use in the waters of the bay, where they are perfectly successful as spat-collectors.

Lieut. Winslow's interesting figures of these tiles form the most complete record of the rate of growth of oysters in the Chesapeake Bay which has ever been obtained, and his results are so valuable that I have copied six of his plates. He made use of a collector which was made by lashing eight or sixteen tiles to a wooden frame, which rested on the bottom upon a natural bed of oysters, while the tiles themselves were raised about six inches, and were joined by a rope to a floating buoy to mark their position. An apparatus of this sort was sunk in Big Annamessex River on July 9, and on August 2, 348 young oysters 


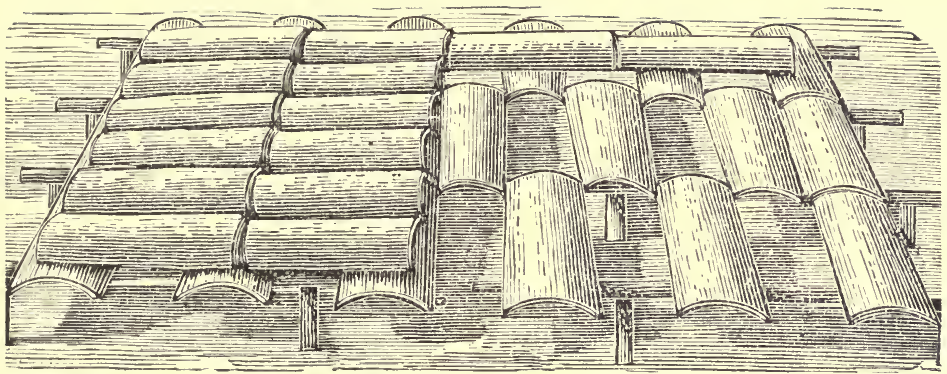

Fit. 5.

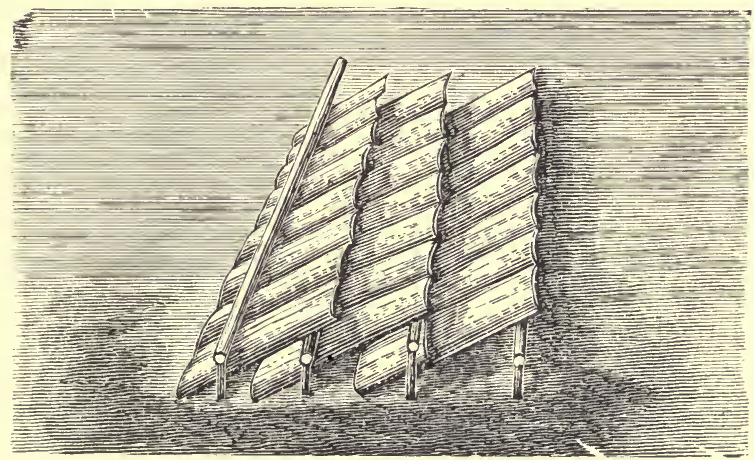

FIG. 6.

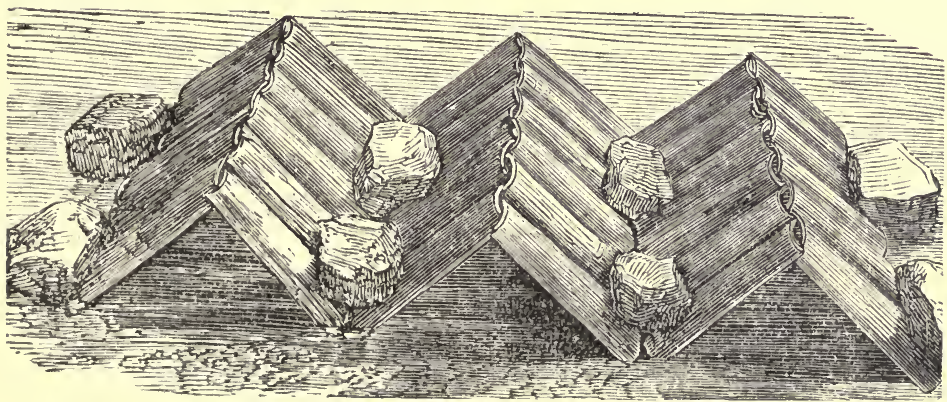

FIG. 7. 


\section{PLATES X, XI, XII, XIII, XIV, XV.}

Tiles which were deposited in the Little Annamessex River by Lieut. Francis Winslow, U.S. N., on July 9, I879, for the collection of oyster spat. From Winslow's Report on the Oyster Beds of Tangier and Pokamoke Sounds.

Plates X AND XI. Upper and lower surfaces of a tile which was removed on August 2, twenty-four days after it had been placed in the water.

Plates XII and XIII. Upper and lower surfaces of a tile which was removed on August 23, forty-five days after it had been placed in the water.

Plates XIV aNd XV. Upper and lower surfaces of a tile which was removed on October Io, about three months after it had been placed in the water. 


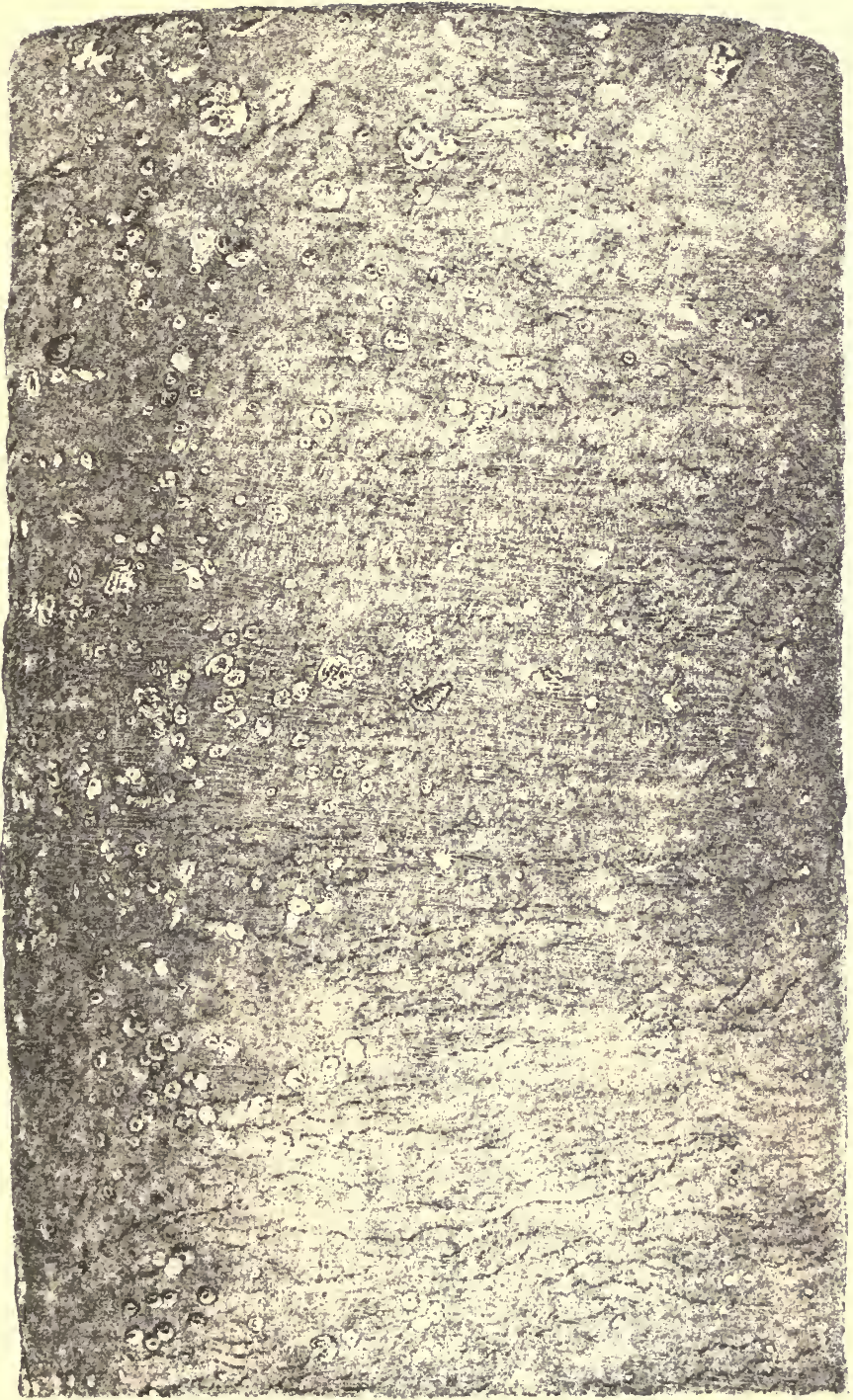





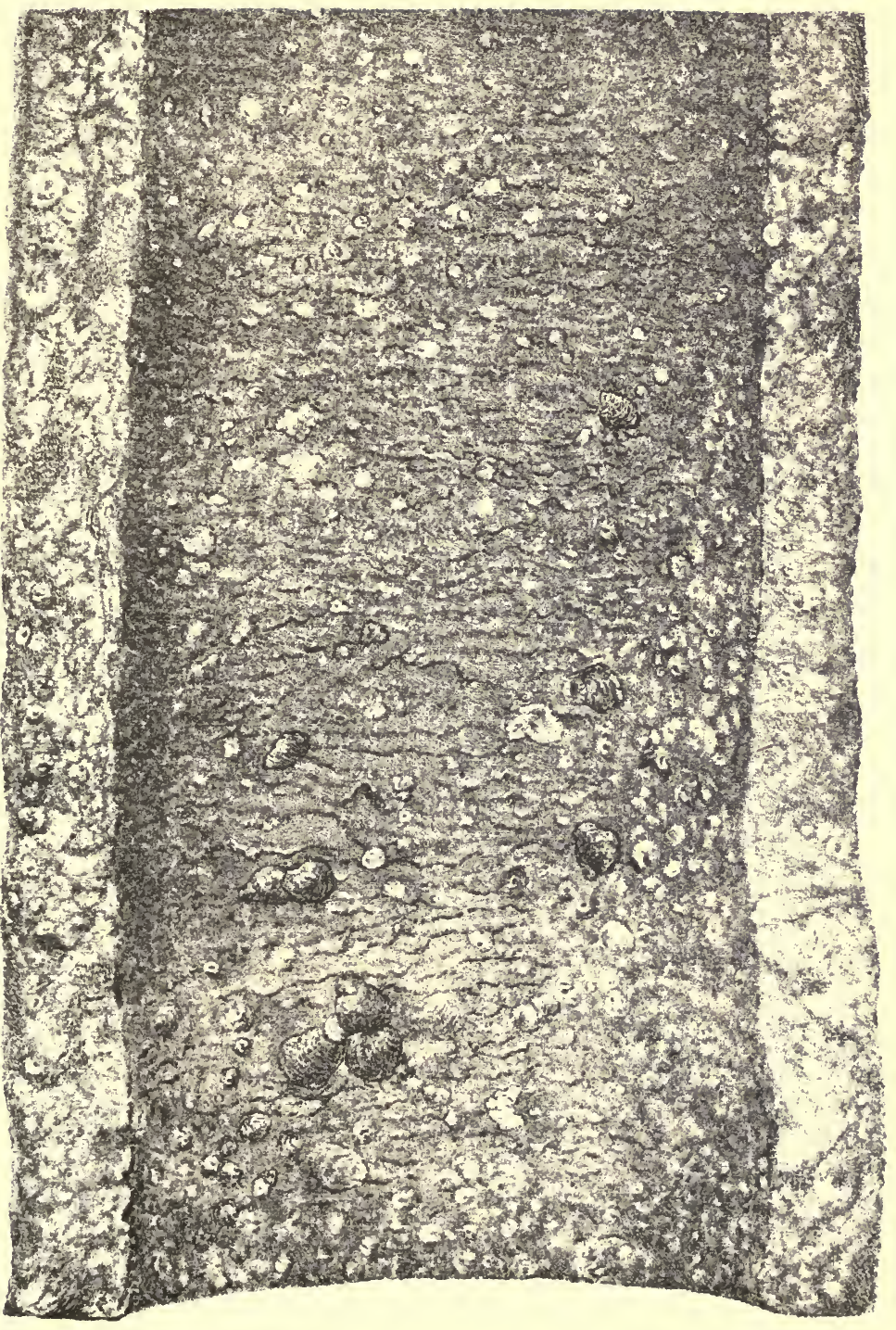





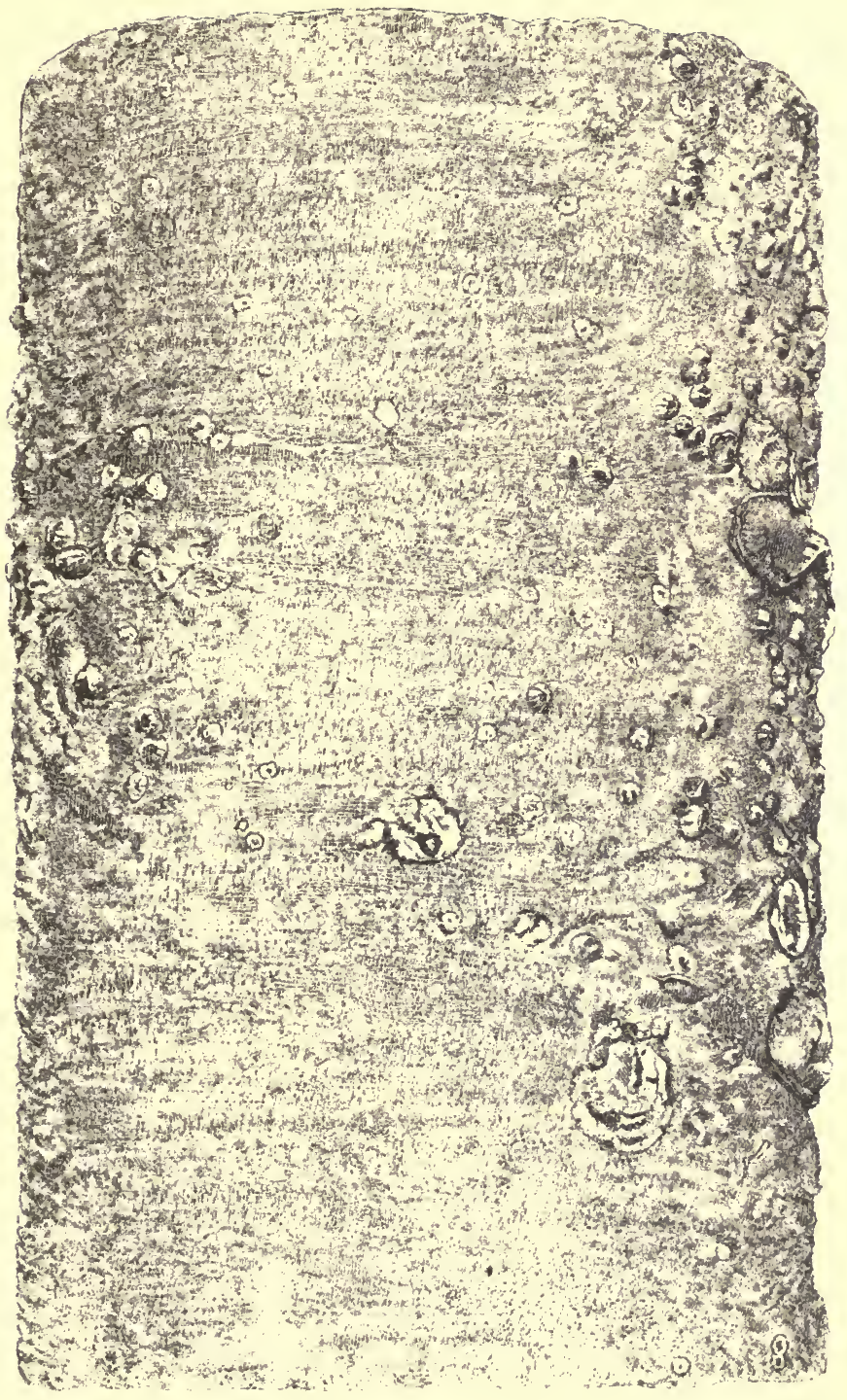





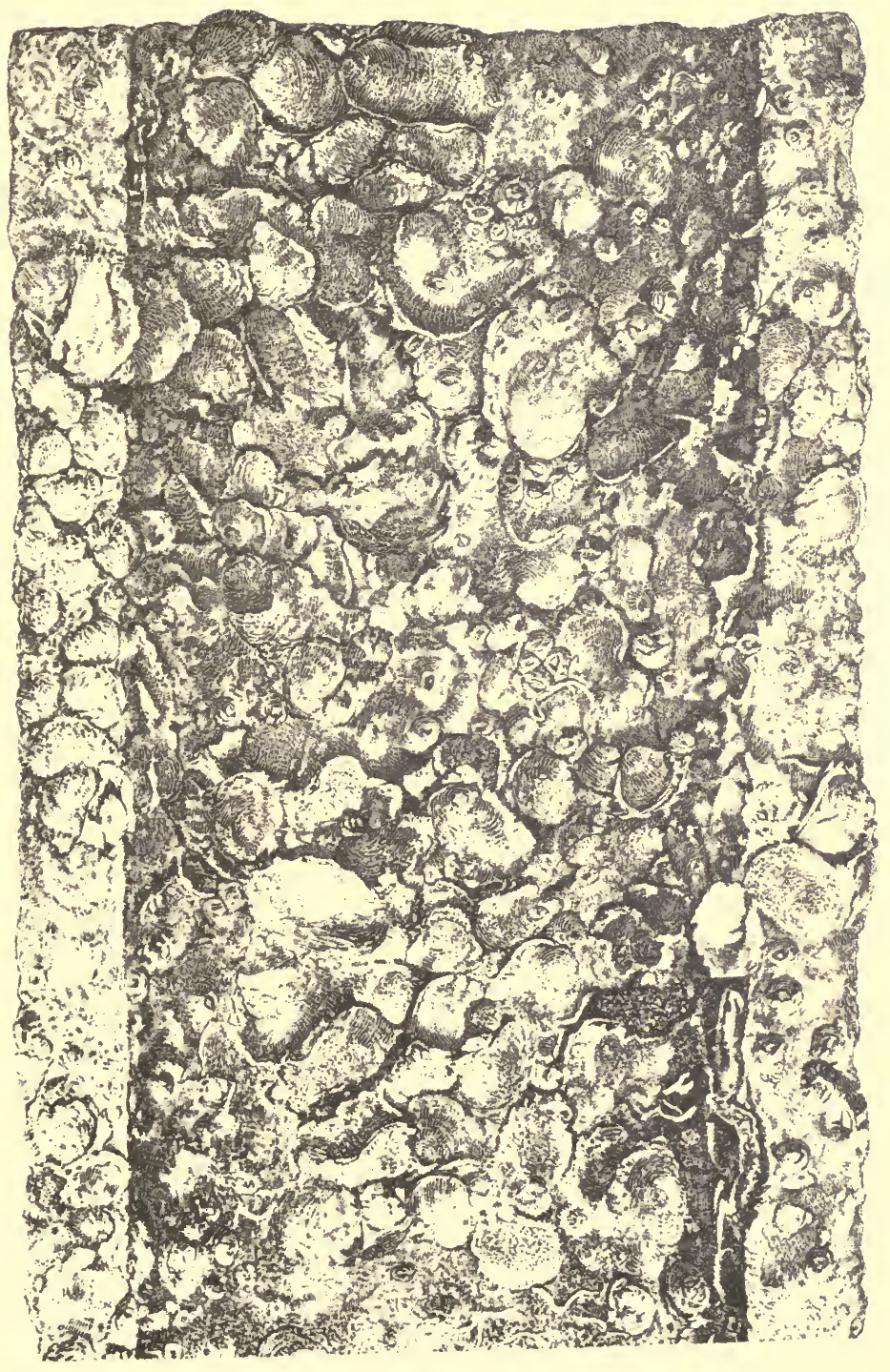





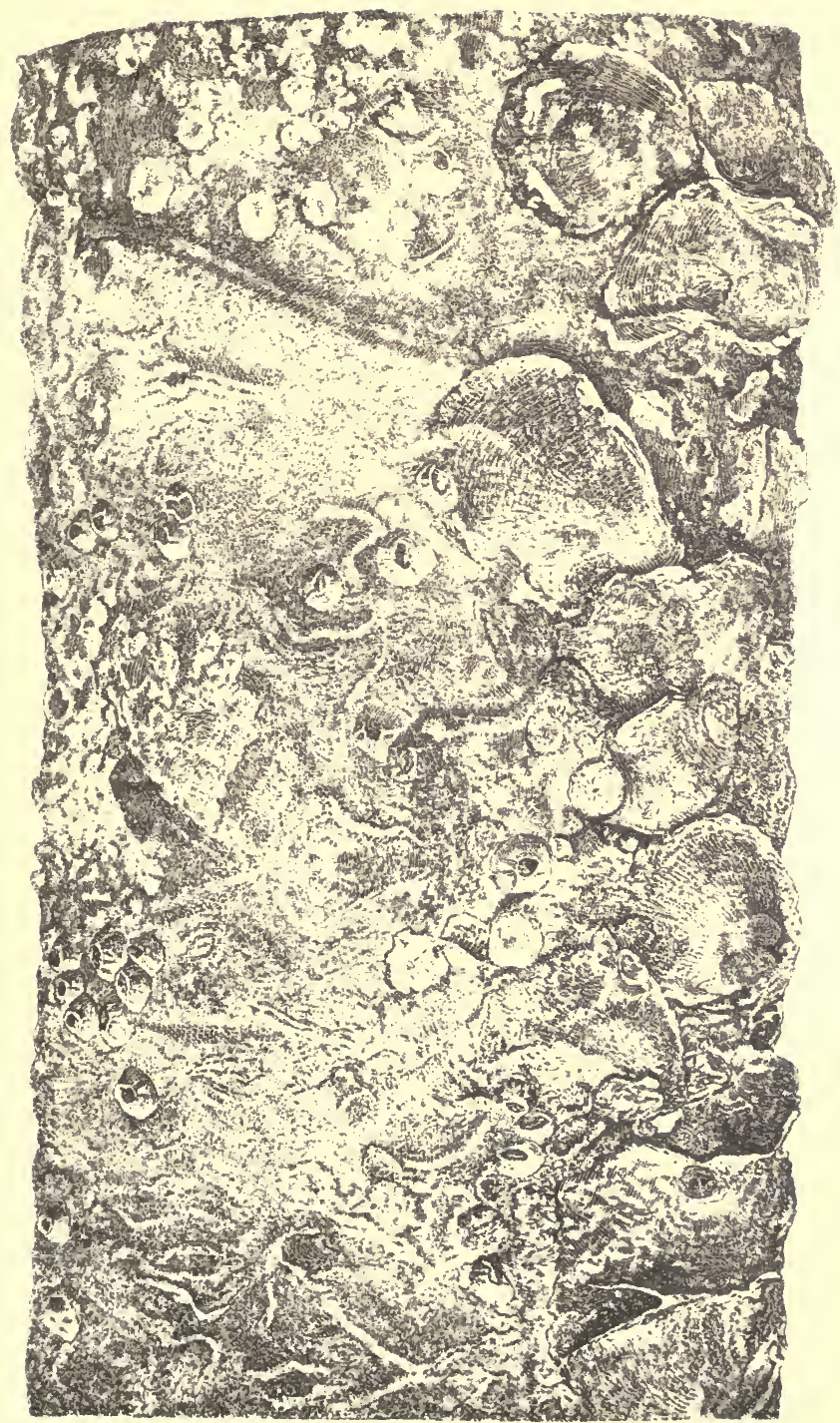



were counted on one tile, which is shown in Plates $\mathrm{X}$ and XI. On October IO, most of these had grown to a size of three-quarters of an inch, as shown in Plates XIV and XV.

Attempts to collect spat by artificial means are not always successful, and experience has shown that clean collectors are essential, and that failure is usually due to the presence of mud or other sediment upon their surface. As this sediment accumulates very rapidly, and as an extremely thin layer is enough to prevent the young oysters from becoming firmly fastened, it is important that the shells or other substances which are employed be perfectly clean, and that they be not put into the water until spawning has commenced.

I have made many experiments in order to discover the conditions which are most favorable for a good "set" of spat, and I have satisfied myself that those collectors are most reliable which are nearest the surface of the water. They are much less exposed to deposits of sediment than those in deeper water, and my studies upon the embryology of the oyster have shown that as soon as the embryo begins to swim it comes to the surface, and swims for about two days within half an inch of the top. I have been very successful with floating collectors, and, in Plate XVI, I have figured a boulder which had been for six weeks in one of them, a few inches from the surface, and had furnished a lodgment for many hundred oysters, 
crowded so closely together that I was unable to count them.

It frequently happens that bottoms where the spat may be present in the water, are so muddy that such collectors as tiles or shells cannot be used. The.French have invented a collector to be used in such cases as this, which they call the fascine collector. This consists of a bundle or fagot of small branches of chestnut, oak, elm, birch, or any other suitable wood, about ten or twelve feet long, bound together in the middle by a tarred galvanized iron wire, which is fastened to a stone, by which the bundle is anchored about a foot above the bottom. These fascines are placed upon or near the beds of oysters at the spawning season, and are distributed in places where the set of the tides and currents will carry the swimming oyster larvæ to them. The young oysters settle upon the branches in great numbers, and attaching themselves, grow rapidly, and it is not unusual for one such fagot to yield several thousand. The bundles are left undisturbed for five or six months, and at the end of this time they are large enough to be detached from the branches, when they are ready for distribution upon the planting grounds.

This method of collecting seed oysters has never, so far as I am aware, been employed in this country, although the experience of all who are familiar with our oyster waters must have shown how readily the young growth become attached to floating or sunken bushes. Our waters abound in places which are well fitted for the employment of this method of gathering 
the seed which is to be used in planting, and the fascine collectors might be used in the mouths of creeks or inlets, or along the edges of the channels, or anywhere where the set of the current will sweep the swimming oysters past the collector. While it would be advantageous to place the collectors near natural beds or rocks, this is by no means essential, for the young of the American oyster survive for a long time in the water, and they are carried to great distances by the current, and there is no part of our oyster area beyond the reach of this floating spat.

The method may be employed on either hard or soft bottom, as the collectors float above the surface of the ground, but is especially adapted for bottoms too soft for planting, and such bottoms may in this way be made valuable as seed farms. The collectors may be placed in either deep or shallow water, wherever there is a current.

With the exception of Winslow's experiments with tiles, very little use has been made in America of anything, except oyster shells, for collecting spat; but at one point in Connecticut, a plan which is essentially like the one last described has been used with good results for capturing spat, and for rearing marketable oysters as well, upon bottoms of soft mud.

These experiments are thus described in the reports of the Connecticut Shell Fish Commission for 1882 and $\mathrm{r} 883$ :

"The soft, muddy tracts, also, which aggregate a 


\section{PLATE XVI.}

Spat six weeks old, from a floating collector. 
5
5
5
5
5
5

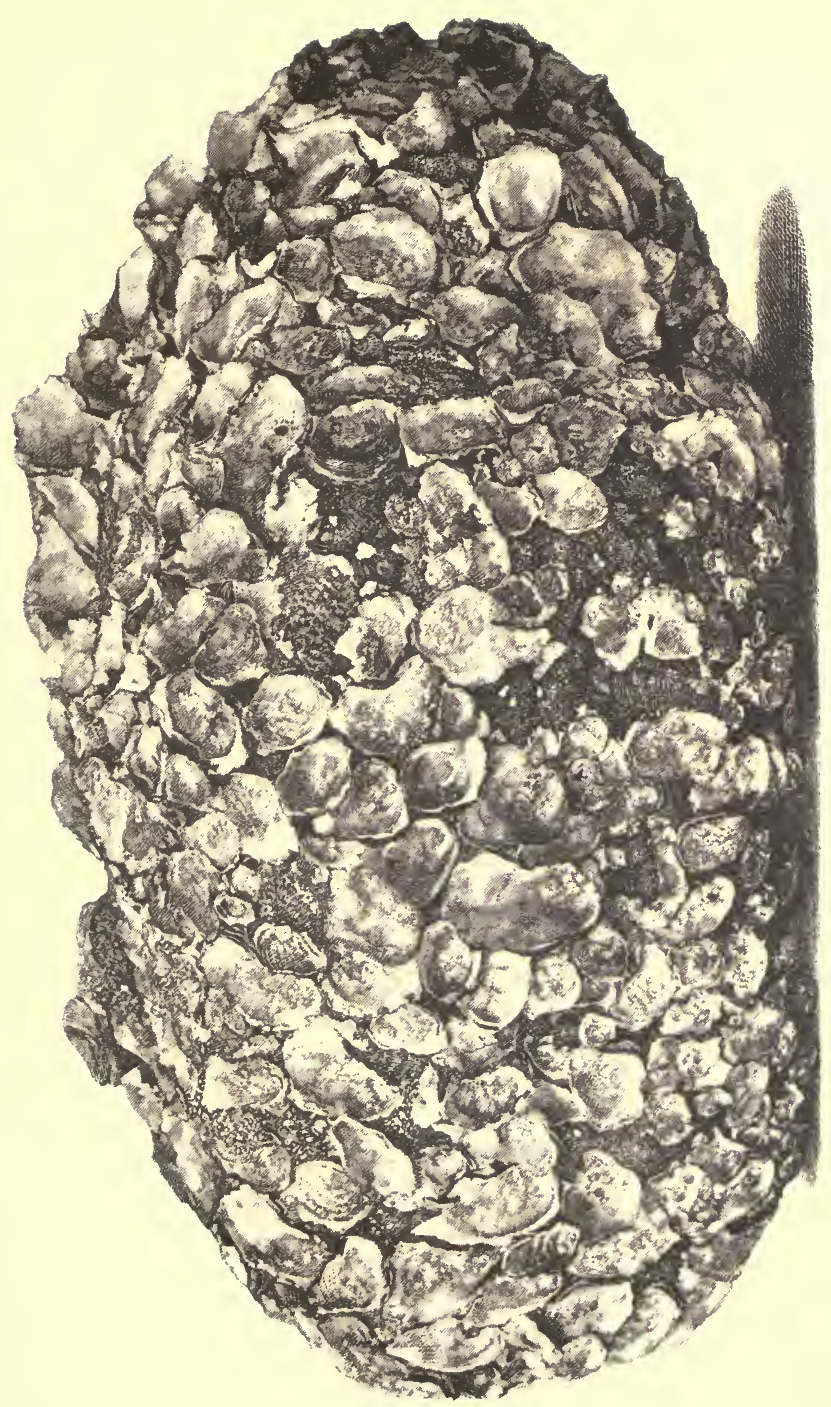



large number of acres now neglected, it is believed will, at no far distant day, become valuable for cultivation. " The efforts made to grow oysters on muddy bottoms in the Poquonock River, near Groton, to which reference was made in the last year's report, have been uniformly successful, as many as a thousand bushels of superior oysters having been obtained from one acre. No particular skill is required in carrying on similar experiments, and it is probable that the method will be generally followed throughout the State, where similar bottoms are found.

" On the Poquonock, River near Groton, white birch bushes are stuck in the river mud, about spawning time, in fourteen or fifteen feet of water at low tide. To these the spat adheres in great quantities. They are left undisturbed eighteen months, by which time the set becomes good-sized seed. On one bush, which was four inches through at the butt, twenty-five bushels of oysters were found, seven of which were large enough for market. The average yield is about five bushels to the bush. The grounds are so soft and muddy that no other method is feasible. About fifty acres are under this kind of cultivation, and the area is rapidly extending. The bushes are grappled out of the mud by derricks. The oysters are of excellent flavor, and the business is profitable."

Besides such simple but very effective devices for collecting spat, there have been invented in France a number of complicated mechanical devices for use under peculiar circumstances. The price of oysters 
is not high enough with us to justify the practical use of any such expensive machinery, so it will be unnecessary to speak of any of it.

The aim of all the methods of oyster culture which have been described is to increase the number of oysters, by furnishing proper substances for collecting the swimming embryos at the time when they are ready. to attach themselves. In all our northern waters, and as far south as the Chesapeake Bay, clean oyster shells are in nearly all cases the best substances to use for the the purpose, and there is hardly a spot anywhere in the bay which might not ultimately be converted into an oyster-bed. by this simple method of cultivation, which has been shown, in all parts of the world, where it has been tried, to yield a very great return for the capital and labor employed.

There are few parts of the world which offer advantages for the prosecution of this industry equal to those afforded by the Bay, and there is no other place where these advantages are presented on such a great area of bottom. Our oyster grounds, of course, vary in value, according to local conditions, and oyster culture is much more easy and profitable in some places than in others; but in course of time even the soft, muddy bottoms of the deepest channels may be brought under cultivation, and there is scarcely a foot of the bottom where oysters cannot be reared. The number of oysters which the Bay might be made to furnish annually is almost too great for computation, but we may very safely assert that it is greater 
than the total number which has been taken from our waters in the past.

All that is needed in order to make this great source of wealth available to our people, is permission to engage in oyster farming. When the citizens of Maryland demand the right to enter into this industry, and to reclaim their property which is now going to waste, a new era of prosperity will be introduced, and the oyster area will be developed with great rapidity.

I have shown that upon undredged natural beds solid substances become so thickly covered with young oysters that they have no room to grow, so that most of them are soon crowded out and killed.

All localities are not equally favorable for the collection of spat, and in the best places the amount which can be collected each season is very much greater than the amount which it needed for stocking the bottom. This excess can be profitably used as "seed" for stocking bottoms in shallow, landlocked bays, rivers, and other places which are less fitted for the collection of spat. While oyster-planting, as the sowing of these "seed" oysters is called, does not result in the production of new oysters, it is a very profitable industry, and it admits of great development.

The profits are smaller and the labor greater than those of oyster farming in deep water, but oyster-planting requires little capital, and the shores of the bay abound in proper spots for the prosecution of this industry, the importance of which has long been recognized by our people. 
There are many bottoms where there are no natural oysters, simply because there is nothing upon the ground for the spat to catch upon, or because they are not places to which spat is carried; and there are other bottoms which are so soft that a very young and small oyster would be buried in the mud and killed, although larger ones are able to live and thrive in the mud. In all these places oyster-planting may be carried on with profit, for while it is true that the total number of oysters which are born is not increased by planting, the number which reach maturity is greatly increased; for the young oysters fasten themselves so close together and in such great numbers that the growth of one involves, under natural conditions, the crowding out and destruction of hundreds of others, which might have been saved by scattering them over unoccupied ground.

Planting also adds very greatly to the value of oysters, as they grow more rapidly and are of better quality when thus scattered than they are upon the natural beds, and Ingersoll, in his "Report on the Oyster Industry of the United States," quotes the statement of Captain Cox, of New Jersey, that thirteen dollars' worth of small "seed" oysters yielded, after they had been planted for two years, oysters which were sold for \$II , besides about thirty bushels which were used as food by the planter's family.

Oyster-planting can be carried on only on private grounds, and it cannot flourish in a community which 
does not respect the right of the private owner to the oysters which he has planted.

The "five-acre law" of Maryland puts it within the power of any resident of the State to obtain land for this purpose, but the industry has never attained to much importance here, partly on account of the absence of sufficient protection, and partly no doubt through the feeling that our large and apparently inexhaustible natural beds render private enterprise unnecessary.

In Virginia more attention has been given to planting, and in some of the States north of us all the land that is fit for the purpose is thus occupied. In many States, as in Delaware, a great part of New Jersey, and especially in Rhode Island, the natural beds have been so heavily drawn upon that they long ago ceased to furnish any marketable oysters, and they are now valuable only as a source from which a supply of small oysters can be gathered each year for planting. The spat from the few mature oysters which escape the fishermen, and that which drifts on to the beds from the planting grounds and from the scattered oysters which still exist in protected places, keep up the supply from year to year, and its value is increased hundreds of times by the planting system.

The industry does not require a large capital, and it can be carried on with profit on a very small scale, although the oysters need constant and intelligent attention. In all places where it has been employed it has added greatly to the prosperity of the communities which have engaged in it, and has greatly increased 
the population of the shores along which it has been encouraged and protected.

A writer about thirty years ago states that the prosperity and rapid increase of the population of Staten Island are chiefly due to the encouragement and growth of the oyster-planting industry. At Prince's Bay, on that island, there has been some planting for more than sixty years, but before the bottom was laid out in private plantations there were very few persons living there, and the land was almost uncultivated; while in 1853 the number of inhabitants who depended directly upon this business for support had increased to over 3000 .

In some of the Northern States oyster-planting has been carried on for many years. Ingersoll states that oysters have been planted in York Bay, in New Jersey, since I81o, and that a suit was brought in Shrewsbury, New Jersey, at about the same date, to determine whether a man has the exclusive right to the oysters which he has planted.

The history of the oyster industry of Rhode Island furnishes an interesting illustration of the value of an intelligent system of planting.

In 1865 laws were passed allowing the leasing to private citizens, for a term of years, at an annual rental of \$10 per acre, of the right to plant oysters on any bottoms which are covered with water at low tide and are not within any harbor line, to be used as a private oyster fishery for the planting and cultivation of oysters, whether these lands contain natural beds or 
not; and efficient laws were enacted for the protection of private rights.

The effect of this measure has been good in every respect. The revenue of the State has been greatly increased, and it is stated that the rentals of the beds will in time pay all the expenses of the State government.

In 1865 oysters sold for $\$ \mathrm{I} .75$ per solid gallon; in I878 the price was \$I.I5 to \$I.Io, and in I879 it had fallen to 90@95 cents.

In 1865 the product of the State was 71,894 bushels, while in 1879 it was 660,500 bushels.

The area which was used for planting in 1879 was only 962 acres, yet this area paid $\$ 6582.90$ into the State treasury; it employed a capital of over \$1,000,000 ; it paid $\$ 125,000$ in wages to the people of the State; it furnished the market with 660,500 bushels of oysters, with $\$ 680,500$ to the producers, and it gave support to 2400 persons.

Until I 883 the Rhode Island grounds had been used only for planting, and most of the seed oysters were purchased from other States, yet the planted oysters sold for three or four times the cost of the seed, and it is doubtful whether there is any farming land in the United States which yields as great a profit to the acre as the bottoms which are used for oyster-planting in Rhode Island.

Our little revenue to the State treasury of about fifty thousand dollars from nearly a million acres sinks into insignificance when compared with the eleven 
thousand dollars which Rhode Island receives from her eleven hundred acres, and her beds are constantly improving in value, while ours are rapidly becoming worthless under our present policy.

In the early days of Rhode Island oysters were found there in the greatest abundance, but although dredging was forbidden in 1766 , under penalty of ten pounds fine, the natural beds have been so depleted by excessive tonging that they are now of little value, and they supply only a very small part of the seed used in planting. If all the area of our own State which is proper for oyster-planting were used in this way, it would, if no more profitable than the oyster grounds of Rhode Island, bring the inconceivable sum of two thousand million dollars into the hands of the planters each year.

The oyster industry of Delaware furnishes an instructive illustration of the value of oyster-planting. The natural beds of this State are not equal to a twohundredth part of those of our State, but under a law which allows any citizen to appropriate fifteen acres of ground where there are no natural oysters, upon payment of a fee of $\$ 25$ and an annual license fee of $\$ 3$ per ton for the boat used, a system of planting has grown up which is encouraged by public sentiment and is a great source of wealth.

Until recent times nearly half of the million bushels of seed oysters which were planted annually upon these beds were taken from our waters, and they cost the planter less than twenty-five cents per bushel, put 
down upon his beds. These oysters were taken up within three or four months, and then sold for more than eighty cents per bushel.

A method of oyster-planting in artificial ponds has been highly developed in France, where it is found to yield an adequate return for the labor and capital invested, as oysters fattened in this way sell for fifty per cent more than those from the natural beds. The method involves considerable labor, and it is doubtful whether the price of oysters in this country is as yet high enough to render this industry profitable.

The culture of oysters in the deeper waters of the Bay, and the establishment of new oyster-beds by collecting the floating spat upon clean shells and other proper substances, is very much more important than the encouragement of oyster-planting; but the various extracts and illustrations which have been given are surely enough to show the very great advantages which we should derive from a thorough system of planting. Deep-water cultivation cannot be undertaken to advantage on a small scale, and it requires both capital and expensive appliances; but oysterplanting can be carried on without any great expense, and as success in it depends to a great degree upon constant intelligent supervision, small cultivators will always have the advantage of those who attempt more extensive operations.

The most serious obstacle to the development of a great planting industry in Maryland is the absence of all respect for private property in oysters. In enclosed 
or artificial ponds oysters would be much more safe from theft than in open water, and the shores of the bay abound in suitable spots for the construction of ponds after the French system. Under our present system oysters are often sacrificed or sold at unremunerative prices, because there is no way to keep them in good condition until they can be sold to advantage. A system of ponds after the French pattern, for the temporary storage of oysters, would be a very profitable piece of property in the vicinity of any large center of the packing business, and the experience of the French planters shows that the construction of storage ponds where the oysters may be kept in good order, and where they will continue to grow and to increase in value, is a very simple matter.

This industry has also the great advantage that it does not need legislative protection. It can be put into practice at once by any one who owns land which is suitable for the purpose, and our State contains hundreds of acres of low, marshy land which is now private property, although it is of little or no value to its owners. Small streams and inlets which are not navigable, and which lie within the limits of private land, may be converted into ponds like the French claires at very slight expense, and with no more labor than what is required for ordinary agriculture they could be made much more profitable than the best farming land.

The oyster-planting industry in the open water is also a most important interest, and the attention of statesmen may well be directed to its development; for 
while legislation alone cannot build up a planting industry, it may do much to prepare the way for it.

In another chapter I shall try to show what our State can do to encourage oyster culture in general, but I wish also to say a few words in this place regarding the encouragement of planting. The most serious obstacle to the growth of the planting industry in Maryland is the absence of protection for planted oysters. They are exposed to the depredations of both tongmen and dredgers. If the private planting grounds could be protected from the dredgers, most of the difficulty would be removed, for the tongmen can be reached by the local authorities, who will have no difficulty in keeping them under control as soon as public sentiment is in favor of so doing.

The restraint of the dredgers within lawful bounds is a more difficult matter, and if dredging on the public beds is to be permitted at all, I do not see how planted oysters can be protected in any way, except by the formation of a public sentiment in favor of private cultivation. The difficulty is so great that many thoughtful persons believe that dredging should be prohibited, but after much careful examination of the subject I am not convinced of the propriety of this measure. If the natural beds are to be retained by the State, and licenses to gather oysters upon them are to be issued by the State, the dredge is the proper instrument to use for the purpose, and the prohibition of dredging would be a step backward.

Any bed which can be reached by tongmen may be 
ruined by unrestricted tonging just as surely as by dredging, and the statement that the small oysters are destroyed by the dredge is not supported by my own observation, while the claim of the dredgers that the area of the natural beds has been enlarged by dredging is strictly true. The natural beds have been overtaxed, and they are in great danger of total ruin, but no particular set of oystermen are to blame for this. Most of the oysters have been taken by dredges, because the dredge is the most efficient instrument for the purpose, but the exhaustion of our beds is the result of our bad system and the absence of all effort to increase our supply by artificial culture. It is not due to any particular way of catching oysters.

The prohibition of dredging would result in great hardship to a very great body of our citizens, and if oystering upon the public beds is permitted at all, I do not believe that any legislative interference with the methods which are to be employed would be wise. It is to the interest of the public that the oysters shall be taken as economically as possible, and the most effective implement for the purpose is the best one. The only way in which public beds can be preserved from ruin is by the restriction of the crop from each bed to the amount which it is found, by periodical examination by an expert, to be capable of yielding without injury, but the most effective way of gathering this crop is the best way.

If after examination any natural bed is found to be so much exhausted that it is no longer fit to yield a 
supply of marketable oysters, it should be closed completely to all fishermen, or else thrown open to all licensed fishermen for a short time in the summer, to furnish seed oysters for planting; and the oyster planters must look for protection in their industry to the growth of a sentiment of respect for private property in oysters, like the sentiment in favor of private agriculture on land. As soon as the community demands the enforcement of the laws, and juries convict and punish depredators as if they had trespassed on private land above water, all the difficulties will disappear, and I do not believe that there is any other remedy.

The question to be considered then is this: How can the people of the State be brought to perceive that private enterprise in oyster culture is to their advantage, and what can be done to develop a sentiment of respect for private property in oysters? This is the question which should occupy the best thought of those statesmen who are sincerely devoted to the welfare of the community, but it is not one which can be answered by those politicians whose only interest in the sentiment of the public centers in the use which they can make of it for their own private ends.

As soon as the planter has become assured that he will be permitted to enjoy the fruits of his industry, the demand for bottoms to be used as planting grounds will arise naturally, and it should be met by more adequate legislative provisions than our present fiveacre law. Riparian owners should receive from the 
State the right to plant oysters upon their own frontage, without any restrictions, unless this contains natural beds, and these should be surveyed and definitely described and set apart by the State. The holders of land for planting under the five-acre law should also be given a more secure and permanent tenure. At present they pay nothing for the right, and as the Legislature may at any time repeal the law, they have no secure possession.

There would be a much greater incentive to the investment of labor and capital in oyster-planting if the planting grounds were made as much like real estate as possible. The present law permits the sale of planting grounds, but no person can hold more than five acres. This limitation has no advantages, and the owner of ground under this law should be allowed to sell as freely as he can sell land above water, and a person who already holds five acres should be permitted to buy or inherit any other grounds which have been lawfully leased from the State.

In some States where grounds are held for private planting, they are taxed, like real estate, and the propriety of this measure is unquestionable, for the holder of a valuable franchise should surely pay for the enjoyment of his advantage. In Maryland, however, this is a minor consideration, and the fostering of a prosperous planting industry is vastly more important to all our citizens than an immediate revenue to the public treasury. 


\section{CHAPTER V.}

\section{A TALK ABOUT OYSTERS.}

An intelligent and successful farmer, visiting an oyster-packer in Baltimore, said: "I know nothing of oysters except what I have heard, but I wish to know more, and I should like to ask you a few questions. Since $I$ have been here I have seen in the newspapers most glowing statements regarding the advantages of Maryland for producing oysters, yet I am constantly being told that all branches of the oyster industry are depressed and in a most discouraging condition. The last two or three winters have been very mild and, I should suppose, very favorable for work upon the beds; yet I hear that few of the oystermen earned enough to pay expenses last year, and they all say that this winter matters have been very much worse. Your friends in the packing business tell me that the oysters are deteriorating in quality, and that they are growing so scarce that some of the packers have moved away from Baltimore. You say that people in Australia and New Zealand, as well as in Europe and in all parts of our own country, who formerly ordered great quantities of Maryland oysters, no longer patronize you. You complain that, while your business is falling 
off, you have more and more difficulty each year in filling your orders, and I can see for myself that your oysters are not as fine and substantial as they used to be. You tell me that you buy Virginia and North Carolina oysters, although your own beds are right here at home. Now I should like to know whether the waters of Maryland are not as fit for growing oysters as those of other States?"

"Certainly they are," answered the packer. "We all know that our waters are capable of producing the finest oysters in the world in immeasurable abundance. Like all citizens of Maryland, I am proud of this great natural resource, and I regard our oyster grounds as by far the most valuable land in our State."

"What is the trouble? Is the demand too great to be supplied from your own waters?"

"That is a difficult question to answer in a word. For some time past the demand has exceeded the supply from the natural beds, which formerly gave us all the oysters we needed; and as the eating-houses and the private consumers in the city take all the best, I am forced to send my customers oysters too young to be palatable and nutritious. But the demand from all sources has never reached anything like the amount which our oyster-beds might easily be made to yield."

"I cannot make your two statements agree. The sale and consumption of immature oysters seem to me like mowing down young wheat to make hay. Why is nothing done to increase the supply? I am told that in Delaware and New Jersey, in Rhode Island and in 
other States which have no great natural advantages, such as you claim for Maryland, the value of the natural supply has been very much increased by placing the young 'seed' oysters on bottoms where they grow and improve until they are ready for the market. In my experience as a market gardener I have found that while onions a year old can be sold, it is much more profitable to plant them as 'seed' a second year, and to give them another season's growth before sending them to market. Instead of packing and selling these small oysters, why do you not treat them as I treat my 'seed' onions? Are there no lands in your State suitable for oyster-planting?"

"You need only to look at a map of Maryland for an answer to that question. We have nearly three hundred miles of coast-line, all of it broken up into creeks and inlets and sounds and bays. All these are well adapted for oyster-planting, and might easily be made much more so. Besides this we have thousands of acres of low, marshy land, of no value at present. At a slight expense this might be converted into systems of artificial oyster-ponds, where oysters could be stored and held for a favorable markt, and where they would grow and increase in value, like your seed onions."

"This is most surprising. How is it that these natural advantages are not seized upon and developed? Do not your people know the importance and profit of oyster-planting?"

"Certainly they do. Oyster-planting has been car- 
ried on in a small way for years, and there are many men in our State who understand the business thoroughly. Besides, we have a remarkable illustration of its value only a few miles beyond our border. At Hampton Roads, in the lower part of the bay, the planting business has recently been pushed with great energy and enthusiasm. It is conducted on such a large scale that a big steamboat is now loaded with very fine oysters every day, from grounds which six years ago did not supply enough to meet the local demand."

"I am told that in Connecticut it has been found possible to grow oysters from the eggs, in the way that I grow wheat and corn; and to establish new oyster-beds in deep water by covering the bottom with oyster shells, to catch the floating embryos. Is there no place in the bay where this can be done?"

"Assuredly there is. No place in the world is better suited for oyster-farming. We have hundreds of thousands of acres which are most valuable for this purpose, and experiments have shown that there is no part of the bay where new beds might not ultimately be established by shelling the bottom, or by the use of other spat-collectors."

"Why don't you do it? How can you complain of the scarcity of oysters when you have such an opportunity for oyster-farming? Is not the business profitable?"

"You may judge of this for yourself when I tell you that, in good places, a crop of five or six thousand 
bushels a year might be harvested from each acre, with very little labor or outlay. No other branch of oyster culture gives as much profit upon the investment of capital and labor as deep-water oyster-farming."

"Does no one in Maryland understand the business?"

"Oh yes! Many of our packers do business in Connecticut, and they have seen for themselves how oyster-farming is carried on. They sell to the Connecticut farmers the shells which they scatter over their land to collect the spat, and there are many citizens of Maryland who know all about the business, and even some who have attempted to put the Connecticut methods into practice in our own waters."

"Were these attempts unsuccessful? Are the oysters exposed here to dangers which do not exist in I ong Island Sound? I am told that in Connecticut oysters in shallow water are often killed by ice, and that the deep-water farms are open and exposed to violent storms which, in the winter, often drive the loose sand and mud over the oysters and bury and destroy them. I hear, too, that the farmers suffer from the ravages of starfish. They tell me that these animals often come up in great armies, on to the beds, from outside, and that they destroy whole farms, leaving behind them only the empty shells. Do these accidents and enemies threaten the farming industry in Maryland?"

"Not at all," answered the packer. "We are so fortunate as to have none of these causes of failure. While 
the water of our bay is perfectly adapted for oysters, it is too fresh for starfish. They are sometimes found in the lower part, near the ocean, but they are never numerous enough to do much damage. Our climate is too mild for the ice to do much harm, and the bay is so well sheltered and landlocked that there are few places where oysters are exposed to much danger from storms. Most of our bottoms are so well protected that the hardest winds cause very little movement."

"You say oyster-farming has been tried in Maryland. Was it successful?"

"That depends upon what you mean by success. I can tell you of one farmer who, on about seventy acres of bottom in Virginia, close to the Maryland line, raised a crop of more than three hundred thousand bushels of fine oysters."

"He must be making a great fortune. How does it happen that his example is not followed?"

"He reared his oysters, but he did not harvest them. They were taken by the dredgers."

"Do you mean that they were stolen?"

"Oh no. That is not the word to use. While he was getting ready to gather his crop, the dredgers, who had paid our State licenses to take oysters, got ahead of him and captured them."

"Were the robbers discovered and punished?"

"They were not robbers, and they were not punished. The owner of the oysters, who knew many of them personally, remonstrated with them, but he could not persuade them to go away." 
"What do you mean? I do not understand the state of affairs which you describe."

"Why, you see, our people have always regarded the oyster-beds as the property of the whole State. They are natural wealth which has not been produced by man, and no one person has any more right to them than another. They belong to all the citizens of the State in common. We all inherit a share of them as part of our birthright as Marylanders. Our people are therefore opposed to any system which would lead to monopoly and would give to a few the exclusive enjoyment of the natural advantages which belong to all."

"That seems wise and just, but most of your citizens have other occupations and do not wish to engage in oystering. How do they dispose of their common rights?"

"We have a system of licensing, and any citizen who wishes to gather oysters on our common property pays to the State treasury a fee for the privilege of doing so, and in this way all the people of the State get the benefit of our natural wealth."

"I see. All your people are enriched by the sums paid by a few dredgers for the monopoly of the common rights of the citizens, for this must be very great, to judge by all you say of the value of your waters." "No; that is hardly true, I am sorry to say. The profits are not so great as you suppose. In fact there are no profits at all. The dredgers themselves are not prosperous, and they do not like to pay this tax out 
of their hard earnings for the use of what they regard as their own. Many of them would evade it if they could, so the State is forced to maintain a navy to prevent unlicensed dredging, and this costs more than the total sum received for licenses."

"How is this deficiency made up-by the taxpayers of the State?"

"Yes."

"I see. But does it not seem to you that this means that the people of Maryland pay taxes for the privilege of giving up their natural rights for the benefit of a monopoly?"

"Yes, I suppose it does; but then we have the satisfaction of knowing that we have benefited a large class of our people, and have afforded employment for many worthy citizens of our State."

"That is true; but I learn from the papers that foreign emigrants are met by the agents of the dredging captains, when they land at the Wharves in New York, and that they are then engaged for service on the Maryland oyster-boats. How can this happen if the right to dredge upon the public beds is so highly prized by your people?"

"A dredger's life is very hard. The boats are small, and when they are loaded with wet, cold, muddy oysters there is not much room left for the crew. The work is done in the most stormy months of the year. The dredgers are exposed to all the hardships and dangers of a sailor's life, and to some which are peculiar to oystermen. The heavy dredges are hauled by 
hand while the boat is under way. If they become foul while they are being hauled in, all the weight of the boat is thrown on to the windlass, and the laborers, benumbed by the icy waters and unable to move quickly, are often struck by the crank. Fatal accidents from this cause are not uncommon. Of late years the business has not been profitable. The boats do not pay expenses, and the owners cannot offer tempting wages. Maryland men, who know all the hardships of a dredger's life, are not anxious to ship as hands on a dredging boat, so the captains are forced to recruit their crews among men who are not so well posted."

"Can nothing be done to improve the dredger's life? Why do they not dredge in the summer and keep the oysters in planting grounds until there is a market for them?"

"The law does not permit dredging in the summer."

"Why do they not use larger vessels, and haul the dredge by steam?"

"As the amount of the license fee depends on the size of the boat, it is for the owner's interest to use a small vessel and pack it as full of oysters as possible. The use of steamboats is not allowed, and the law requires that the dredge shall be hauled by hand."

"How does it happen that with all your natural advantages the work is so unprofitable?"

"Our people have always been taught that our natural beds are inexhaustible, so nothing has ever been done to determine just how many oysters they 
could furnish each year without injury, and the result is that they have been overworked until they are so nearly exhausted that they no longer furnish a living for the oystermen."

"I think," said the farmer, "that I begin to understand the situation. It seems something like this. As the beds belong to the community, private oyster culture has not been permitted, since it would be a monopoly. Yet the common property of the citizens of the State has been given up to one class of citizens in order that they might have profitable employment. They have not managed their trust wisely, and have brought it so near the verge of ruin that it is no longer attractive to Marylanders, and they have called in the cheaper labor of foreigners. To give these foreign laborers employment the people of the State have not only given up their rights, but have also paid taxes for the support of the navy. This state of things cannot last. What do you propose to do about it?" 


\section{CHAPTER VI.}

THE REMEDY.

Looked at as a question in natural history, the oyster problem is very simple. The demand has outgrown the natural supply, but it is easy to increase the supply indefinitely by oyster culture, and this is all that is needed.

As a practical question it is anything but simple. It demands the best thoughts of all who are interested in the welfare of our people. The practical application of the remedy is proper work for statesmen of the greatest ability and widest experience, rather than for a naturalist who knows little or nothing of complicated social questions.

The interests at stake are so important and vast that they are worthy the best efforts of the best intellects in our community, and any statesman who wishes to devote himself to the unselfish, disinterested service of the people will find in the complications of the oyster problem an ample field for the exercise of all his powers.

So many divergent and conflicting interests are involved, and so many side issues are to be considered, that hasty, ill-advised action is sure to do 
more harm than good; yet we have permitted matters to run on so long without attention, that little time now remains for deliberation or experiment.

It is with reluctance that I venture to speak at all on the practical question of the reconstruction of our oyster policy. I feel that I have done my part by showing the capacity of the oyster for cultivation; by calling attention to the unexampled opportunities for oyster-culture afforded by our waters, and by describing the methods which should be used to improve these opportunities and to develop our resources. So far I have dealt with facts, not opinions; and as facts have permanent value, I hope that what I have written will help to a clearer understanding of the needs of our oyster industry, and that it will thus lead in time to the adoption of wise measures for its protection, and for promoting its growth and development.

Here I feel that my work should end, and that the practical details should be left to those who have had experience in public affairs; and if I venture to discuss details, I do so with the full knowledge that I am outside my proper province; that I am no longer dealing with facts, but with opinions which must meet with criticism and discussion. The reflections of any one who has thought seriously upon the oyster problem are worthy of attention, for the true solution can only be reached through the examination of all sides of the question, and I have therefore decided to devote the concluding chapters of this book to the expression of 
my own opinion of the way in which a new oyster policy should be introduced.

Every one agrees that, whatever may be the remedy, our method of managing the oyster industry so far has been a failure. It has had a thorough trial, extending through many years, and here are some of the results: It has yielded on the average some ten million bushels of oysters annually from grounds which are capable of yielding five hundred million bushels each year. It has led to the ruin of some of our finest beds, and to the very great injury of all of them, while other States have greatly increased the value of their beds at the same time that they have enlarged and extended the fisheries instead of restricting them.

It has given a precarious employment for a few months in each year to about fifty thousand oystermen, while our grounds should give profitable employment, the year round, to five hundred thousand.

It has paid to the oystermen about two million dollars a year, although our grounds should pay their cultivators more than sixty million dollars a year. Our six hundred thousand acres of oyster-ground have paid to the State treasury about $\$ 50,000$ a year, which it has cost the State about $\$ 52,000$ to collect; and it has paid about $\$$ Io,ooo a year to the School Fund, while our revenue would be more than $\$ 6,000$,ooo if it were no greater per acre than the revenue from the oyster-grounds of Rhode Island.

In other States, money invested in the oyster business has paid an annual interest of more than 200 per 
cent, while our oysters have never paid to either packers or vessel-owners more than Ioo per cent, and of late years they have paid nothing at all.

The interests of our people demand a complete change in our oyster policy, as rapid and radical as it can be without inflicting avoidable injury or unnecessary hardship upon any one who is now engaged in the business; for however advantageous to the public in general a change may be, the hardship of a few should overbalance benefit to many, and we should hesitate to demand any great sweeping change if it is possible to devise any plan to open the way for improved methods without infringing the rights of those who are now engaged in the business. If proper measures had been taken years ago it might have been possible to have preserved our natural beds from complete destruction, without restricting the fishing, while a new system was being gradually introduced.

We have delayed action too long, however, and the oyster business has been overtaken by disaster. There is no escape, under any system, from a few years of scarcity and depression, and all persons who are engaged in any branch of the business must suffer more or less. It is the duty of the people of the State to see to it that our resources are developed and made as profitable and productive as possible, but while it is quite true that our beds might easily be made to support many more persons than have ever gained a living from them in the past, we are bound to see to it that the welfare of those persons who are now depend- 
ent upon them be not unnecessarily obstructed while we are preparing the way for a better system.

The question of State revenue from the public beds is of general interest, but we must not attach undue importance to it, nor to any plan for public improvements in other parts of the State by this revenue. For several years past it has amounted to nothing, and under our present system it will never be worth considering. As this is the case, the question of revenue for the next few years should not enter into the discussion of our policy regarding the public beds. If any plan for restoring and protecting them without expense to the people of the State can be put into practice, that is all we should expect.

We often hear that, as their value in the past has not been the result of human industry, the oysterbottoms are a natural source of wealth which belongs to the people of the whole State. This is unquestionably true, but it may be well to inquire more minutely into the exact nature and significance of this ownership, for common rights bring with them common duties and obligations.

Our first duty is to protect those citizens who are most immediately and directly dependent on the oyster, and, among them, those who fish the public beds to get oysters as food for themselves and their families have the first claim.

Of the $10,500,000$ bushels of oysters which were gathered in 1880 in our waters, $8,670,000$, or more than four-fifths of the whole, were consumed outside the 
State, and those who hold that the people of our tidewater counties, or the people of Maryland, have a natural right to this supply of food, may truthfully affirm that if the sale of four-fifths of our oysters to people outside our State were prohibited, there would, even now, be an abundance for our own people on our natural beds. Under any intelligent system of management our natural beds would supply all the oysters we need for food, and would still leave a great surplus for commercial purposes, and we do not need to kill the oyster business in order to get our own supply.

It must therefore be clear to every one that our natural right to oysters for food does not justify us in destroying a business which gives profitable employment to a large class of citizens. All civilized communities recognize the advantage of selling their products in the best market, and it is not necessary to state that the destruction of our commercial business in oysters would inflict great injury, not on a few capitalists alone, but on thousands of fishermen, shuckers and canmakers, and our people have as much natural right to make an honest living by selling oysters to outsiders as they have to use them as food for themselves and their families.

If our right to oysters for our own food were the only one, the emergency could be met by legislation to prohibit dredging and wholesale fishing, and to drive the oyster business out of our State; but we can hardly conceive a greater misfortune to our people than this. Still, if it were the only way to protect our 
oysters, and to preserve for the people of our tidewater counties and for their children the supply of cheap food which nature has given them, I should be among the first to recommend this course.

Fortunately this is not the only remedy, and it is possible to increase our supply so that the tide-water people shall have all they want without destroying the oyster business.

Our next duty is to protect the interests of the citizens who support themselves by work upon the public beds-the tongmen and dredgers who fish for oysters in order to make their living by supplying the market. As their business is an honest and useful one, they have a natural right to pursue it, and it is the duty of our people to see that this right is preserved and protected. It is equally clear, however, that they can claim no right to deprive the tide-water people of food by plundering private supplies of oysters, or by destroying the natural beds. Every one knows that private planting grounds have been robbed without mercy by some of our fishermen, and even the men who are most prejudiced by their own interests are no longer able to deny the well-known fact that our public beds have been brought to the verge of ruin by the men who fish them to supply the market.

If fishing cannot be carried on upon the natural beds without this result, the interest of our whole people demands its prohibition. The citizens of Maryland do not desire to deprive any one of the right to earn his living, but our own interest requires that oystering 
upon the public beds shall be prohibited unless the oystermen can convince us that they can be intrusted with this right, without placing our common property or the property of any citizen in peril. The question which we should ask them, which they are bound in justice to ask themselves, is whether they are able to give this assurance to the people of the State. They cannot satisfy the community by calling for more laws to keep them within bounds, or by asking for an armed police force to prevent them from destroying their own interests.

They must satisfy the people that they themselves have enough public spirit to organize themselves for their own government and regulation, and that they have enough self-restraint and forethought and intelligent self-interest to provide for the protection and improvement of the property which is intrusted to them. If they can give the community this assurance, all the people of the State will be on their side and will aid them by all means in their power. The question of immediate revenue to the State will not be considered for a moment, as compared with their prosperity.

The tongmen and dredgers must acknowledge, however, that as the home consumer of oysters has no right to oppose the commercial business, it is equally clear that the public fishermen have no right to oppose the development of our resources by private oyster culture, unless it destroys their own livelihood.

So long as they draw on the natural supply without the devotion of any part of their labor or earnings to 
its increase by artificial means, they can claim no right to anything more than the natural beds; nor can they claim any right to gain a living from these beds at the expense of posterity, or by any means which tend to ruin the property. It is also clear that they have no rights which conflict with the wider right of our people to increase our prosperity by rearing oysters.

In discussing the measures which should be adopted for the restoration and development of our oyster business, the interests of four classes should be kept in view: the tongmen who resort to the beds for food; the dredgers and tongmen who make a living by gathering oysters for sale from our natural beds; the persons who wish to engage in oyster culture, either by planting or by the various methods of oyster-farming; and the dealers, packers, shuckers, canmakers and others who are supported by the oyster business.

Fortunately we need not ask which of these interests is to give way. Our waters are prolific enough for all, and it is the right as well as the duty of our people to see to it that our natural inheritance in the bay be fully developed and used to the best advantage for the good of all.

The protection of the people who now depend upon the natural beds for a living must always be kept in view, but our people should awaken to a sense that interest in the matter is not confined to the men who are engaged in the oyster business.

To ourselves and to our posterity we owe it that our resources shall be fully developed, for our oyster- 
beds are our greatest source of wealth, and upon them, more than upon our commerce, our manufactures, or our farming land, the future wealth and prosperity and population of our State depend.

Every one of us appreciates that it is for his interest to get his little private supply of oysters for home use as cheaply as possible, but scarcely any one, except the oysterman, realizes that this is the least of his interests in the matter. If our population were increased fifty-fold, the oysters needed for home consumption would even then be only a small part of the supply which our waters can be made to furnish; and every one who is interested in Maryland, all business men who will be benefited by an increase in wealth and population, all farmers who pay taxes to the State, and all persons who own property here, should awaken to the fact that our greatest source of wealth is almost absolutely undeveloped.

The wealth which is within the reach of our people and their descendants from the oyster-grounds of the State is great, almost beyond expression, and it is not too much to affirm that the money value of the grounds under the water is equal to that of the dry land.

I have attempted to form a rough approximation to the area which is at present occupied by oysters in Maryland, and while, in the absence of exact surveys, the result cannot be regarded as strictly accurate, the conclusions which are given in the following table are certainly not excessive. 
TABle No. 4.-Areas of Oyster-Beds Approximately AsCertained. 1883.

Square Yards.

Fishing Bay Beds.................... 25,600,000

Were Point ................................. $1,800,000$

Shark Fin Point..................... 1,850,000

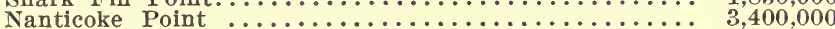

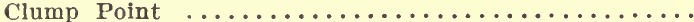

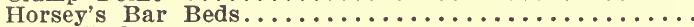

Tyler Beds

400,000

200,000

700,000

$2,400,000$ 300,000

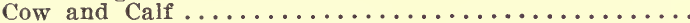

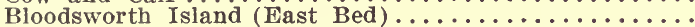

Cedar Beds

$4,000,000$ 400,000

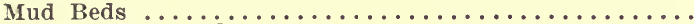

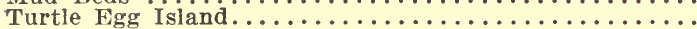

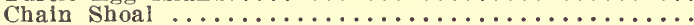

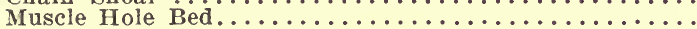

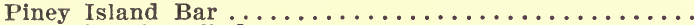

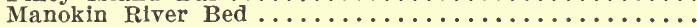

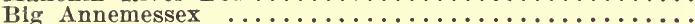

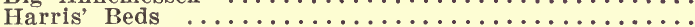

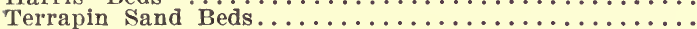

Paul's Bed

$1,800,000$

$1,650,000$

$1,200,000$

$3,000,000$

$7,000,000$

$6,200,000$

$3,000,000$

$3,400,000$

$1,400,000$ 800,000

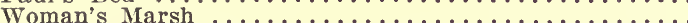

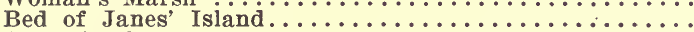

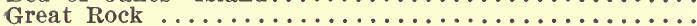

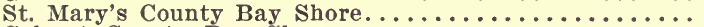

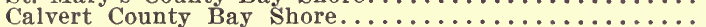

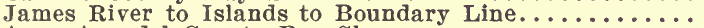

Anne Arundel County Bay Shore.................

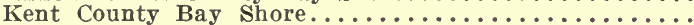

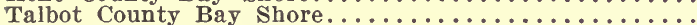

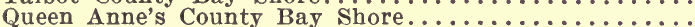

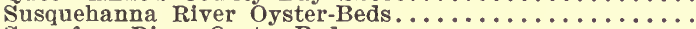

Sassafras River Oyster-Beds. . . . . . . . . . . . . . .

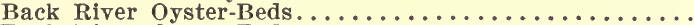

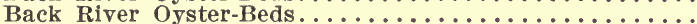

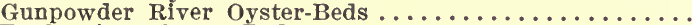

Bush River Oyster-Beds . . . . . . . . . . . . . .

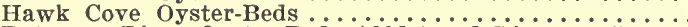

Patapsco River Oyster-Beds (old Road River to Sollers' Point)

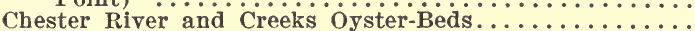

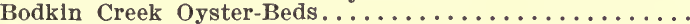

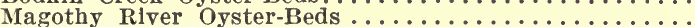

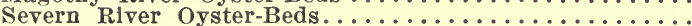

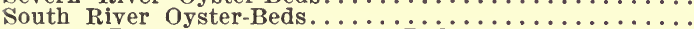

Choptank River to Cambridge Oyster-Beds.......... 13,300,000

Little Choptank River Oyster-Beds............... $7,100,000$

Patuxent River to Benedict Oyster-Beds............ 17,300,000

Total..................578,224,000

Five hundred and seventy-eight million square yards are about one hundred and ninety-three square miles, or one hundred and twenty-three thousand five hundred and twenty acres. 
As Winslow found by actual survey that there are I03 square miles of natural oyster-beds in Tangier Sound alone in I879, this estimate of I93 square miles for our whole territory is certainly not excessive, and it will be noticed that the Potomac River is not included in this estimate.

Only a very small part of the bottom which is proper for oyster-farming is now occupied by natural beds, and it is safe to estimate the total area of valuable oyster-ground in our State at one thousand square miles, or six hundred and forty thousand acres.

Much of this ground could be made to yield to its cultivators an annual profit of $\$$ rooo per acre, and the profit on the whole, under a thorough system of cultivation, would not be less than $\$$ roo per acre. It is not too much to affirm that when the whole of this area shall have been deveioped, the future citizens of our State will be able to draw an annual income of over sixty million dollars from our waters. At present, however, their value is very much below this estimation, and under the present system of management it is rapidly disappearing altogether. The oyster crop has never been very much more than 10,000,000 bushels, and its value to the fishermen has never, in all probability, exceeded $\$ 2,000,000$. It is not easy to ascertain its precise value with great accuracy, but $\$ 2,000,000$ annually is a safe estimate, and the actual annual value of the oyster-beds, under a system which is rapidly leading to their complete destruction, is thus 
seen to be less than three per cent of their possible value.

An abstract statement in figures is always open to distrust, and in order to guard against any impression that the value stated above for our oyster-grounds is imaginary, we wish to call attention here to results which have been actually realized.

In I888, Mr. Fred. A. Gunby, formerly a resident of Crisfield, Maryland, obtained from the State of Virginia a right to cultivate oysters on about sixty-eight acres of bottom in Accomac County, Virginia. The tract lay in Tangier Sound, near the Maryland line, and opposite that part of Smith's Island which is in Virginia, lying just south of Horse Hammock. He planted that year 28,000 bushels of oyster shells, at a cost of $\$ 1200$. Since that time he has employed a watchman to keep off intruders, at a cost of about \$3000. In April, I890, it was estimated that there were 30,000 bushels of oysters on his beds. The shells were found full of young oysters, which were growing rapidly. In December, I890, it was calculated that there were 350,000 bushels of oysters on the ground, worth at least thirty or forty cents a bushel in the market.

He was not permitted to gather the harvest which he had sown, but his experience shows the rich return which would be yielded by this sort of oyster-farming if private rights could be respected; and it rests with the people of Maryland to decide whether our resources shall be developed. Until we determine to 
avail ourselves of our natural advantages and to enjoy the rich harvest which lies within our reach, nothing can be accomplished.

There is no fear that the market will ever be overstocked with an article of food so cheap and dainty and nutritious as the oyster; and as improvements in the method of packing and transporting oysters are introduced, the demand for oysters to supply the rapidly increasing population of our country will fully tax all the resources of our waters. This great business can be secured just as soon as we are prepared to demand opportunities to develop our resources.

Since all efforts to engage in oyster culture in our State at present, even on the smallest scale, are frustrated by the claim that they are growing upon natural beds, the first step in dealing with the matter must be an actual, careful survey of the waters of the State, for the purpose of designating, first, the natural beds, or those areas over which the oysters are now so abundant as to furnish steady production, and employment for the men engaged in gathering oysters for the market; and, secondly, those areas which are now under cultivation as planting grounds; and, thirdly, the area which now produces no oysters for the market, but where oyster culture can be carried on.

After this is provided for, the next step is to decide what shall be done for the encouragement of each of the chief subdivisions of the oyster industry.

It will be most convenient to discuss, first, the measures which should be adopted to promote the in- 
terest of the tongmen and dredgers who now earn their living by fishing the public beds to supply the market, for every one appreciates that the destruction of their means of employment would be a great misfortune to all the people of the State.

After much thought upon the matter and careful examination of all the opinions which have been expressed, I am able to perceive only one way to protect and develop this branch of the oyster industry, and I am sorry to say that I am not at all sure that even this plan is practicable.

It is the co-operative organization of the oystermen themselves for the purpose of improving the public beds.

If they were to form an association for this purpose, and were to organize it in such a way as to satisfy the people of the State that the desired end would be attained, they ought to be aided and encouraged to make this experiment.

The people of the State should, however, require ample assurance that all industrious, law-abiding oystermen who are citizens of Maryland shall have a chance to join the association and to share its advantages; that the number of oysters taken from the public beds each year shall be restricted to the amount which they can yield without injury; that a proper proportion of the proceeds of the sale of these oysters shall be spent in the improvement of the beds; that the equitable distribution of the balance among the members of the association shall be provided for, and 
that all the influence of the association shall be exerted to enforce its rules and to secure respect for law and for private property.

If the people of Maryland can have a reasonable assurance that all these ends will be secured by the association, I believe that it will be wise for the State to give up for the present all hope of immediate revenue from the public beds, and to intrust them for a term of years to this association, for the use and profit of its members.

If my opinions carry any weight, I wish to impress upon the people of the State the fact that the prosperity of our citizens is very much more important than all the money which we have ever received from dredging and tonging licenses, and I also wish to convince the oystermen that they must depend upon their own efforts rather than upon the State government.

If I tell the oystermen that it is useless for them to look to the Legislature for the improvement and development of the public beds, I only tell them what they already know by long experience.

It has been proved, over and over again, that our public domain cannot be protected without the aid of the oystermen; but if they would co-operate for the enlightened administration of their own business, they would need no new restrictive laws. They do not even need to send men to the Legislature to look after their interests, nor do they need to fee lawyears to make out a case for them. The enlightened sympathy of our people is worth more to them than 
any number of men in the General Assembly, or than all the advice of the best lawyers in the State. For support they must rely upon public sentiment, and for success they must trust to their own efforts. If our public beds are to be saved from ruin, it must be by the efforts of the oystermen themselves, by organization and co-operation for the purpose. I do not see any other way to bring it about, and I hope that the plan which I have proposed will be considered by the oystermen.

While there are some reckless, short-sighted men in the business, most of the captains and vessel-owners are men who have the respect and confidence of their neighbors, and the intelligence and personal influence which are needed to direct and control public sentiment.

I ask them whether it is not worth while to consider whether a plan for the organization of a co-operative oyster company cannot be drawn up and put into good shape. If they can accomplish this, I am sure that they could present it to the Legislature, with an endorsement by all the people of the State, so enthusiastic and unanimous that it would command the support of every one who is interested in their welfare, and that it would meet prompt recognition by the Legislature, even if there were not a single member who depended on the votes of the oystermen.

The complicated details of the organization; the qualifications for membership; the mode of enforcing the laws of the association; the way in which rent for 
the use of vessels and apparatus is to be assessed and collected; the sums which are to be paid by the association for the experience and business standing of captains and other officers; the way in which fishing is to be kept within the capacity of the beds; the means to be adopted for restoring and improving the beds; the adjustment of the conflicting interests of different localities: all these and many other matters of detail will require close attention, self-sacrifice and careful thought, but I do not believe that the difficulties will be found insuperable if an earnest effort is made to work out a plan of co-operative organization.

The people of the State would rejoice to see such a plan developed and put into successful operation, and no obstacles would be thrown in the way of the oystermen by outsiders. The only difficulty is the one which comes from human nature.

The native American is too ambitious, too fond of competition, and too desirous of full scope for his own individual energy and intelligence and business sharpness, to take kindly to a co-operative organization; but the only way to afford a field for these selfish qualities is private oyster-culture, and if our natural beds are to be retained as public ground they must be managed on a co-operative system.

No one can say whether such a system would succeed or not, but it is well worth trying for a term of years. If at the end of this period the result were satisfactory, all the people of the State would be proud 
of our oystermen, and it could then be renewed for another term, or forever, as seemed best.

If the organization should break down or fail through internal dissension or personal ambition or conflict of interests, no great harm would be done, for the system of private culture could then be tried.

Some of the oystermen will assert that they have no money to invest in the improvement of the beds, and that the State ought to help them out; that what little capital they had has been lost in the last few years, and that, in order to be successful, the fishery would require so much restriction for the next two or three years that there would be no profits, and only a very scanty living. Unfortunately, this is true, but it will be true under any system, and at present things are growing worse with no prospect of improvement, while under intelligent co-operation they would improve rapidly after the first two years. The oystermen complain that they have no capital to bridge over this gap, but they will have to get over it somehow, in any case. At present they cannot borrow, for they have no prospect of better times ahead.

If, however, the community were convinced that the organization could be relied upon to develop and improve the property intrusted to it, there would be no difficulty in raising the necessary capital, and the amount which is now paid by the State for licenses would go a long way towards the improvement of the beds.

The only plan for the management of the oyster- 
grounds as public property, except oyster culture by a co-operative organization of oystermen, is cultivation by the State, and our past history shows conclusively that the State can do nothing unless it be supported by the intelligent co-operation of the oystermen. If they are able to co-operate effectively for the enforcement of the laws, they are able to co-operate for the improvement and protection of their own business; they can manage it for themselves very much better than the State can do, and they do not need State aid. Every oysterman will agree with me that if the money which is now paid for licenses is to be be spent in the improvement of the public beds, the oystermen themselves would be more able, under a co-operative system, than any salaried officers who might be appointed by the State, to use it to advantage.

State protection has so far proved a total failure, and I do not see any way to save the public beds, as common fishing grounds, except the one which I have proposed. If this is not practicable, the sooner the natural beds are thrown open to private cultivators, the better it will be for all concerned.

The artificial culture of salt-water food-fishes is proper work for the State, for these fishes are migratory; they cannot be confined or restricted to one spot, and there is no way to secure to individuals the enjoyment of the fruits of their own industry in this field of work. The case of the oyster is quite different. The animal is as fixed and sedentary as a potato, and its cultivation is as simple as any other branch of agri- 
culture. State aid is unnecessary, and experience has shown that it is totally inefficient, and our public beds must either be cultivated by the oystermen as an organized body, for the good of all, or they must cease to be public ground, and must be cultivated by individuals for their own profit.

It now remains to consider the measures which should be adopted for the protection and development of the other branches of the oyster industry, but this is comparatively simple.

First, as regards the tide-water consumers of oysters. So far as they are fishermen upon the public beds, they should become members of an oystermen's association for the preservation, restoration and development of the public domain.

So far as they are planters upon private grounds, their greatest need is protection in their rights and encouragement to invest their time and money in the extension of the planting business. As soon as the first condition of success, respect for private property, has been secured, the planting industry will grow rapidly, and I have already devoted considerable space (pp. I25-I4O) to the discussion of improved methods.

Success in planting requires security in the tenure of bottoms to be used for the purpose, and I believe that the following provisions for the growth of the industry should be made by the State:

Any owner of land the lines of which extend under the navigable waters of the State, should have the exclusive right to use the bottom within the lines for 
oyster culture; the owners of any land bordering on any landlocked water should have the exclusive right to use it for oyster culture above the line where it first ceases to be one hundred yards wide at low water; any one who shall construct an artificial pond for the culture of oysters on any land of which he is the owner shall own the pond and its contents; any owner of land in which there may be any landlocked water which might be converted into a pond for the cultivation of oysters without injury to navigation, should be permitted to construct dams or gates in order to convert it into an oyster-pond, and should have the exclusive right to cultivate oysters upon its bottom. In addition to these provisions, any riparian owner should be permitted to purchase from the State, at a nominal price, the right to cultivate oysters upon the bottoms of his own water-front, to a specified distance-say one hundred yards-beyond low-water mark; and any citizen of Maryland should be permitted to purchase from the State, at a nominal price, the right to cultivate oysters upon an area not to exceed fifteen acres, on any bottom not already appropriated or set apart as public ground.

In all these cases the right to cultivate oysters should be made as much like a title to real estate as possible, and the State treasury should look for its income from future taxation of the property rather than from the price of the franchise. After the planting industry has become well established it will be able to bear its proper share of the burden of taxation, but an 
infant industry should not be hampered or taxed for the sake of public revenue.

These provisions, if sustained by a sound and liberal public sentiment, would put it in the power of any citizen to engage in oyster-planting, and thus to provide for the support of his family.

The encouragement of oyster-farming upon the bottoms in the open waters of the bay now remains to be considered.

After the natural beds have been surveyed and mapped and set apart as public grounds, provision should be made, ultimately, for the encouragement of private oyster culture upon all bottoms, outside those limits, not otherwise appropriated.

As nearly all of this book has been devoted to the subject of oyster-farming, it is not necessary to add anything more to show its great importance. Its encouragement is a matter of vital interest to every citizen of Maryland, for, wisely fostered, it will be an inestimable contribution to the prosperity of all our people; it will provide permanent, stable employment for our oystermen; it will increase the packing business, it will benefit all oyster dealers, all shuckers and canmakers, all the business men of the community; it will provide cheap and abundant food for our people, and it will contribute to the revenues of the State; but from its very nature it cannot be successfully carried on upon a small scale, and steps must be taken to attract capitalists to this field of industry.

Many thoughtful persons believe that all private 
ownership of land is objectionable and injurious to the best interests of society, and they are for this reason opposed to private oyster culture. I believe, however, that it will be found, on careful examination, that most. of their arguments and objections to private ownership lose their weight when applied to oyster culture.

Private lands above water are often used in such a way as to exclude other uses more beneficial to society; but this cannot happen with oyster franchises, for the State has no power to grant any absolute title to the bottoms under navigable water, or to grant any right to use them for other purposes than those specified in the lease. It has power to convey to private citizens the right to cultivate and harvest oysters, but it can do no more, for all the citizens of Maryland have the common right to catch fishes in our waters, and all citizens of the United States must always retain and enjoy the right of free access to all such lands for purposes of navigation. It is clear that a lease of the bottoms for oyster culture could not give any exclusive personal right to use them for other purposes, nor could it deprive our citizens of their common right to use our waters for other purposes.

It is also urged that the private ownership of land is unjust, inasmuch as it enables individuals to appropriate to themselves the unearned increase of value; but as the whole bay is a natural highway, where no public improvements will ever be needed, as no towns will ever grow up on the water, and as transportation by water is so cheap that the distance of the market 
counts for nothing, and as the bottoms can never be used for any other purpose than oyster culture, the only way in which the value of the oyster bottoms can increase is by the extension of the market, and if this is brought about by the energy of the oyster farmers it will not be just to assert that they have not earned it. The value of our bottoms, for rearing oysters, is as great now as it will ever be, and while the selling price of land will rise as the industry extends, the increased price will not be due to increased value, but to more general recognition of its value. Interest in the subject will awaken and spread, after the success of the first experiments, and as appreciation of the value of the ground becomes more general, and the demand increases, the price must rise, although the actual value of the land for the production of food will not be any greater than it is now.

The only danger to be guarded against is that some of the land may fall into the hands of speculators, who, instead of cultivating it and adding to our resources, will keep it idle and unproductive until they can sell their unimproved rights at a profit, on account of the increased price of neighboring improved lands.

This difficulty seems very formidable on paper, but it can never exist on any extensive scale, for it would in that case defeat its own end, and it is clear that it is from its own nature transitory, and that it will disappear as soon as oyster culture becomes general and all the land comes into profitable use.

I believe that ultimately it will be found to be the 
wisest policy for the State to make the franchises for oyster culture perpetual, but since most of the advantages of private enterprise can be secured by leases for a term of years, it may perhaps be wise to try this plan for one or two terms, and to leave the question of absolute sale for future consideration. 


\section{CHAPTER VII.}

THE PROTECTION OF OUR NATURAL BEDS; AND THE CAUSE OF THE DECLINE OF OUR OYSTER INDUSTRY.

Every one knows that the condition of the oyster industry gives good reason for great anxiety. In times of hardship it is natural to look for some one to bear the blame, and for a long time our daily papers have been filled with letters from packers, dealers, brokers, dredgers, tongmen and planters, all throwing the responsibility on some one else. The important question is, what can be done to improve matters? Every one knows that there has been ignorance and error and mismanagement in many quarters, but no good can be done by blaming others.

It is necessary, however, to study the causes of the present state of things, not as an excuse, but as a basis for the intelligent discussion of remedies; for a little knowledge of the subject will show that no relief can be expected from most of the protection measures which are advocated in the newspaper correspondence.

If wise measures had been adopted years ago we might have passed gradually to a better state of things without exposing to hardship any one who is engaged in any branch of the industry, but our people have 
always been so firmly convinced that our supply was inexhaustible, that all warnings have been disregarded, and we have never taken the first step towards reform -a thorough examination of the exact condition of our resources.

The world will scarcely believe that in a State whose largest and most characteristic industry depends on the oyster, the oyster-beds have never been thoroughly examined or even surveyed and mapped, but this is the case. For many years I have urged the importance of thorough periodical examinations of the beds as a basis for the intelligent regulation of the fishery, but this work has never been undertaken by the State. If it had been, the result would long ago have proved to every one with absolute conclusiveness, before the damage was past remedy, what has been perfectly obvious for many years to all who have studied the subject, that our beds are being exhausted and ruined by our present system.

In I882 I was appointed a commissioner to examine the condition of the oyster-beds of the State and to report the same to the next General Assembly, but no means for the prosecution of a survey of the beds were provided. This would have required a large force of trained assistants, with expensive appliances, and even then it would have been the work of years, and I was forced to content myself with a mere superficial examination. In this I was most effectually aided by the intelligence and enthusiasm of my fellow-commissioner, the late Capt. Jas. I. Waddell, and the Governor 
of the State furnished from his "emergency fund" a small sum for the purchase of a few pieces of simple apparatus. The Trustees of the Johns Hopkins University allowed me to devote to the work two years, during which they paid me for my service to them, and they also furnished aid in other ways, so that the results of our examination of the beds were, in great part, a gift from the University to the State.

With such scanty means as we could command we organized a plan of work, and soon accumulated enough data to prove that our oyster policy is destructive and sure to result, ultimately, in ruin to the industry. Our first step was to try to ascertain the condition of the beds by personal examination, but we found that the absence of any exact data as to their condition in past years rendered any inference from our observations very difficult.

In a small part of the bay exact data were on record. The beds of Tangier Sound were very carefully surveyed in 1878 and 1879 by Lieutenant Francis Winslow, U. S. N., acting under the direction of the Superintendent of the United States Coast Survey. His published report is one of the most important documents ever printed on the subject, and while it covers only a small part of the waters of Maryland, it gives a very exhaustive account of all the oyster-beds of the region examined, with their areas, location, boundaries, position, general character, the number of oysters to the square yard, the ratios between oysters of different ages, etc., so that we were 
able to ascertain without difficulty the changes which these beds have undergone in the three years which had passed since this work was finished, but we were unable to obtain exact information of this kind regarding the great mass of the beds of this State. Lieutenant Winslow was employed for nearly two years in the survey of Tangier Sound, and a similar survey of all the oyster area of our State would have required four or five years more, and as we had no means at our disposal for exact surveying, even if there had been time to undertake it, we adopted a more rapid method of gaining a crude idea of the condition of the beds.

It is obvious that a bed where there are many oysters to the yard is in a more fertile condition than one where the oysters are few. It is also clear that a bed in which the living oysters are few as compared with the dead empty shells, is less vigorous than one where the dead shells are less numerous.

It is clear, too, that a bed upon which many young oysters are growing up to replace the old ones is more prolific than one where the young oysters are few. During the first year of its life the oyster is much more exposed to accidents and enemies than it is after it reaches maturity, and it is therefore plain that if the average life of the oyster upon our worked beds is three years, any bed upon which the oysters one year old are not much more than one-third of the whole number must soon be destroyed.

We therefore attempted to ascertain these three points for all the larger beds in our waters: first, the 
number of oysters to the square yard; second, the ratio of living oysters to empty shells, and, third, the ratio of mature to immature oysters. To ascertain the number of oysters to the square yard, a dredge with a mouth a yard wide was dragged over the bottom, for a measured distance, at a definite rate of speed, and its contents were then brought aboard and counted. This method does not give perfect accuracy, for the dredge does not, as a rule, take all the oysters; the number varying with the weight of the dredge, the speed of the boat, the depth of the water, the length of the line, the character of the bottom, etc. Still examinations of this sort, made upon different beds by the same dredge used by the same persons in the same boat and managed in the same manner, give results which are comparable with each other, although it is more difficult to compare the results of two or more examiners.

The oysters captured in this way were carefully separated from the empty shells and other refuse, and both oysters and debris were measured and counted. The oysters of various ages were then separated into four sets: large oysters, or those less than 200 to the bushel; medium oysters, or those between 200 and 300 to the bushel; small oysters, or those over 400 to the bushel and over an inch long; and young growth, or those less than an inch long.

During this work we examined sixty-one beds and made three hundred and forty hauls of the dredge; and the results of this examination are here given in full, together with an analysis, and a comparison of 
our results with those which had previously been obtained by Winslow and others.

In 1878 and 1879 Lieutenant Winslow found that there were about 419 oysters to the square yard in Tangier Sound, or one oyster to every two and three hundred and eighty-six thousandths square yards. As the beds of Tangier Sound showed, at that time, indications of exhaustion, this number, .419 to the square yard, is less than it would be upon uninjured beds, and it is probable that the beds outside the Sound would have given a much greater number at that time. If we now find that the average is below this number, we can safely assume that the difference is entirely due to the injury which the beds have sustained since 1879, and we may thus form some estimate of the time which will be required for their complete destruction. We made use of the method which was employed by Winslow in his examination. A dredge, a yard wide, was dragged slowly over the bed until we ascertained that we were upon the oyster grounds. The dredge was then emptied, lowered on to the bed, and as soon as it began to take hold of the bottom it was timed, and the rate of the steamer was also ascertained by the ground-log. The area covered was not the same in all cases. Where oysters were abundant the steamer was stopped and time was taken as soon as the dredge was full. In other cases five minutes were allowed to pass and the steamer was then stopped. The dredge was then hauled in, and the oysters were counted and measured. 
This method does not give the actual number of oysters upon the bottom, for the dredge does not always sweep clean, and it is necessary to pass over the ground several times to thoroughly exhaust it, but results obtained in this way give the relative condition of the bed with great accuracy.

Whenever the contents of the dredge showed that we were off the bed, or near its limits, the haul was not counted, and the results therefore show the number of oysters upon the beds; not the number per yard over the whole bay.

Fifty-nine beds were examined in this way, and the results are given in the accompanying table, which shows that forty-four of these beds are below Winslow's average, and fifteen above it. Upon one of these beds, in Hooper's Strait, we found 8.2 oysters to the square yard, and we here obtained 4000 oysters in six hauls. These oysters were all very small, averaging four hundred to the bushel, and we probably struck an area where there had been a good catch of spat a year or two before, but where there were no large oysters. At any rate, this condition is exceptional, and I have therefore omitted the dredgings in Hooper's Strait in the average for the bay. Leaving this out, the average for the other fifty-eight beds gives .235 oysters to the square yard, or one oyster to each $4{ }_{1}^{243}$ yards, while three years before there was one oyster to each $2 \frac{386}{1000}$ square yards.

Startling as this result is, it is by no means the whole truth. We must remember that in 1879 Tan- 
gier Sound itself was more exhausted than the bay, so there were undoubtedly more than .4I9 oysters to the square yard at this date. Then, too, we have examined many beds where dredging is not permitted, and other beds where the oysters are unmarketable, and the high results which we obtained from these beds are included in the average. If these were omitted our total would show nearly 50 per cent of exhaustion to the most valuable beds of the State. The accompanying table, which is compiled entirely from the facts which we observed by personal examination of all the beds, must speak for itself. It is the most trustworthy evidence which we have been able to obtain, and it certainly justifies the widespread belief that the oyster property of the State is in imminent danger of complete destruction unless radical changes in the methods of managing the beds are made at once.

Great importance should not, however, be given to the exact quantitative result which we obtained, as it is based on only one examination. If the beds could have been examined every year or two in the same way, as we recommended at the time, the results of successive examinations could have been compared with considerable accuracy, and definite data could thus have been obtained, but it is difficult to estimate the exact value of a single examination.

EXPLANATION OF TABLE NO. I.

The first column gives the name of the bed; the second the number of dredgings which were made 
TAble No. 1.-Showing the Number of Orsters to a Square Yard in the Waters of Maryland in 1882 and 1883.

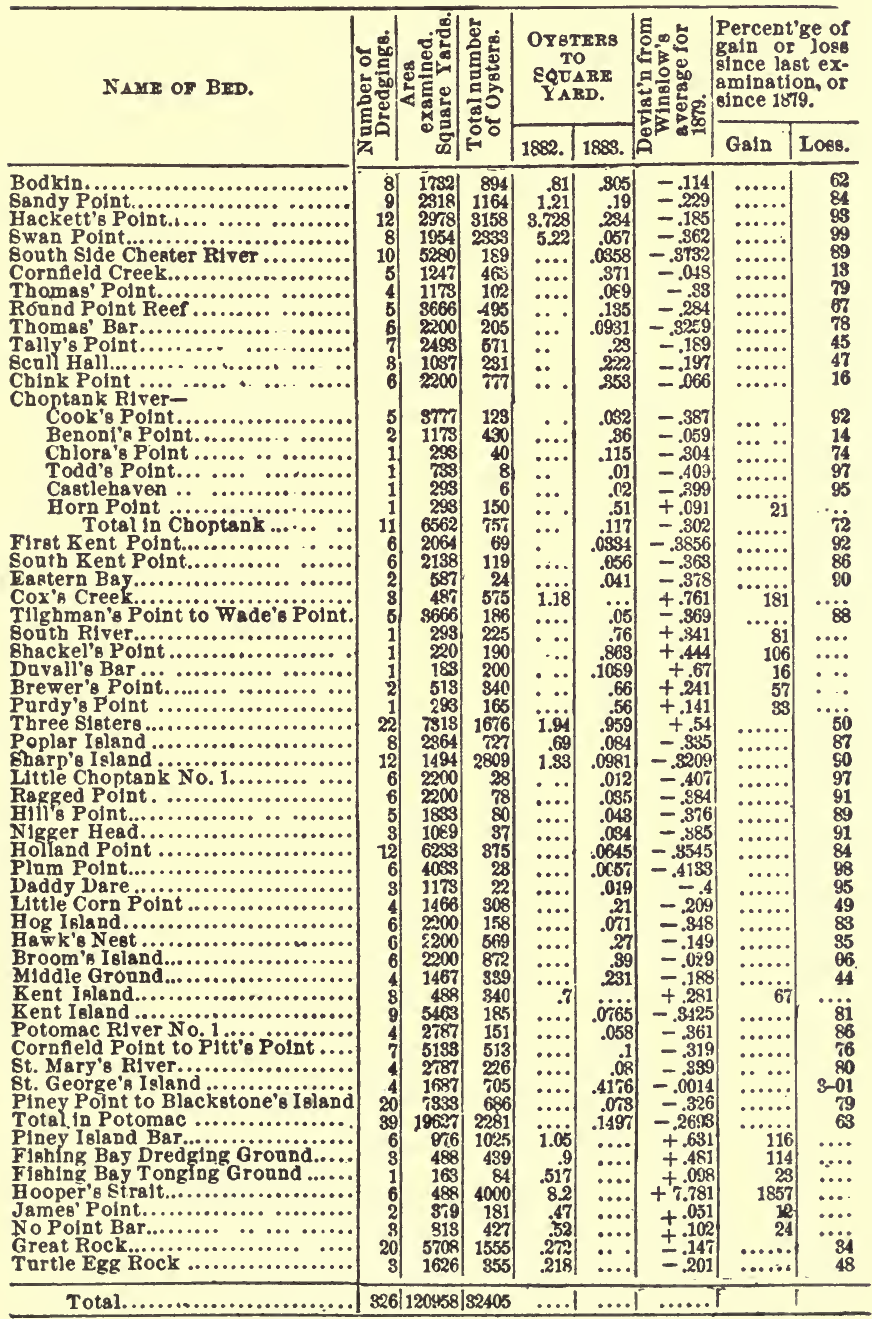

Total number of beds examined ................................. 59

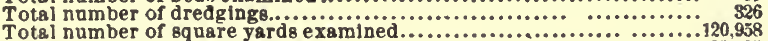

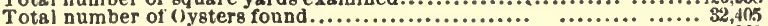

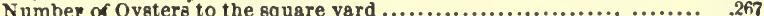

Number of Oysters to the square yard, exclusive of Hooper's Strait.... 285 
upon it by us; the third the number of square yards dredged; the fourth the number of oysters taken; the fifth the number found by us in 1882 ; the sixth the number found by us in 1883 ; the seventh the amount of deviation from Winslow's average for 1879, of .419 oysters to the square yard, and the eighth the percentage of gain or loss since the last examination. Thus the first line shows that eight dredgings were made upon the Bodkin; that I732 square yards were examined; that 894 oysters were obtanied; that the bed had lost $\frac{50}{100}$ oysters to each square yard since I882, and that it has lost 62 per cent of its value in that time.

\section{RATIO BETWEEN LIVING OYSTERS AND DEAD SHELLS.}

When the oysters are culled upon the beds where they are caught, the dead shells are thrown back, and the oysters upon a bed which has been overworked will therefore form a smaller part of the total contents of the dredge than they will upon a more prosperous and valuable bed. In a dredge which has been hauled over an unexhausted bed, the living oysters are many and the shells are few, while the dredge brings up from an exhausted bed a great mass of rubbish which must be lifted and handled in order to obtain a few oysters.

The ratio between the living oysters and the dead shells therefore furnishes us with a means for deciding whether a bed is deteriorating or not. This method of estimating the condition of the beds is a very rough 
one, and the evidence is not of much value when only a single bed is examined. The dead shells are swept into the channel in some places, and covered up by sand or mud in others, so that the dredge may come up filled with shells when it happens to strike a bed where they have been swept together, and in another case, where most of the shells are buried, it may contain few. If the dredge is heavy and is dragged with a long line, it may dig into the mud and become filled with old shells, where another dredge, or the same dredge dragged in a different way, may contain few or none. The contents of the dredge are determined by so many accidents that single observations of the ratio between shells and oysters are of little value, but the case is different where a great number of dredgings is made. In $1876 \mathrm{Mr}$. Otto Lugger visited most of our beds, and measured the quantity of shells and of oysters obtained from each. As he made a great number of observations, his results give us a means of ascertaining the average ratio in 1876 . His results, obtained by the examination of twenty beds, show that in 1876 the dredge brought up $3 \frac{68}{100}$ bushels of oysters for each bushel of shells. In 1878 and 1879 Lieut. Winslow examined in the same way seventeen beds in Tangier Sound, and found that only $I_{106}^{96}$ bushels of oysters were obtained for each bushel of shells.

In November, I882, we examined fourteen beds in this way, and found that the average had fallen from $3 \frac{68}{100}$ in 1876 and $I_{\frac{96}{100}}$ in 1879 to $I_{\frac{31}{100}}$ bushels in 1882 . Thirty-two beds were examined in the same way in the 
summer of 1883 , and nearly the same ratio was obtained, there being $I_{\frac{2}{5}}$ bushels of living oysters for each bushel of dead shells.

The results of this examination are given in full in the following table.

Table No. 2.-To Show the Number of Bushels of Oysters to Each Bushel of Dead Shells.

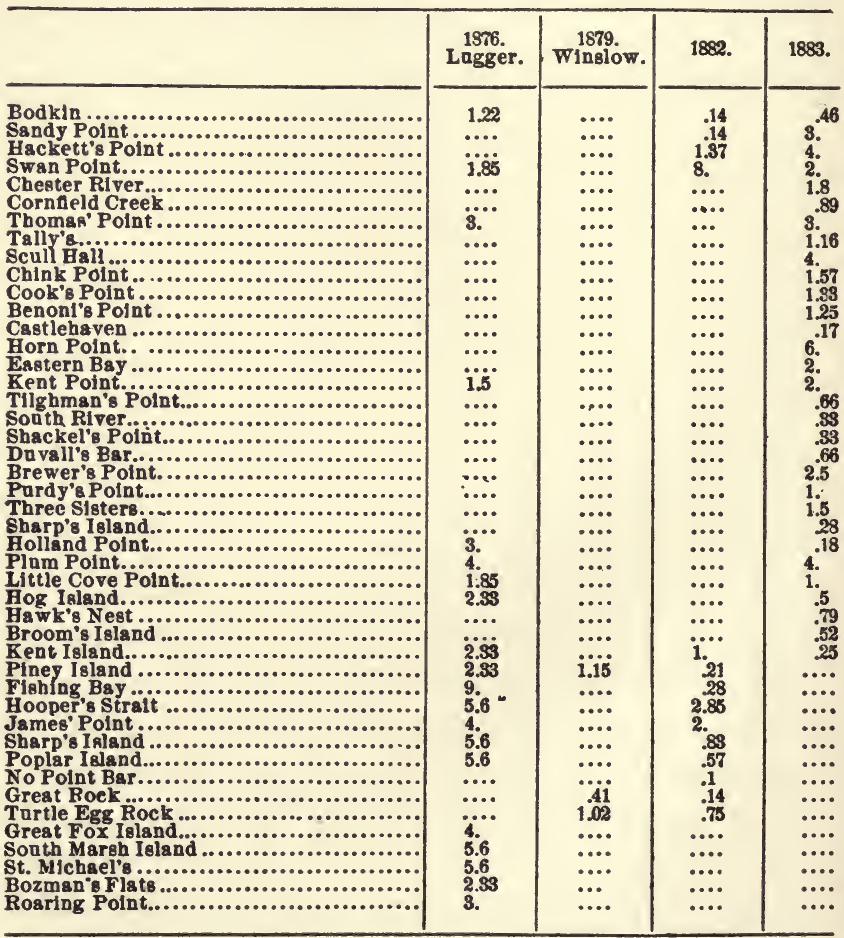

In 1876 Lugger fonnd as the aversge for twenty beds 3.682 bushels of oysters for each bushel of shells.

In 1879 Winslow fonnd as the average from seventeen beds 1.962 bushels of oysters for each bushel of shells.

In 1882 we fonnd as the average for fonrteen beds 1.31 bushels of oysters for each bushel of shells.

In 1883 we fond as the average for thirty-one beds 1.4-10 bushels of oysters for each bushel of shells. 
This table shows that while it is necessary, in 1883 , to handle I6I bushels of oysters and shells to obtain IOo bushels of oysters, it was necessary to handle only I5 I bushels in 1879 and only 127 bushels in 1876 .

This evidence, in connection with that which has been given in Table I, seems to prove that the whole oyster area of our State is being exhausted.

THE RATIO BETWEEN LARGE AND SMALL OYSTERS.

Any bed is on the road to destruction if the number of old oysters which are removed from it each year is as great as the number of young ones which are growing up to take their places. Oysters, like other animals, are exposed to many accidents, and the number which can be taken from a bed annually is equal to the number which are growing up to take their places, less the number which will be destroyed by the accidents of nature.

An accurate count of the oysters of various ages upon a bed, therefore, gives us a means of deciding whether it is or is not in danger of exhaustion.

We have examined in this way the oysters upon the beds which we have visited, and have divided them into four classes. The first class includes large oysters, or all oysters of which a bushel does not contain more than 250 ; the second class includes medium oysters, or those between 250 and 400 to the bushel; the third class includes the small oysters, those which are large enough to be seen and counted without difficulty, and more than 400 to the bushel; and the fourth 
class, or "young," those which are less than one-half inch long.

The accompanying table shows the number of oysters of each class which we obtained upon the beds which we visited, and the ratio between them.

Thus we found upon the Bodkin bar in November, I882, no large oysters, 225 medium oysters, 355 small ones, and no young, and there were at that time 100 small ones for each 67 of medium size.

In June, I883, we found no large ones, and the small ones which we had found in November had grown to a medium size, and there were no small ones growing up to take the places of these when removed by the season's dredging. This result seems at first sight to indicate that the fishing this season (I884) will exhaust the Bodkin bed and put an end to work there, but in truth the case is not quite so discouraging, for our second examination was made before the end of the spawning season, and an examination in the fall might have given a different result.

In order to be trustworthy, an examination of this kind should be made every year, in the same month, and if the oysters of various sizes upon each bed could be counted twice every year, in May or June, and in September or October, the results would be very valuable and would soon furnish a very exact means for ascertaining the condition of the beds. This evidence would be the more valuable, as it would soon enable us to determine, a year or more in advance, how many marketable oysters a bed could yield without injury. 
Table No. 3.-To Show the Number and Ratios of Oysters oF VARIOUS SIzes.

\begin{tabular}{|c|c|c|c|c|c|c|}
\hline & 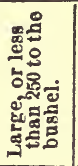 & 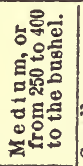 & 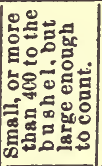 & 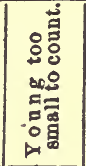 & 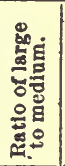 & 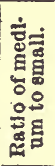 \\
\hline Bodkin, Nov & 0 & 225 & 855 & 0 & $\cdot \cdot$ & .67 \\
\hline $\begin{array}{l}\text { Bodkin, June, } 1883 . . . . . . . . \\
\text { Sandy Polnt, June, } 1883 . . .\end{array}$ & $\begin{array}{r}0 \\
138\end{array}$ & $\begin{array}{l}314 \\
176\end{array}$ & $\begin{array}{l}0 \\
0\end{array}$ & $\begin{array}{l}0 \\
0\end{array}$ & $\ddot{75}$ & 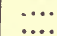 \\
\hline Sandy Point, Nore & 100 & 155 & 700 & many. & & $\ddot{20 i}$ \\
\hline ber, 1882. & 600 & 2,025 & 0 & & 29 & r \\
\hline $\begin{array}{l}\text { Hackett's Point, June, } 1883 \ldots \ldots \ldots \ldots \\
\text { Swan Point November, } 1882 . . . \ldots . .\end{array}$ & $\begin{array}{l}108 \\
300\end{array}$ & $\begin{array}{r}425 \\
2,250\end{array}$ & 0 & few. ${ }^{0}$ & $\begin{array}{l}.254 \\
.138\end{array}$ & \\
\hline Swan Point, June, $1883 . . . . . . .$. & 34 & 49 & 0 & & .69 & $\because$ \\
\hline Chester Rive & 110 & 79 & 0) & 0) & 2.14 & •- \\
\hline fiel, Creek, June, $1883 \ldots \ldots \ldots$ & 0 & 463 & 0 & few & $\cdots \cdot$ of & - \\
\hline $\begin{array}{l}\text { Thomas' Polnt, June, } 1883 . . . \ldots \ldots \ldots . . \\
\text { Tally's Point, June, } 1883 . . . \ldots \ldots \ldots \ldots .\end{array}$ & $\begin{array}{l}102 \\
197\end{array}$ & 271 & 100 & $\begin{array}{l}0 \\
0\end{array}$ & $\ddot{p} \ddot{z} \dot{r}$ & 2.63 \\
\hline Eastern Bay, June, $1883 . . . . . . . .$. & 13 & 146 & 58) & & .088 & 2.75 \\
\hline Eastern Bay, November, 1882 ....... & 50 & 525 & 0 & few. & .009 & \\
\hline $\begin{array}{l}\text { Tllghman's Polnt, June, } 1883 \ldots \ldots \ldots \ldots \\
\text { Scull Hall, June, } 1863 \ldots \ldots \ldots \ldots \ldots \ldots\end{array}$ & 91 & $\begin{array}{l}101 \\
140\end{array}$ & 85 & 0) & $\ddot{6}$ & 1.2 \\
\hline Chink Point, June, $1883 . . . \ldots \ldots$ & 0 & 77 & - & a & .00 & $\because \cdots$ \\
\hline Cook's Point, June. $1853 . . . . . .$. & 인 & 123 & o & & $\ldots$ & $\because$ \\
\hline Benonl's Point, June, $1883 . . . \ldots \ldots$. & - & 0 & 450 & few & $\cdots$ & $\because$ \\
\hline $\begin{array}{l}\text { Chlora's Point, June, } 1883 . . \ldots \ldots . . \\
\text { Todd's Point June, } 1893 .\end{array}$ & 0) & $\begin{array}{l}0 \\
8\end{array}$ & 40 & 0 & $\cdot \cdot$ & i. \\
\hline Castlehaven, Jüne, $18 \times 3 . . . \cdots \cdots . .$. & 0 & 6 & 0 & & $\therefore$. & \\
\hline 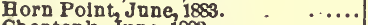 & 0 & D) & 150 & $\mathbf{w}$ & $\cdots$ & $\cdots$ \\
\hline Choptank, June, 1883.... : ...... & 0 & 137 & 620 & & ... & 22 \\
\hline & 0 & of & 225 & many. & ... & $\cdots$ \\
\hline $\begin{array}{l}\text { Shackel's Point, June, } 1883 . \\
\text { Dnvall's Bar, June, } 18 \lessdot 3 . . . .\end{array}$ & 인 & 190 & 200 & few 0 & $\cdots \cdot$ & ‥s \\
\hline & 0 & & 20 & 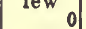 & $\cdots$ & .... \\
\hline Purdy's Point, June. $1883 . . . \ldots \ldots \ldots \ldots$ & 0 & 165 & 0) & 0 & $\ldots$ & $\because$ \\
\hline Ronnd Point Reef, June, 1889. ....... & 495 & 0 & 0 & 이 & … & $\therefore$. \\
\hline Sannders' Polnt, June, 1833 .... & 218 & 802 & 210 & & 24 & $\because \ddot{q}$ \\
\hline $\begin{array}{l}\text { Poplar Island, November, } 1882 . . \\
\text { Poplar Ieland, June, } 1883 . . . . . \text {. }\end{array}$ & $\begin{aligned} 218 \\
0\end{aligned}$ & $\begin{array}{l}175 \\
124\end{array}$ & 210 & w. & 1.24 & .08 \\
\hline Three Sisters, November, ise.... & 450 & 208 & 0 & few & $\ddot{1} \ddot{9 i}$ & … \\
\hline Three Sisters, June, $1883 \ldots \ldots \ldots \ldots \ldots$ & 2 & 193 & 0. & & 1.19 & .... \\
\hline November, 1882 & 400 & 900 & 0 & $\operatorname{mang}$ & .44 & .... \\
\hline July, $1883 . . .$. & 21] & 148 & 0 & 이 & .146 & .... \\
\hline tank, July, $18 \times 3 . . . \ldots$. & 0 & 0 & 28 & 0. & .... & ... \\
\hline Ragged Point, July, i\&83... & 0 & 78 & 0 & 0 & .... & -. \\
\hline Hill's Polnt, July, i883......... .. & 80 & 0) & 이 & 0 & $\cdots \cdot$ & *. \\
\hline r Hesd, July, $1893 \ldots \ldots \ldots$ & 0 & 37 & 0 & 0] & .... & $\cdots$ \\
\hline Holland Point, Jaly, 18s8.. · . & o. & 182 & 0) & ! & $\cdots \cdot$ & $\cdots$ \\
\hline $\begin{array}{l}\text { ind Point, July, } 18 \times 3 \ldots . . . \\
\text { Point, July, } 18 s 3 . \ldots . . . .\end{array}$ & 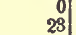 & 0 & 198 & 0 & $\cdots \cdot$ & $\cdots$ \\
\hline $\begin{array}{l}\text { Point, July, } 1893 . \ldots . . \ldots . . \\
\text { Dare, July, } 1898 . . . . . . .\end{array}$ & $\begin{aligned} 25 \\
0\end{aligned}$ & 121 & 0 & $\begin{array}{l}0 \\
0\end{array}$ & $\cdots$ & .... \\
\hline $\begin{array}{l}\text { Dare, July, } 1883 \ldots \ldots \ldots \ldots \\
\text { July, } 1883 \ldots \ldots \ldots \ldots \ldots \ldots\end{array}$ & 0 & $\begin{array}{r}121 \\
22\end{array}$ & $\begin{array}{l}0 \\
0\end{array}$ & 0 & $\because \cdots$ & $\cdots$ \\
\hline 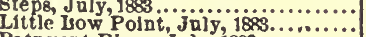 & o. & 208 & 0 & 0 & $\begin{array}{ll}\cdots \\
\cdots\end{array}$ & $\cdots$ \\
\hline it River, July, $1883 . .$. & o] & 0 & 158 & many. & .... & $\ldots$ \\
\hline aly, $1383 \ldots \ldots$ & 0 & 0 & 569 & many. & .... & ... \\
\hline 8s3. . & 0 & 0 & 872 & 0 & & ... \\
\hline nd, July, & 0 & 339 & 0 & 0 & ... & ... \\
\hline o............... & 0 & 0 & 205 & 0 & & ... \\
\hline November, $1822 . .$. & 180 & 160 & 0 & 0 & 1.12 & \\
\hline $853 \ldots$ & 22 & 59 & 10 & t & 37 & 5.9 \\
\hline .. & 45 & 49 & 0 & 0 & .91 & ... \\
\hline Pot & 이 & 151 & 이 & many. & .... & ... \\
\hline 1889. & 0 & 0 & 513 & many. & & $\ldots$ \\
\hline \& Riv & ( & r & ¿26 & many. & .. & ... \\
\hline t, 1883. & 인 & 705 & 0 & many. & $\cdots \cdot$ & .... \\
\hline$\cdots \cdots \cdots$ & 0 & 0 & 686 & many. & isi & 101 \\
\hline$\ddot{1882 \ldots . . .}$ & 0 & $\begin{array}{l}407 \\
700\end{array}$ & $\begin{array}{l}401 \\
325\end{array}$ & 엉 & 1.85 & 2.15 \\
\hline . & of & 227 & 212 & 0 & $\ldots$ & 1.07 \\
\hline Fishi & 0 & 46 & 38 & 이 & .... & 1.21 \\
\hline 8 Straj & 이 & 0 & 4,000 & many. & .... & $\because \ddot{0}$ \\
\hline James Poin & 0 & 70 & 111 & many. & & \\
\hline Nov & 84) & 213 & 130 & & 39 & 1.60 \\
\hline Iurtle & & 164 & & ev & 1.16 & ... \\
\hline Total..... & ,717 & 15,673 & 11,848 & ..... & ... & $\ldots$ \\
\hline
\end{tabular}


In the absence of any records of the numbers of oysters of various sizes in previous years, our table is of no particular value, but we give it in full, in order to facilitate the work of comparison in the future.

The precise significance of this table cannot be understood until similar examinations have been carried on for a term of years, and at the same time in each year.

It will be observed, however, that it shows a total of 20,390 large and medium oysters to only II,848 small ones. Four thousand of these small oysters were taken at one time in Hooper's Strait, in a " pocket" which had escaped the dredgers, and this haul should be omitted in order to show a typical average. If we leave it out we shall have 20,390 large and medium oysters to 7848 small ones, or only a little more than one small one to three marketable ones. It is very probable that if all our examinations had been made in the fall, the number of small oysters would have been found much greater, and they are above the average on the beds which we examined in November.

Still the summary of the whole table shows that the beds are losing their fecundity, and that the crop this winter (I83-I884) will be greater than it will be the year after.

The reasons for the small number of young oysters we believe to be, in part, the scarcity of mature oysters to furnish spawn; in part the wanton destruction of great numbers of very young oysters through the violation of culling laws, and in part the absence of enough 
clean shells on the beds to furnish attachment for the spat.

There are unlimited numbers of old, decayed and dirty shells on all the beds, but on many of them we found hardly a single shell proper for the attachment of spat.

We regard the annual examination of the beds, in the way we have employed, as a matter of very great importance. In the absence of such observations it is impossible to state with perfect certainty how many oysters a bed may yield annually without injury. This examination should be made every year, during the same months, and it should be made under the superintendence of the same person, in the same way, in order that the results may admit of direct comparison. Provision should be made for the annual examination of all the beds under the direct control of the State. The proper time for this examination is the closed season. An examination after the year's dredging would show how many full-grown oysters remain and how many the bed might safely yield during the next season. If the examination were made late in the summer it would also show how many young oysters have become attached during the spawning season.

While our own work was not exhaustive enough to give the information which is necessary for this purpose, it was amply sufficient to show that in 1882 and I883 the deterioration of our beds had made rapid progress, and that our system of managing the beds is a failure. 
The next step in our inquiry was to find the defects in our system, and to point out the reason for its failure, and this task was found to be an easy one, for the experience of other countries which have passed through the same history gave a clear and simple cxplanation.

THE CAUSE OF THE EXHAUSTION OF THE BEDS.

While the reason for the exhaustion of our beds is perfectly clear and simple, the greatest ignorance upon this point exists in the minds of our people.

Certain writers have attributed the destruction of the oysters to disease, like the pious oystermen of Wellfleet, on Cape Cod, who, after they had exterminated their oysters by over-fishing, laid their loss upon Providence, which had, they said, punished them for their sins by inflicting a fatal disease upon the innocent oysters.

Some of the explanations of the destruction of the oysters come from persons who have enjoyed such opportunities for observation and study of the subject that broader views might fairly be expected from them.

Thus, to explain the disappearance of oysters from the New England coast north of Cape Cod, a wellknown conchologist, Dr. Gould, says that he does not believe there were ever any oysters there; while a very eminent naturalist, Prof. Verrill, holds that the climate of New England has undergone a change within the last century or two, and that it is now too cold for oysters, although a few scattered oysters are found 
there still, and although they are still abundant at some points on the much colder coast of New Brunswick, and although we have the minute accounts which the early settlers have given us of the gradual destruction of their oysters as the population increased.

We can hardly be surprised that our people should exhibit total ignorance of the true cause of the destruction, when we recollect that there is not a single word in any of the laws of Maryland which indicates that our legislators are aware that the supply of oysters can be artificially increased, or that there is need for any such increase.

The contrast between the views upon the oyster question which are now prevalent among our people, and those which come from a broad-minded consideration of the question in all its relations, can be illustrated by an example. The uncivilized Indians are able to supply all their wants from the natural resources of their hunting-grounds, but as population increases, food grows scarcer and hard to procure, and it soon becomes evident that the natural supply is not enough. The first impulse, in such an emergency, is to restrict the demand, by driving away or starving out the superfluous population; and if savage tribes were able to enact and enforce laws, they would no doubt try to preserve their game by laws restricting the quantity to be killed, or by laws forbidding the use of improved appliances for capturing it.

Civilized races have long recognized the fact that the true remedy is not to limit the demand, but rather 
to increase the supply of food, by rearing domestic sheep and cattle and poultry in the place of wild deer and buffaloes and turkeys, and by cultivating the ground instead of searching for the natural fruits and seeds of the forests and swamps.

It is not in a spirit of harsh criticism, but in the hope that our people may be awakened to their own interest, that we point out the similarity between the veiws of our people and their legislators and the opinions of savage races. We live in a highly civilized age, and if we fail to grasp its spirit we shall go to the wall before the oyster cultivators of the Northern States, and those of Virginia and North Carolina, just as surely as the Indians have been exterminated by the whites. We cannot resist the progress of events, but we can control it if we will be wise in time.

It is not essential that a patient should know the nature and cause of his disease, but this knowledge is of the greatest importance to his physician, and it is of equal importance that the men who are called upon to legislate for the preservation of our oysters should clearly understand the true reason for their destruction.

I state, then, in capital letters, that our beds are in danger,

BECAUSE THE DEMAND HAS OUTGROWN THE NATURAL SUPPLY.

There are only two possible remedies. Either we must diminish the demand by killing the packing in- 
dustry which has created it, or we must increase by artificial means the natural supply of oysters.

Even if our natural beds could be restored and placed as they were twenty years ago, this would only delay for a few years their final exhaustion, for the demand is now far beyond the natural productive powers of our waters, and it is growing greater every day.

The daily papers often publish letters from oystermen who think that they can point out the true remedy, and the proposed remedies are almost as numerous as the authors, and nearly all the letters give statements which, while they are perfectly true, are based upon such narrow experience that they are of little or no value as contributions to a broad, comprehensive view of the problem.

The tongmen know that most of the oysters have been taken away by the dredgers, and they therefore advocate the prohibition or restriction of dredging. Ignorant of the fact that in localities where no dredging has been allowed, the natural beds have been exhausted by tongmen just as soon as a demand for the oysters sprung up, they believe that the prohibition of dredging is all that is needed to restore the beds. The dredgers, on the other hand, attribute the injury to the law which allows the tongmen to take oysters for private use in the summer, forgetting that the beds of Connecticut are rapidly increasing in value under a law which allows not only tonging, but dredging as well all through the year. The small dredgers and scrapers hold that the larger vessels are destroying the 
oysters by the use of heavy dredges, although the Connecticut farmers find it to their interest to use on their own private beds far heavier dredges, which they drag over the beds by steam.

Many of the oyster-packers, who carry on their business only in the winter, believe that all the damage is due to the oystermen who fish in March, April and May, and men who have money invested in the oyster business in Maryland believe that the exportation of oysters in the shell, and especially oysters for planting in Northern waters, is the cause of the mischief.

All agree in throwing the blame on some one else, and all believe that some form of the business in which they are not interested is responsible for the present state of things and should be prohibited; but as the oyster navy is a convenient scapegoat, all parties unite in throwing the blame upon the officers of the Fishery Force.

While the views of the oystermen are in this state of confusion, all students of the subject are agreed as to the cause of the mischief. As Lieutenant Winslow well said in 1883 , not only must the fecundity of the beds be preserved, but the market supply must also be kept up to the present demand, if not actually increased; and is a cessation of dredging likely to accomplish the latter end, when at present the vast fleet of pungies and canoes are straining every rope and windlass and openly violating every law of two powerful States in order to find oysters in the required numbers? The truth is that the Chesapeake beds are no 
longer equal to the demands made upon them. Some policy must be adopted which will supplement the supply granted by nature, or else the supply will surely fail.

No mere restriction of the fishing can possibly accomplish the desired end. It may prevent the extinction of the beds as they are now, though that is doubtful. It certainly will not relieve in the least the present condition of the market. What should be done is to adopt a policy similar in essential features to that of Connecticut. The fishery of that State is one of the few instances of recuperation on record. I know of many destroyed oyster fisheries and I know of a few that have been rebuilt, and I find one cause common to all failures and as common to all successes. In the first instance, the fishery has been common property, its preservation everybody's business-that is, nobody's -and consequently it has not been preserved. In the second instance, the fishery has been conducted and owned by persons singly and together as private property; it has been this, that, or the other man's business to see to its preservation; that is, its preservation has been everybody's business instead of nobody's and consequently it has been preserved.

Maryland cannot escape the action of universal laws, and the sooner those interested in the matter recognize the fact that a man does best by his own, whether it be a wheat or oyster farm, the sooner will a correct conclusion be reached regarding the oyster question.

It seems as if there were little probability, even at 
the present day, of the necessary change in Maryland's policy. Things of this kind, which so vitally interest our whole.community, rarely get better until they have become decidedly worse. The current of public opinion must be turned in the right direction by disaster, caused by allowing ruinous systems to remain in force; but it is to be hoped that a point will soon be reached where our people will become alive to the situation and apply the remedy.

If, however, the present system must remain in force, there are some suggestions which may be offered which, though they could never restore our lost industry, might save our natural beds from complete destruction.

One explanation which has been urged to account for the destruction of our oyster-beds is the wanton or unnecessary destruction of young oysters. Upon the piles of shells which are thrown out from the packinghouses great numbers of young shells can often be found. They are, of course, dead, and as they are too small to be of any use, their destruction is a clear loss to our people. It is impossible to prevent this from happening occasionally, as in many cases the little oysters are so small and so firmly fastened to the old one that they cannot be removed without destroying them, and even if the oystermen could be compelled to throw back on to the beds any large oyster which has small ones fastened to it, there is reason to doubt whether this would be advantageous, for one fullgrown oyster, like a bird in the hand, is more valuable 
than two small ones which may or may not grow up to maturity. I believe, however, that in cases where great numbers of young are fastened to the large ones, the use or destruction of them at the packing-house should be discouraged. This difficulty will disappear with the growth of the planting industry, for small oysters will then be valuable as seed, and they will pass into the hands of the planters instead of going to the packing-houses. The true remedy, therefore, is the encouragement of planting, and if our people would develop this business immediately, all need for special legislation would disappear.

The destruction of young oysters at the packinghouses is trifling, however, compared with that which results from violations of the culling laws. When a dredge is brought up from an oyster-bed it usually contains a few marketable oysters and great quantities of empty shells, which are often covered with young oysters. The law requires that these shells shall be thrown back upon the beds where they are taken, under a penalty of three years' imprisonment, or three hundred dollars fine, or the forfeiture of the boat used, but the enactment of this law has failed to remedy the evil. It is and always must be very difficult to enforce a culling law, and as the captain of a dredging boat wishes to improve his time on the beds to the best advantage, and to make the most of pleasant weather while it lasts, it is, of course, to his interest to fill his boat as quickly as possible, and all hands are therefore so fully employed in catching oysters that there 
is no time to cull them. Even when a captain is disposed to cull on the beds, he may be compelled by stormy weather, to run for harbor, and will then employ his crew in culling the oysters while lying in harbor. The shells are then dumped overboard in heaps around the anchorage, and even if the bottom should by chance be favorable for the growth of the oysters, they are smothered and killed under the heaps of shells.

The only way in which this can be prevented is by making it to the interest of the fisherman to save rather than to destroy the small oysters, and this can be done by the encouragement of planting. There is enough suitable ground under our waters to rear to maturity all the seed oysters which the natural beds now yield, and the time is sure to come when it will not pay the fisherman to destroy those which cannot be sold to the packers, and it will not be necessary to legislate for their protection.

The aim of the culling law is twofold: first, to preserve the young oysters, and secondly, to compel the return of the dead shells to the beds, that they may serve for the attachment of spat.

The value of these shells for this purpose is not very great, as they are usually decayed and slimy and covered with sponge, but it is undoubtedly true that they are sufficiently valuable to justify the culling law. The dry, clean shells which accumulate at the packing houses during the winter are far more valuable, and if these could be returned to the beds in the summer, a great increase in fertility would certainly follow. 
The improvidence of the people of the United States in dealing with their oysters, so long as they were abundant, has been almost beyond belief. The early settlers found at their doors a supply which they regarded as inexhaustible, and they not only used them freely as food, but they also spread them upon their fields as manure, and poured them, alive, into their lime-kilns and iron furnaces. In the Northern States the beds soon showed signs of exhaustion, and these practices were prohibited by law.

As it has taken our people nearly two hundred years to discover that we cannot afford to destroy oysters in this way, we. can hardly expect them to perceive that clean, empty shells are also so valuable that their use for lime, road-making, etc., should be prohibited.

I called attention to the very great value of oyster shells in 1879 , in an appendix to the report of the Fish Commission, and showed that a great increase of fertility would follow the return of the shells to the waters of our bay.

If this advice had been followed at the time it was given, our oyster-beds would now be much more valuable, but no attention was paid to it.

The Commissioners of Shell Fisheries of the State of Rhode Island, in their annual report for the year I882, make the following statement upon this subject:

"The oyster shells which have for years back been considered almost worthless, have, within a short time, become valuable to the oyster fisheries. It is a well- 
known fact that large quantities of shells are purchased here from the oyster business, and these shells, which have until a short time been considered worthless, are now selling for from eight to ten cents per bushel, to be carried out of the State (mostly to New Haven) for the purpose of planting them in deep water in Long Island Sound, to catch the oyster spawn and for the raising of oyster seed. These shells are taken up at the expiration of two years, and, with the increase of oysters adhering to them, are brought back to the same parties selling the shells in the first instance, for the purpose of planting in our waters, and the price paid for them is from forty to fifty cents per bushel."

The statement which I made twelve years ago, that this is a matter of great importance, has been passed over in absolute silence and has attracted no attention. It seems now as if it were almost time that the enterprise of practical Connecticut oystermen should have taught our people a lesson which they would not learn from a scientific student. Years ago I recommended that laws be passed requiring the return of shells to the beds. The simplest way in which this could be done would be to adopt the Connecticut plan of private farming, and we may be sure that just so soon as the fruits of private enterprise are secured to the cultivators, private interest will lead to the return of the shells to the water, as it has already done in Connecticut.

One of the causes to which the destruction of our oyster-beds is often attributed is the exportation of 
small oysters into other States. I have tried to gather information as to the extent to which this is practiced, but it is difficult to obtain exact statistics.

In discussing this subject we must bear in mind the fact that Northern fishermen or boats are not allowed to catch oysters in our waters, and that the industry contributes to our State treasury and gives employment to our people; for all the oysters which are exported for planting must be purchased from our licensed fishermen. Any person who lawfully owns oysters clearly has the right to dispose of them in the best market, and nothing can be done directly to prevent our oystermen from selling to Northern planters when it is to their interest to do so.

So far as the exported oysters are mature and marketable for food, it is obviously to our interest to encourage the business, which is perfectly legitimate.

The only ground upon which the practice can be objected to is, that it leads to the sale by our people of oysters which would be much more valuable to them if they could be kept in our own waters until they reached maturity. Oysters which cost the Delaware planters twenty-five cents per bushel are resold in a few months for eighty cents per bushel, and many of them are bought by Maryland packers. The policy of allowing our impoverished beds to enrich the citizens of another State is an unwise one, but it is proper to point out the fact that there is no reason why our own people should not themselves have this profit of 55 cents a bushel. 
It must be obvious to every one that the true remedy is to encourage planting in our own waters. We have vastly more land suitable for the purpose than the State of Delaware, and as our own planters are on the ground, they would have no canal fees or transportation to pay, and they could, if they choose, secure all these oysters for their own use, and gain the profit which now goes elsewhere. The development of the Maryland planting industry is, therefore, the true remedy for the evil. When we have, as we easily might, more seed oysters than we can use, the exportation of seed will become a legitimate and profitable branch of the industry well worthy of encouragement.

The favorite remedy for the difficulty, at least among those fishermen who are not dredgers, is the prohibition of dredging. Every one knows that our beds have deteriorated because they have been excessively fished, and every one knows, too, that most of this fishing has been done by dredgers. It is therefore natural to conclude that since the dredgers have done the damage, the prohibition of dredging will cure the mischief, but this is by no means true. The great demand for oysters, which has come from the growth of the packing industry, has been supplied by dredgers, because the dredge is more effective and economical than the oyster-tongs; but if dredges had not been invented, the demand would still have been supplied by the much more expensive and laborious method of tonging, and the prohibition of dredging now would simply cause an increase in the number of tongmen. 
It would not, however, cause any increase in the wages of tongmen or in the price of oysters, unless the importation of oysters from States where dredging is permitted were forbidden, and this would require an amendment to one of the most important clauses of the Constitution of the United States. The beds in deep water would escape, but they would then be, like many of the deep-water beds of Virginia, of no use to any one except pirates, and all the beds which could be reached by tongs would be as badly off as ever.

In order to show that this is the case, and that the excessive working of beds with tongs soon causes their destruction, when dredges are not used, we must note a number of cases where beds have been exterminated with tongs alone.

In 1874 the officers of the United States Coast Survey found a number of fine beds of valuable oysters near Portsmouth, New Hampshire. Many fine beds were found in this region by the earlier settlers, but they were destroyed so long ago that none of the natives had any knowledge of oyster-fishing or any instruments for taking the oysters; but it happened that an old oysterman from the Chesapeake Bay was living near-by, and he sent to Providence for oystertongs and began tonging upon the newly discovered beds. His example was imitated so effectively that in five years the beds were exhausted and ceased to be productive.

Ingersoll tells us that from the earliest times the 
borders of the Quinepiac River, near New Haven, Connecticut, have been the scene of oyster operations. The earliest settlers found on its shores great mounds of oyster shells, which showed that the Indians had resorted to its beds, season after season, for an unknown period. The first white fisherman found natural beds scattered over the bottom of the whole river, as well as in favorable areas along the eastern shore of the harbor. All of the beds were easy of access, and the result was that the raking of oysters was soon adopted as a business by many persons who lived near the water, and a considerable retail peddling trade was thus kept up throughout the neighborhood, in addition to the home supply. Wagon loads of opened oysters traveled in winter to the interior towns, even as far as Albany, and thence westward by canal.

These beds continued to supply fine oysters for all the inhabitants of the surrounding country for many years, but they have long been worthless as a supply of food, although they still yield small oysters, which are used as "seed" for planting. The beds were exhausted by tongs, and it is interesting to note that nearly all of the oysters were removed in a single day in each year. After the beds were closed by law until November I, great crowds assembled on the banks of the river, on the last night of October, and at the striking of midnight by the town-clock, began an attack which cleaned the beds of most of their marketable oysters before the end of the day, and a few hours of 
this fishing resulted in the capture of all marketable oysters.

Native oysters were abundant at Wellfleet, on Cape Cod, at the time of the first white settlements, and for more than a hundred years the town was famous for its oysters, but they became extinct in 1775 , through excessive tonging, although the inhabitants attributed their destruction not to their own rapacity, but to a disease sent by Providence upon the oysters, as a punishment for the sins of the fishermen, who were more worthy of such an infliction than the helpless oysters.

In all of these cases the exhaustion of the beds has been brought about almost or entirely without the use of dredges, although in a few cases dredges may have been used to a slight extent.

The list might be greatly extended were it not for the fact that upon all the more southerly beds dredges as well as tongs have been used.

Enough instances have been given to show that the prohibition of dredging will not save any bed which can be reached with tongs, and as the dredge is much more scientific, effective and economical apparatus than the rude tongs which it has superceded, there is no reason why its use should be prohibited.

In one way the use of dredges is a positive advantage to the beds. On a natural bed which has never been dredged, the oysters grow side by side in clusters, so crowded together that they have no room to grow. Most of them die when very young, and the 
others become long and thin. The dredge breaks up and scatters these bunches, and gives the oysters room to grow and to become valuable; and by scattering the shells, dredging causes an increase in the area of the natural bed.

It is asserted that the heavy dredges crush and kill the young oysters, and drag them into the mud and smother them, but the private farmers of Connecticut find it to their advantage to drag over their farms, by the aid of steam, dredges very much larger than any which are used in Maryland. They use these heavy dredges in the summer when the young oysters are very small and fragile, as well as in the winter, yet their farms are improved by this treatment.

It is undoubtedly true that little oysters are sometimes broken and killed by the dredge, but the destruction of oysters in this way is so slight as to have no significance. I have paid especial attention to the matter while dredging for oysters, and the number broken or injured by the dredge is surprisingly small. Young oysters fasten themselves flat upon the surface of attachment, and they do not begin to grow up and to become erect until they are large enough to crowd each other, and by this time they are large enough to withstand the dredge without injury.

After most careful examination of the subject I am convinced that there is no objection to dredging which does not apply with equal force to all other methods of oystering, and the interest of the community de- 
mands the employment of improved methods and cheap and effective labor-saving appliances.

What is needed is more oysters : not the prohibition of effective methods of catching them.

No animal upon earth, large enough to be valuable as human food, can long survive the attacks of an enemy who brings against it the resources, the destructive weapons and the intelligence of civilized man. Fortunately, the resources which render man the most irresistible of enemies, also enable him to become a producer as well as a destroyer; and while the fear of him and the dread of him is upon every beast of the earth and upon every fowl of the air, and upon all that moveth upon the earth and upon all the fishes of the sea, while they are all delivered into his hands and are powerless to resist him, he alone, of all animals, is able to make good his ravages, by agriculture and by domestication, by the selection and improvement of animals and plants, and by artificial propagation.

In the year I880 the fisheries census, and special investigations under the direction of the U. S. Fish Commission, proved that there had been a most rapid and alarming decline in the value of the shad fisheries in the rivers and bays and sounds of our Atlantic coast, and that there was every reason to fear that in a few years the shad would cease to be of any value as a food supply.

The adult shad are oceanic fishes, but each spring they enter our inlets and bays and make their way 
up to the fresh-water streams where they deposit their eggs.

The supply for the market is caught during this spring migration, when the fishes enter our inland waters heavy and fat after their winter feast upon the abundant food which they find in the ocean. They spend most of the year gathering up and converting into the substance of their own bodies the minute marine organisms which would otherwise be of no value to man, and their instincts impel them to bring back to our very doors this great addition to our food supply; for their economic importance is very great, and their extinction would be a national calamity, as, without their aid, a great and fertile tract of ocean would be beyond our control and valueless to man.

In 1880 the fishermen of the interior believed that the fishermen in lower waters, nearer the ocean, were to blame for the decline of the fisheries. They complained of the erection of pounds and weirs along the shores of the salt-water bays and sounds, where the fishes were captured in great numbers far away from their spawning grounds. They believed that legislation could save the fishery, and that if these obstructions were prohibited by law and removed, and all the shad were permitted to reach fresh water before they were captured, enough eggs would be deposited to keep up the supply, but that the destruction of such numbers in salt water must necessarily result in extermination.

This seemed to fresh-water fishermen to be good 
logic, but the salt-water fishermen took a different view of the matter. They wanted more legislation themselves, but of a different sort, and claimed that what was needed was protection for the shad upon the spawning ground. They said that they themselves furnished most of the shad for the market; that without them the cities could not be supplied, and that enough shad escaped their nets and reached the fresh water to supply all the eggs that were needed, if they could be left to lay their eggs in peace.

In 1880 there seemed to be good sense in this view also, and it was difficult for a disinterested outsider to tell who was right. The only thing which seemed clear was that the shad were growing scarce, and that, if the Legislature did not do something to protect them, they would soon be exterminated.

In 1888 more shad were caught in salt water than were caught altogether in 1880 , and yet the shad fisheries are now increasing in value from year to year, and this change has been brought about, not by the enactment of new laws to restrict the fishery, but by the production of more fishes.

In 1880 the U. S. Fish Commission began, systematically and upon a large scale, the work of collecting the eggs from the bodies of the shad which were captured for the market in the nets of the fishermen. These eggs were artificially fertilized and the young were kept for a short time in hatching jars, and the waste of eggs was thus prevented. This work has been prosecuted steadily ever since, and the results, up 
to the end of the season of 1888 , are given in the following table:

TOTAL NUMBER OF SHAD TAKEN EACH YEAR.

In Salt and

Brackish water. In Rivers.
Percentage of inTotal. crease over 1880 .

I885 3,267,497 I,906,434 5,I72,93 I 25 per cent. $\begin{array}{llllll}1886 & 3,098,768 & 2,485,000 & 5,584,368 & 34 & \text { “ }\end{array}$ $\begin{array}{llllll}1887 & 3,813,744 & 2,90 I, 66 I & 6,715,405 & 62 & \text { “ }\end{array}$ I888 5,OIO,IOI $2,650,373 \quad 7,660,474 \quad 85$ “

The money value to the fishermen of the excess in I 888 over the total catch of I880 was more than $\$ 700,000$. I have no record for 1889 or 1890 , but last year, 1890 , the fisheries were more profitable than they have been for many years, and our markets were stocked with an abundance of fine shad, which were sold at prices which ten years ago would not have been thought possible. The percentage of increase in 1889 and 1890 has been much greater than it was in any of the years given in the table, and this result is not due to any change in the method of fishing. It is exclusively due to the increase in the supply.

The conditions are now more unfavorable than ever to natural reproduction, and it can be proved that if no shad had been produced by man, while the other factors had remained as they now are, the fisheries would be completely ruined and abandoned.

The mature fishes are now excluded by dams and 
other obstructions from the most valuable spawning grounds, and the area which is now available is restricted to the lower reaches of the rivers, where there is little proper food for the young, and where the bottoms are so continually and assiduously swept by drift nets and seines that each fish is surely captured soon after its arrival. The number of eggs which are naturally deposited is now very small, for while the spawning-grounds have increased from $1,600,000$ to $2,600,000$, the take in salt water has increased from $2,500,000$ to $5,000,000$, and the shores of our bays and sounds are now so lined by fyke nets and pounds that the number of shad which reach the spawning-grounds at all is proportionately much less than it was in 1880 , and more shad are now taken each year in salt water, where spawning is impossible, than were taken altogether in 1880 .

This fact, rightly considered, means that the shad is now an artificial product like the crops of grain and fruit which are harvested on our farms and orchards.

If more shad than the natural supply were taken in I880 in all waters, and if still greater numbers are now taken each year in deep water, before they reach the spawning-ground, it follows that we are now entirely dependent upon the artificial supply.

This short history will serve to show that we must look to an increase in the supply of oysters as the only remedy for the scarcity, and that we can hope for no benefit from new laws to regulate the method of taking the oysters. 
I must insist, however, upon one most important difference between the shad and the oyster. The shad goes out into the ocean to pasture, and it is at this time beyond the direct control of man. During its migration it may pass through the waters of two or three States before it reaches its feeding-ground, and private ownership and protection of shad is impossible. The work of shad-hatching is therefore a proper object for the employment of the Government, but there is no reason for Government oyster-farming, as the oyster is as sedentary as a potato, and it is therefore perfectly adapted for propagation by individuals.

Among the remedies for the destruction of the oyster-beds the shortening of the season is a favorite measure, and it has many advocates. This remedy seems, at first sight, to be an effective one, but a little thought shows that it is, in reality, of no very great value.

So long as our present oyster policy is maintained it will be necessary to have a closed season to facilitate the enforcement of other legal measures, but as it is clear to every one that a great number of fishermen working upon a bed for a short season will do just as much damage as a lesser number working for a longer time, we cannot hope that laws to shorten the season will, in themselves, effect any great improvement in the condition of the beds.

Ingersoll gives a very vivid description of the method of fishing in early days, upon one of the natural beds of Connecticut, which was finally exter- 
minated by little more than one day's fishing in each year.

As oysters grow scarce and the demand for them increases, the only effect of a closed season is to assemble all the oystermen upon the bed at the end of the season. The oysters which would otherwise have been removed slowly are then taken away rapidly, and the plan has no advantages as a means of protection unless the closed season is long enough to allow a new generation of young oysters to grow up and replenish the beds.

Although the closure of the beds for a part of each year is of very little value in itself, a closed season is a great help in the enforcement of other means of protection, and many of the States which own oyster-beds have passed laws to prevent the taking of oysters in certain months.

In Maryland in 1884 no dredging was allowed between April Ist and October I5th, and no oysters in the shell could be carried outside of the State between April Ist and September Ist. There is also a State law in the following words: "It shall be unlawful for any person or persons to take or catch oysters, except for private use, to the amount of five bushels per day, or for sale of the same to any citizen or citizens of the neighborhood, and to them only for the purpose of being consumed when sold, or for the purpose of replanting or bedding in the waters of the counties wherein they are caught, or for sale to the citizens of the county wherein they are caught, and to them only 
for the purpose of replanting or bedding in the waters of said counties, between the $15^{\text {th }}$ day of April and the Ist day of September."

A special act of the Legislature is needed to explain what the ambiguous wording of this section is intended to prohibit or permit; but Sec. I3, of the Act of 1874 , for which the words above quoted were substituted in 1880, forbids the taking of oysters during the closed season, except for private use, or for the purpose of replanting, or for sale to the citizens of the county next adjoining. It is, therefore, probable that the framers of the present law wished to permit by it the taking between April I5 and September Ist of oysters to be sold to residents of the neighborhood for food, or to citizens of the county for planting, and also to permit the taking of five bushels a day for private use.

Almost the only thing which the prohibitory laws of the different States have in common is the prohibition of oyster-fishing in the summer months, and to this there are exceptions, as some of the Rhode Island beds are open only in the summer, while those of Connecticut are open at all times. This provision, which is borrowed from the laws for the protection of game, is based upon the fact that this time is the spawning season. Game birds soon desert a region where they are disturbed in the breeding season, and as they lay few eggs and care for their helpless young, the destruction of an old bird at this time may result in the death of the whole brood. The provision of the game law which forbids the capture of game during the 
breeding season is therefore a wise one, but oysters are very different from game birds. They discharge vast numbers of eggs into the water, but they take no care of their young, and while it is true that the removal of too many mature oysters from a bed destroys its productiveness, the time when they are removed is a matter of no consequence, and overfishing in December is in this respect as bad as overfishing in May.

I have made a study of the spawning time of our oysters, and have carried my observations over several years. I have found spawning oysters in our waters in every month in the year except December, January and February, and I have had no opportunty to visit the beds during these three months.

By far the greater number of these oysters, however, are found to spawn between May 2oth and July Ist, and although the temperature of our spring months causes considerable variation, this period may properly be called the spawning season. At any time before May 2oth, the disturbance of the beds can do little harm, and the experience of the Connecticut oysterfarmers shows that the thorough raking of the beds just before the spawning season is a positive benefit. The young oysters cannot attach themselves to dirty and slimy shells, and if all the sponges, hydroids and sea-weeds could be dragged from our beds in April and May, and if the old decayed and slimy shells could be plowed under and covered with the cleaner shells from below the surface by dredging just before the spawning season, the fertility of the beds would be 
greatly increased, and there is, therefore, nothing in the nature of the oyster to demand the closure of the beds in April and May.

I believe that no increase in the value of our beds can be hoped for until it is brought about by private cultivation, and that the State should use every possible means to foster and encourage the oyster-planting and oyster-farming industries. I show elsewhere that the States where the oyster industry is most prosperous have found it necessary and to their advantage to use the natural beds chiefly as a supply of seed for planting, and I believe that whenever the people of our State are prepared to use our great natural advantages for oyster culture, it will be wise to throw open the natural beds in the summer time, but at present such a measure would result in the depletion of the beds, without any compensating advantage.

Soon after the young oysters are born they fasten themselves to stones, gravel, bricks, plaster, bottles, empty shells, living oysters and other clean, hard substances. They are at first so small and flat that they are in no danger of injury by dredgers, and there is, therefore, no reason why the taking of marketable oysters should not be continued all summer if the large oysters could be taken away without the young ones, but these are at first so small that they are invisible, and for several months they are too small to be removed from the shells of larger oysters. As it is very difficult to enforce culling laws, the opening of the public beds immediately after the spawning season 
would cause millions of the small oysters to be carried away on the shells, and even if the culling laws could be enforced, many of the small oysters would be carried away on the large ones.

This would be a great advantage if the small oysters were used as seed for planting, but at present most of them are destroyed.

I therefore believe that, for the present at least, the public beds should be closed for as long a time as possible in the fall, in order to give the young oysters time to grow large enough to render it possible to detach them from the larger ones and from the shells. I also think that each public bed should be examined annually in order to determine how many oysters it can yield without injury. This examination should be made in August or September, in order to learn how many young oysters have settled upn the bed, and as the analysis and publication of the results of this examination would require at least two months, the opening of the public beds should be postponed as long as possible.

After the closure of the packing-houses in the early spring, most of the oysters which are taken are sold outside the State at a very low price to planters, who, in many cases at least, resell to Maryland packers in September and October at a great advance.

If our own people would themselves engage extensively in the planting business, or if our beds were not already overtaxed, it would be wise to encourage the taking of seed to be sold to Northern planters, as this 
is one of the legitimate sources of the demand for our oysters.

As soon as our people engage extensively in oyster-planting, and need these months to gather their seed oysters, and as soon as our beds are sufficiently prolific to supply Northern planters, we believe that the beds should be thrown open until June Ist, or even longer.

The experience of Connecticut, where both public and private beds are open throughout the whole year, and are rapidly increasing in value, shows that a closed season is not necessary for the preservation of the beds.

As the closed season is a matter of policy, and is not due to the nature of the oyster, I believe that it should be made absolute, and that all laws which permit any one to take oysters from the public beds at that time should be repealed.

It is possible to stock oyster-farms and plantinggrounds without drawing upon the public beds, and there is no reason why those oyster-planters who wish to get their seed from the public beds should not do so after the oyster season is opened. It is true that they would then have to compete with the prices paid by the packers, but as our present oyster policy is opposed to any private interest in the beds, there is no good reason why a planter should have oysters from the public beds any more cheaply than any one else.

The law which allows any person to catch oysters from the public beds at any time for family use or for sale in the neighborhood, is a wide loophole for in- 
fringement of the law, and so long as our present oyster policy is adhered to, I believe that the public beds should be absolutely closed during the closed season. 




\section{DAY USE}

RETURN TO DESK FROM WHICH BORROWED

\section{LOAN DEPT.}

This book is due on the last date stamped below, or on the date to which renewed.

Renewed books are subject to immediate recall.
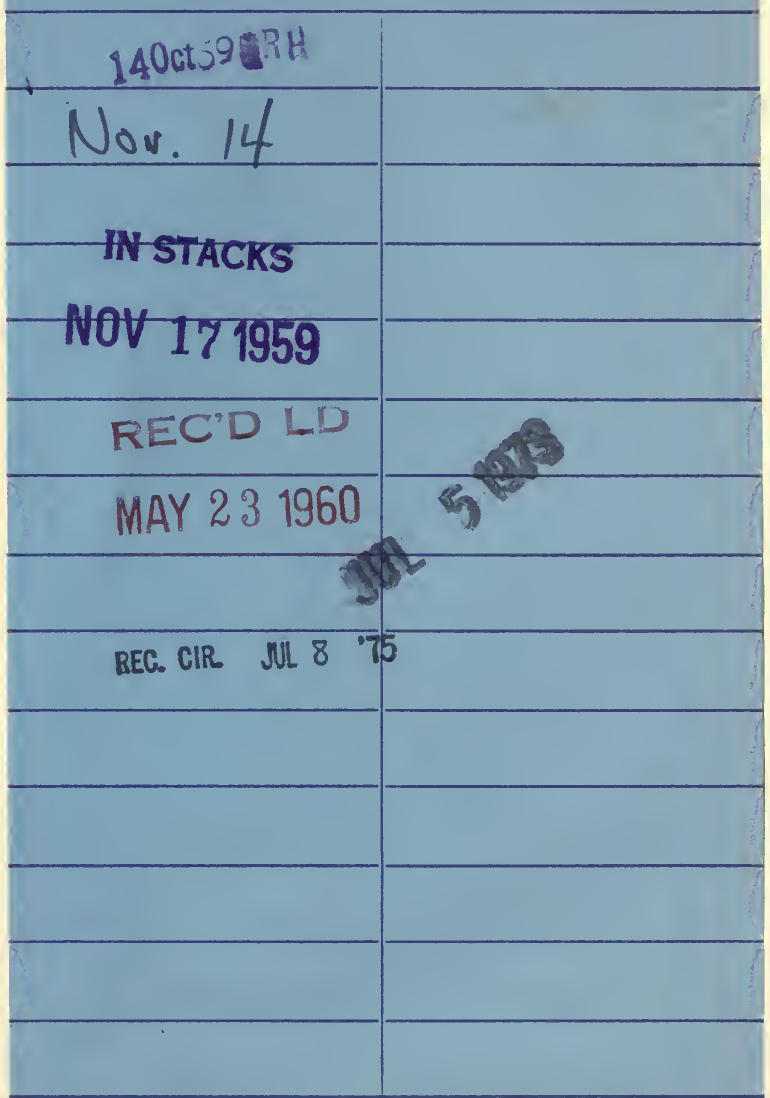

LD $21 \mathrm{~A}-50 m-4, ' 59$

(A1724s10) 476B

General Library

University of California Berkeley 
$\therefore$ 的。 
